\title{
Management of Chronic
} Graft-vs.-Host Disease in Children and Adolescents With ALL: Present Status and Model for a Personalised Management Plan

\section{OPEN ACCESS}

Edited by:

Adriana Balduzzi,

Clinica Pediatrica Università degli

Studi di Milano Bicocca, Italy

Reviewed by:

Maria Teresa Lupo Stanghellini, San Raffaele Hospital (IRCCS), Italy

Daniel Wolff,

University Hospital

Regensburg, Germany

Samppa Ryhänen,

Hospital District of Helsinki and

Uusimaa, Finland

${ }^{*}$ Correspondence:

Anita Lawitschka

anita.lawitschka@stanna.at

tThese authors have contributed equally to this work and share first authorship

Specialty section:

This article was submitted to

Pediatric Hematology and

Hematological Malignancies,

a section of the journal

Frontiers in Pediatrics

Received: 03 November 2021

Accepted: 24 January 2022

Published: 18 February 2022

Citation:

Sobkowiak-Sobierajka A, Lindemans C, Sykora T, Wachowiak J,

Dalle J-H, Bonig H, Gennery $A$ and Lawitschka A (2022) Management of Chronic Graft-vs.-Host Disease in Children and Adolescents With ALL: Present Status and Model for a Personalised Management Plan

Front. Pediatr. 10:808103. doi: 10.3389/fped.2022.808103

\author{
Agnieszka Sobkowiak-Sobierajska ${ }^{1 \dagger}$, Caroline Lindemans ${ }^{2,3 \dagger}$, Tomas Sykora ${ }^{4 \dagger}$, \\ Jacek Wachowiak ${ }^{1}$, Jean-Hugues Dalle ${ }^{5}$, Halvard Bonig ${ }^{6}$, Andrew Gennery ${ }^{7}$ and \\ Anita Lawitschka ${ }^{8,9 *}$
}

\begin{abstract}
${ }^{1}$ Department of Pediatric Oncology, Hematology and Transplantology, Poznan University of Medical Sciences, Poznan, Poland, ${ }^{2}$ Department of Pediatrics, Wilhelmina Children's Hospital, University Medical Center Utrecht, Utrecht University, Utrecht, Netherlands, ${ }^{3}$ Pediatric Blood and Bone Marrow Transplantation, Princess Máxima Center, Utrecht, Netherlands, ${ }^{4}$ Department of Pediatric Hematology and Oncology - Haematopoietic Stem Cell Transplantation Unit, National Institute of Children's Diseases and Medical Faculty, Comenius University, Bratislava, Slovakia, ${ }^{5}$ Hematology and Immunology Department, Robert-Debré Hospital, Assistance Publique-Hôpitaux de Paris and University of Paris, Paris, France, ${ }^{6}$ Goethe University Medical Center, Institute of Transfusion Medicine and Immunohematology, and German Red Cross Blood Center Frankfurt, Frankfurt, Germany, ${ }^{7}$ Medical School, Institute of Cellular Medicine, Newcastle University, Newcastle upon Tyne, United Kingdom, ${ }^{8}$ Stem Cell Transplantation Unit, St. Anna Children's Hospital, Medical University Vienna, Vienna, Austria, ${ }^{9}$ St. Anna Children's Cancer Research Institute, Vienna, Austria
\end{abstract}

Herein we review current practice regarding the management of chronic graft-vs.-host disease (cGvHD) in paediatric patients after allogeneic haematopoietic stem cell transplantation (HSCT) for acute lymphoblastic leukaemia (ALL). Topics covered include: (i) the epidemiology of cGvHD; (ii) an overview of advances in our understanding cGvHD pathogenesis; (iii) current knowledge regarding risk factors for cGvHD and prevention strategies complemented by biomarkers; (iii) the paediatric aspects of the 2014 National Institutes for Health-defined diagnosis and grading of cGvHD; and (iv) current options for cGvHD treatment. We cover topical therapy and newly approved tyrosine kinase inhibitors, emphasising the use of immunomodulatory approaches in the context of the delicate counterbalance between immunosuppression and immune reconstitution as well as risks of relapse and infectious complications. We examine real-world approaches of response assessment and tapering schedules of treatment. Furthermore, we report on the optimal timepoints for therapeutic interventions and changes in relation to immune reconstitution and risk of relapse/infection. Additionally, we review the different options for anti-infectious prophylaxis. Finally, we put forth a theory of a holistic view of paediatric cGvHD and its associated manifestations and propose a checklist for individualised risk evaluation with aggregated considerations including site-specific cGvHD evaluation with attention to each individual's GvHD history, previous medical history, comorbidities, and personal tolerance and psychosocial circumstances. To complement this checklist, we present a treatment algorithm using representative patients to inform the personalised management plans for patients with CGvHD after HSCT for ALL who are at high risk of relapse.

Keywords: haematopoietic stem cell transplantation, chronic graft-vs.-host disease, paediatric, adolescent, management 


\section{INTRODUCTION}

Allogeneic haematopoietic stem cell transplantation (HSCT) is a curative treatment for an increasing number of children and adolescents with various malignant and non-malignant haematological diseases, due to improved transplant procedures and reduced early mortality. However, successful long-term outcomes can be limited by chronic graft-vs.-host disease (cGvHD), which is often severe and is the most common complication post HSCT (1). This complex immune disorder resembles multiorgan autoimmune diseases and can result in adverse psychomotor development, functional impairment, disability and poor quality of life (2). It is believed to correlate with the graft- vs.-leukaemia effect $(\mathrm{GvL})$ and contributes to a lower risk of relapse of malignancy (3). Moderate-tosevere $\mathrm{cGvHD}$ is the major cause of treatment-related mortality (TRM) and inferior overall survival (OS) following HSCT, and little progress has been made in recent decades regarding outcomes (4).

The publication of the National Institutes for Health (NIH) consensus criteria for cGvHD diagnosis and grading for use in clinical trials in 2005, as revised in 2014, represented a major advancement in the field $(5,6)$. Correspondingly, the German-Austrian-Swiss GvHD Consortium published a number of expert recommendations for daily clinical practice, including some considerations for the paediatric population (7). Recently, our understanding of cGvHD pathogenesis has improved substantially (8-10). The $2020 \mathrm{NIH}$ Consensus Project has published documents aiming to move the field forward by summarising current knowledge and expert opinion, identifying the unmet needs of clinical care and gaps of knowledge, and outlining future research efforts (11-13).

Unfortunately, cGvHD in children and adolescents has been relatively understudied compared with in adults. Paediatric data on cGvHD pathophysiology, clinical manifestations, diagnosis and outcome are scarce. Furthermore, the NIH consensus criteria were primarily developed from adult data: their validation and clinical applicability for use in paediatric populations have been rarely investigated since their publication (14).

After HSCT to cure acute lymphoblastic leukaemia (ALL), paediatric patients are at high risk of developing various longterm sequelae, with cGvHD being one of the major risk factors (15). In view of the now longer life expectancy of children post HSCT and the significant CGvHD-related morbidities within a growing body, better understanding and management of paediatric $\mathrm{CGvHD}$ is imperative.

To aid this, we herein review the current knowledge regarding the management of paediatric cGvHD. Specific topics covered include: the epidemiology and pathogenesis of cGvHD, risk factors, biomarkers and paediatric aspects of the $2014 \mathrm{NIH}$ criteria for diagnosis and grading. Furthermore, we present current options for treatment, with emphasis on topical therapy, immunomodulatory interventions and supportive care and with consideration for the delicate counterbalance between immunosuppression and immune reconstitution, risk of relapse and risk of infectious complications. We aim to present a new perspective on how management strategies can be tailored to the specific needs of individual patients and provide a framework for the personalised treatment of paediatric patients with cGvHD after HSCT for ALL to support clinicians in daily clinical practice.

\section{Methods}

We searched PubMed to find English-language articles from 1970 to 2021 emphasising on paediatric data whenever possible. We used the following terms: "chronic GVHD with and without paediatric/children," "pathogenesis, pathophysiology," "epidemiology, incidence," "diagnosis and grading," "risk factors," "biomarker," "immune reconstitution," "treatment," "management," "topical treatment," "ECP," "MSC," "supportive and ancillary care," "relapse," and "infections and infectious complications." The reference lists in the selected studies were reviewed to identify additional articles. No limits were applied in the initial search, but we then excluded articles that contained only adult case series focusing on experimental approaches.

\section{CURRENT KNOWLEDGE AND PRACTICE Epidemiology of cGvHD in Children and Adolescents}

Nowadays, the criteria for diagnosis of cGvHD are based on the combination of clinical manifestations and time of onset according to the NIH consensus criteria (5). This should be kept in mind for comparison of published data on the incidence of acute GvHD (aGvHD) and cGvHD.

The incidence of paediatric cGvHD shows great variety (ranging from 6 to 65\%), with some differences explained by the specific transplant indication (malignant vs. non-malignant), heterogeneity of transplant procedures, and age-related immune reconstitution post transplantation (16). In general, paediatric cGvHD tends to be less common and somewhat milder than cGvHD in adults (17-19).

Stem cell source can influence risk of GvHD. The lowest incidence of cGvHD (6\%) was observed among paediatric patients undergoing cord blood HSCT $(20,21)$. In historical data from the 1990s and early 2000s, the incidence of paediatric cGvHD after HSCT for haematological malignancies ranged from $28 \%$ with a sibling donor to $52-65 \%$ with an unrelated donor. The incidence and severity of cGvHD was higher in patients after peripheral blood stem cell (PBSC) HSCT than after bone marrow (BM) HSCT $(22,23)$.

Underlying disease and age can also affect cGvHD risk. Zecca et al. reported in $2002 \mathrm{a}$ higher incidence of cGvHD in patients with malignant (35\%) vs. non-malignant (13\%) diseases in a retrospective analysis of 696 children. Furthermore, the lowest incidence of $\mathrm{cGvHD}(9 \%)$ was described for children $<2$ years of age, and the highest (44\%) for patients $>15$ years of age (24). Likewise, Qayed et al. found in a retrospective analysis of 476 paediatric ALL patients after matched sibling donor (MSD) BM HSCT during the years 2000 to 2013 a cumulative incidence of cGvHD of $16 \%$; a lower risk of cGvHD was observed for the age group 2 -12 years in comparison to patients $>12$ years old (25). A retrospective, single-centre analysis of 146 children with malignant and non-malignant diseases transplanted at the St. Anna Children's Hospital, Vienna, between 2004 and 2012 
revealed a cumulative incidence of reclassified NIH-defined cGvHD (2005 criteria) of $18 \%$ and $21 \%$ at 1 and 3 years post HSCT, respectively. A multivariate analysis identified donor age $>5$ years as risk factor for the development of $c G v H D$ but there was no association between recipient age and cGvHD risk (Lawitschka et al., unpublished data). One of the most recent prospective multicentre studies of paediatric cGvHD, by Cuvelier et al., indicated an incidence of $21 \%$ of accurately assessed NIHdefined cGvHD in 243 paediatric patients with various malignant and non-malignant diseases undergoing a range of transplant procedures. Recipients $\geq 12$ years of age were at higher risk for cGvHD in comparison to younger patients, and de novo cGvHD occurred almost exclusively in patients $\geq 12$ years, indicating a crucial role of aGvHD in the pathogenesis of cGvHD in infants (14).

The overall incidence of $\mathrm{cGvHD}$ in paediatric patients has decreased over recent decades. This is contrary to the pattern observed in adult studies, probably due to the widespread use of granulocyte colony-stimulating factor (G-CSF)-mobilised PBSCs over BM grafts in adults (26). The older age of transplanted patients, and the use of reduced intensity regimens which require GvL effect also contribute to the higher incidence of $\mathrm{cGvHD}$ in this group $(27,28)$.

\section{Pathogenesis of cGvHD in Children and Adolescents}

The immunobiology of cGvHD differs distinctly from that of aGvHD (29). Despite major advances in the field, the complex and multifactorial pathogenesis of cGvHD is not fully understood and incorporates failure of central and/or peripheral tolerance mechanisms in the presence of minor (and major) major histocompatibility complex (MHC) polymorphisms (30). It is well-known that cGvHD is a pleomorphic syndrome resembling many autoimmune diseases but, in addition, appreciation of its correlation with monogenic immune disorders may lead to better understanding of its pathogenesis, especially in paediatric populations (31).

Cooke et al. (8) has proposed a triphasic model of cGvHD pathogenesis which involves: (i) acute inflammation with tissue injury and vascular inflammation (which may be subclinical); (ii) dysregulated immunity, thymic damage and dysfunction with the transition to chronic inflammation; followed by (iii) dysfunctional tissue repair resulting in the deposition of collagen and development of fibrosis. Recently, major advances in cGvHD research have been made but these are largely based on murine models that do not reflect the whole clinical spectrum of human cGvHD (10).

In general, a complex cytokine-driven cellular network (32) involving damage of the thymus and germinal centres with aberrant interactions between donor-derived subsets of effector $\mathrm{T}$ and $\mathrm{B}$ cells contributes to both the immune pathology of cGvHD and innate immune responses with unusual antigen presentation. Of note, multiple pathogenic pathways may operate simultaneously.

Regarding the T-cell compartment, various models have demonstrated a critical role of naïve $\mathrm{T}$ cells with further dysregulation of $\mathrm{CD}^{+}{ }^{+} \mathrm{T}$ helper (Th17), $\mathrm{CD}^{+} \mathrm{T}$ cell $(\mathrm{Tc} 17)$ and T-follicular helper (Tfh) cell differentiation $(32,33)$ together with reduced numbers of regulatory $\mathrm{T}$ cells $\left(\mathrm{T}_{\text {reg }}\right)$ (34). High interleukin (IL)-6 levels after HSCT lead to IL-17-secreting Th17 and $\mathrm{Tc} 17$ differentiation $(35,36)$. This process is augmented by stem cell mobilisation with G-CSF. Th17/Tc17 produce multiple cytokines, including interferon gamma (IFN- $\gamma$ ), tumour necrosis factor (TNF), IL-22, colony-stimulating factor-1 (CSF-1), and granulocyte-macrophage colony-stimulating factor (GM-CSF) which promote the migration and differentiation of monocytes into pathogenic macrophages. Simultaneously, Tfh produce IL21 which is critical for germinal centre B-cell formation and antibody secretion (both autoreactive and alloreactive) (37).

Regarding the B-cell compartment, an expansion of germinal centre B cells with subsequent allo/autoantibody secretion has been shown (38). B cells of cGvHD patients have increased survival capacity and signal through B-cell activating factor (BAFF) and B-cell receptor (BCR) signalling pathways. BAFF is produced primarily by myeloid cells, stromal cells and some lymphoid cells. BAFF:B-cell ratios are elevated in patients with active cGvHD (39). The BCR-signalling molecules Syk and Bruton tyrosine kinase (BTK) appear to be hyper-activated in B cells during cGvHD (37).

Additionally, a role of the gut microbiome has been observed in $\mathrm{CGvHD}$, with the loss of flora diversity after HSCT recently reported to correlate with inferior outcome (an increased risk of mortality) $(40,41)$.

In the context of the transition to fibrosis, the involvement of macrophages producing the profibrotic cytokines tumour growth factor beta (TGF- $\beta$ ) and platelet-derived growth factor alpha (PDGF- $\alpha$ ) leads to the deposition of collagen secreted from activated fibroblasts (42).

Better understanding of the pathogenic pathways of cGvHD is being translated into the clinic in the form of rationales for specific treatment schedules. This may pave the way for novel promising therapeutic approaches that potentially target various cytokines, cell subsets and signalling pathways (30). Furthermore, it serves as a basis for more individualised treatment plans in cGvHD (10).

\section{Biomarkers for Paediatric cGvHD}

The multisystemic, polymorphic nature of cGvHD and challenges in clinical diagnosis such as lung involvement in infants (14) makes the identification of potential GvHD biomarkers of utmost importance. Biomarkers are defined as biochemical or cellular variables categorised according to how they are used. Three subtypes of biomarker in cGvHD are recognised: (i) diagnostic biomarkers used to identify GvHD patients at the onset of the disease and to aid differential diagnosis; (ii) prognostic biomarkers used to identify patients with different degrees of risk for GvHD occurrence, progression or resolution before the onset of clinical cGvHD manifestation of the disease; and (iii) predictive biomarkers used to categorise patients based on their likelihood to respond to therapy $(43,44)$.

Great effort has been put into identifying relevant cGvHD biomarkers. It is important to keep in mind that patients with $\mathrm{cGvHD}$ represent a heterogeneous group with various 
characteristics having only the diagnosis but not the phenotype in common. Variables such as age, primary disease for which HSCT was indicated, treatment modalities and transplant procedures, and post-transplant complications have a great impact on immune reconstitution (45) and may influence the biomarkers present $(10,44)$.

Among those considered to be validated plasma biomarkers are soluble BAFF, a panel consisting of 4 biomarkers [ST2, chemokine (C-X-C) motif ligand 9 (CXCL9), matrix metalloproteinase 3 (MMP-3) and osteopontin], CXCL10, and chemokine (C-C motif) ligand 15 (CCL15) (Table 1) (46-63). Validated cellular biomarkers include CD163, B cells expressing toll-like receptor 9 (TLR9), B cells defined as $\mathrm{CD} 19^{+} / \mathrm{CD} 21^{\text {low }} \mathrm{B}$ cells, a high BAFF:B cell ratio in the plasma, $\mathrm{T}_{\text {regs }}, \mathrm{CD} 4^{+} \mathrm{CD} 146^{+} \mathrm{CCR} 5^{+} \mathrm{T}$ cells and Tfh cells (Table 1) (64). We briefly discuss these biomarkers below.

\section{Plasma Biomarkers}

\section{Soluble B-Cell Activating Factor}

High levels of sBAFF have been found in patients with active cGvHD and have been linked with both early onset (3-8 months) and late onset ( $\geq 9$ months) disease $(46,47)$. A significant decrease in sBAFF was found in responders to corticosteroids 2 months after their initiation (46). Moreover, Saliba et al. (47) described increased sBAFF levels at the time of diagnosis of $\mathrm{cGvHD}$ as a potential predictor of non-relapse mortality (NRM) (48). Because of its significant presence in various settings of $\mathrm{cGvHD}$, sBAFF is described as both a diagnostic and prognostic biomarker (64). One major limitation is the steroid sensitivity of sBAFF, which becomes undetectable on steroid doses $>0.5 \mathrm{mg} / \mathrm{kg}$ prednisolone independent of response to treatment.

\section{A Panel of ST2, CXCL9, MMP-3 and Osteopontin}

In a study of $\mathrm{Yu}$ et al. (61), a panel of 4 proteins (ST2, CXCL9, MMP-3, and osteopontin) was found to significantly correlate with cGvHD diagnosis, cGvHD severity and NRM. When measured at day +100 , the panel could predict cGvHD occurring within the next 3 months, even in the absence of known clinical risk factors. In addition, increased MMP-3 is associated with the development of bronchiolitis obliterans (50). Solely elevated plasma concentrations of CXCL9 are considered to be an independent cGvHD biomarker (49, $50)$.

\section{CXCL10 and CCL15}

Similarly to CXCL9, CXCL10 is an inflammatory chemokine involved in the activation and recruitment of T cells, eosinophils, monocytes and natural killer (NK) cells. In a study by Kariminia et al. (52), CXCL10 met the criteria for replication as a clinical biomarker for the diagnosis of cGvHD. Although plasma concentrations of CCL15 were found to be elevated in cGvHD patients compared with controls and were associated with NRM, levels at day +100 could not predict cGvHD occurring within the next 3 months with clinically relevant sensitivity/specificity (63).

\section{Cellular Markers}

In a study of Inamoto et al. (54), a higher cellular expression of CD163 at day +80 was associated with de novo cGvHD. CD163a macrophage receptor-is expressed at increased levels during oxidative stress; therefore, the authors concluded that monocyte or macrophage activation may contribute to the pathogenesis of cGvHD.

Sarantopoulos and colleagues in 2009 suggested that B cells play a role in $\mathrm{CGvHD}$ pathogenesis through the presence of alloantibodies and high plasma sBAFF levels: both are found in patients with cGvHD. Detailed phenotypic and functional analyses of peripheral $B$ cells in patients after HSCT showed that, in patients with $\mathrm{cGvHD}$, significantly higher BAFF:B cell ratios are observed compared with patients without $\mathrm{CGvHD}$ or with healthy donors $(38,47)$. Other B cell subsets associated with the development of cGvHD are those that express TLR9 (55) and CD21 low B cells (56).

Tfh cells play an important role in the regulation of $\mathrm{B}$ cell immunity. Extensive phenotypic and functional analyses of circulating Tfh cells demonstrated that patients with active cGvHD had a significantly lower frequency of circulating Tfh cells compared with patients without cGvHD (60).

$\mathrm{CD} 4{ }^{+} \mathrm{CD} 146^{+} \mathrm{CCR} 5{ }^{+} \mathrm{T}$ cells are frequent in $\mathrm{cGvHD}$ patients. According to Forcade et al. (59), these cells proved to be sensitive to pharmacological inhibition (59).

Zorn et al. (58) conducted a phenotypic study of $\mathrm{T}_{\text {regs }}$ and demonstrated a decreased frequency in patients with cGvHD compared with patients without cGvHD $(p<0.001)$ and healthy individuals. A different study has connected an increased Th17: $\mathrm{T}_{\text {reg }}$ ratio to the development of liver cGvHD (65). Moreover, Alho et al. (66) confirmed a decreased frequency of $\mathrm{T}_{\text {regs }}$ and shortened $\mathrm{T}_{\text {regs }}$ telomeres in patients with cGvHD.

\section{cGvHD Biomarkers in Children: Children Are Not Small Adults}

It is known that children have a lower rate and perhaps different presentation of cGvHD compared to that seen in adults (25). One of important aspects of cGvHD pathophysiology is the variability of immune reconstitution between patients after HSCT, which is age related and dependent on thymic hormones (as described in a companion article by Eyrich et al. in this supplement of Frontiers in Paediatrics). Therefore, it is important to determine differences among cGvHD biomarkers in adult and paediatric populations.

Few studies have investigated age-related differences in the biology of cGvHD $(16,67)$. Recently, Lawitschka et al. (45) demonstrated for the first time in a highly homogenous paediatric patient cohort that both cGvHD and its activity were associated with the perturbation of the $\mathrm{B}$ cell compartment, including low frequencies of $\mathrm{CD} 19^{+} \mathrm{CD} 27^{+}$memory B cells and increased frequencies of circulating $\mathrm{CD} 19^{+} \mathrm{CD} 21^{\text {low }} \mathrm{B}$ cells. The immunological profile of patients with $\mathrm{cGvHD}$ in a paediatric cohort studied by Schultz et al. (67) had distinctive features, with increased activated T cells, naïve Th cells and cytotoxic T cells, loss of CD56 $6^{\text {bright }}$ regulatory NK cells, and increased levels of 
TABLE 1 | Validated Biomarkers in CGvHD.

\begin{tabular}{|c|c|c|c|c|c|}
\hline \multicolumn{2}{|c|}{ Biomarker } & \multirow{2}{*}{$\begin{array}{c}\text { References } \\
(46)\end{array}$} & \multirow{2}{*}{$\begin{array}{c}\begin{array}{c}\text { Age range, } \\
\text { years }\end{array} \\
1-29\end{array}$} & \multirow{2}{*}{$\begin{array}{c}\text { Association } \\
\text { with cGvHD } \\
\qquad \uparrow\end{array}$} & \multirow{2}{*}{$\begin{array}{l}\text { Use } \\
\text { Diagnostic }\end{array}$} \\
\hline Plasma & sBAFF & & & & \\
\hline & & (48) & $18-68$ & $\uparrow$ & Diagnostic/prognostic \\
\hline & $\begin{array}{l}4 \text { biomarker panel } \\
\text { (ST2, CXCL9, MMP-3, and } \\
\text { osteopontin) }\end{array}$ & (49) & $1-79$ & $\uparrow$ & Diagnostic/prognostic \\
\hline & CXCL9 & (49) & $13-59$ & $\uparrow$ & Diagnostic \\
\hline & & (50) & $0-79$ & $\uparrow$ & Diagnostic \\
\hline & CXCL9, CXCL10 & (51) & $21-68$ & $\uparrow$ & Diagnostic \\
\hline & CXCL10 & (52) & $\leq 18$ & $\uparrow$ & Diagnostic \\
\hline & CCL15 & (63) & $19-79$ & $\uparrow$ & Diagnostic/prognostic \\
\hline & MMP-3 & (53) & $19-73$ & $\uparrow$ & Diagnostic \\
\hline \multirow{5}{*}{ Cellular } & sBAFF:B cell ratio & $(47)$ & $19-66$ & $\uparrow$ & Diagnostic \\
\hline & & (57) & $23-59$ & $\uparrow$ & Diagnostic \\
\hline & $T_{\text {regs }}$ & (58) & NR & $\downarrow$ & Diagnostic \\
\hline & $\begin{array}{l}\mathrm{CD} 4{ }^{+} \mathrm{CD} 146^{+} \mathrm{CCR}^{+} \mathrm{T} \\
\text { cells }\end{array}$ & (59) & $25.9-75.6$ & $\uparrow$ & Diagnostic \\
\hline & Tfh cells & (60) & $25-75.6$ & $\downarrow$ & Diagnostic \\
\hline
\end{tabular}

$\uparrow$, increased in CGVHD; $\downarrow$, decreased in CGVHD; CCL15, chemokine (C-C motif) ligand 15; CGvHD, chronic graft-vs.-host disease; CXCL, chemokine [C-X-C] motif ligand; MMP-3, matrix metalloproteinase 3; NR, not reported; SBAFF, soluble B-cell activating factor; Tfh, T follicular helper; TLR9, toll-like receptor 9; $T_{\text {regs, }}$ regulatory T cells.

ST2 and soluble CD13. When cohorts of adults and children who had undergone HSCT were compared, significant differences were found (16). Elevated levels of ST2 and naïve Th cells, and depression of NK regulatory cells were present in both children and adults. However, children presented with broad suppression of newly formed B cells whereas adults demonstrated increased T1-CD $21^{\text {low }} \mathrm{B}$ cells and decreased $\mathrm{T} 1-\mathrm{CD} 24^{\text {high }} \mathrm{CD} 38^{\text {high }} \mathrm{B}$ cells. $\mathrm{T}_{\text {reg }}$ abnormalities in children were primarily present in memory $\mathrm{T}_{\text {regs, }}$, whereas in adults the abnormalities were in naïve $\mathrm{T}_{\text {regs. }}$. Aminopeptidase $\mathrm{N}$ (sCD13) and intercellular adhesion molecule 1 (ICAM-1) were significantly increased only in prepubertal children with cGvHD (16). The authors concluded that the recipient's age at the time of HSCT impacts on the immune profile of cell populations and cytokines occurring in $\mathrm{cGvHD}$.

Even though there are several validated biomarkers for cGvHD, studies that associate biomarkers with severity, activity and resolution of the disease are lacking. Studies with mixed age cohorts may show trends, but immune reconstitution is age related and this needs to be taken into consideration when evaluating biomarkers and the pathophysiology of cGvHD. The verification and validation of candidate biomarkers in paediatric populations is highly relevant since this is a notoriously underrepresented population within clinical trials and adult data may not be extrapolated to the paediatric population (44). Thus, more age-specific studies of biomarkers are needed because children are simply not "small adults."

\section{Risk Factors for the Development of cGvHD and Prevention Strategies}

Since cGvHD is a highly polymorphic complication of HSCT, much clinical research has been done to characterise disease severity at onset and to define risk factors for the development of $\mathrm{cGvHD}$ and for predicting poor survival $(1,68)$. However, published data on risk factors for paediatric cGvHD often stem from combined adult and paediatric studies and are mutually incomparable because important details of patient and transplant characteristics are incomplete, such as use of conventional vs. high-resolution human leukocyte antigen (HLA) disparity, details of GvHD prophylaxis including blood concentrations and duration of given agents, kinetics of engraftment and chimerism with imminent relapse, and antigenaemia and infections.

Below we provide an overview of risk factors for the occurrence of cGvHD (Table 2) (14, 17, 24, 25, 27, 69-82) and prognostic factors associated with poor outcomes in patients with cGvHD (Table 3) (75, 76, 81, 83-99), prioritising paediatric data wherever possible.

\section{Risk Factors for the Development of cGvHD}

The following risk factors for cGvHD post HSCT have been published and summarised in reviews and recommendations: preceding aGvHD, the use of an unrelated donor or mismatched donor, PBSCs as the donor source, older ( $\geq 12$ years) recipient or donor age, female donor for a male recipient, parity of female donor, malignant primary disease and the use of total body irradiation (TBI) (Table 2). 
TABLE 2 | Summary of risk factors for cGVHD identified in studies, with an emphasis of paediatric cohorts.

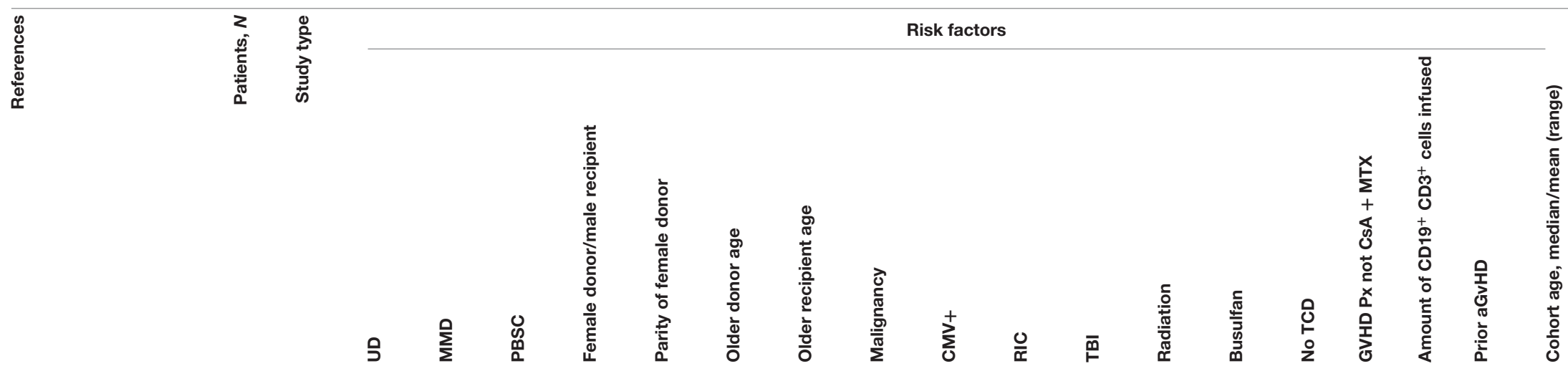

\begin{tabular}{llll}
\hline Zecca et al. (24) $\quad 696 \quad$ MC & $\checkmark$ \\
& & Median 7 \\
& $(0.3-17)$
\end{tabular}

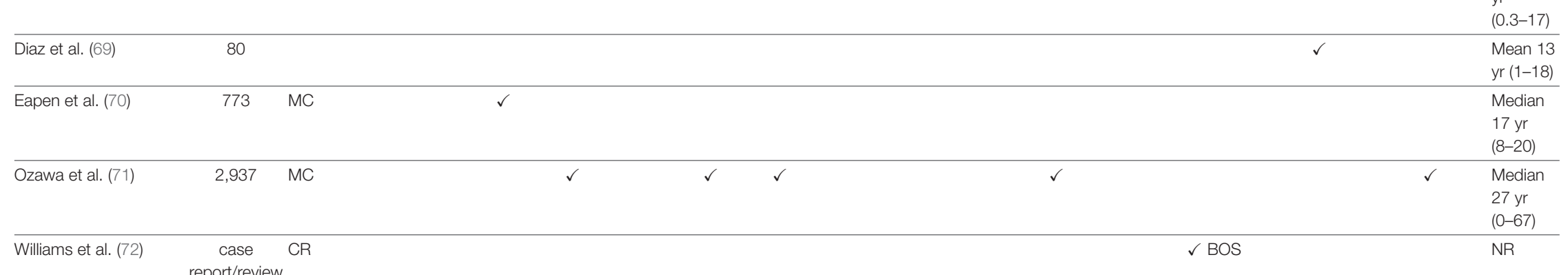

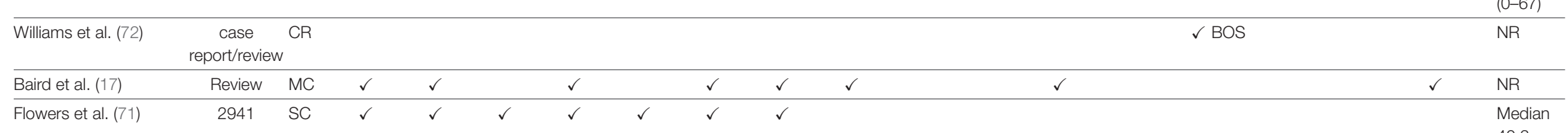

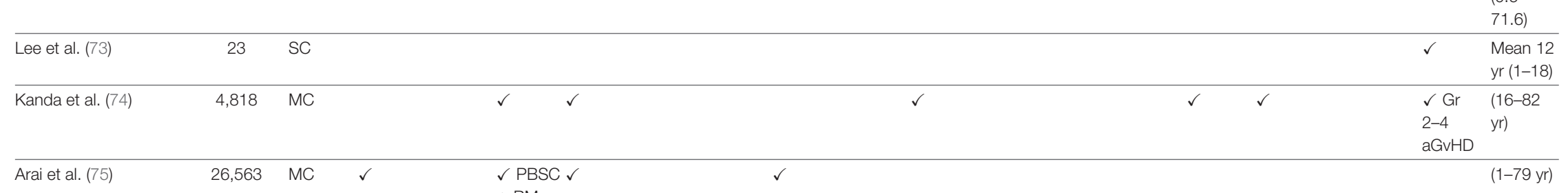

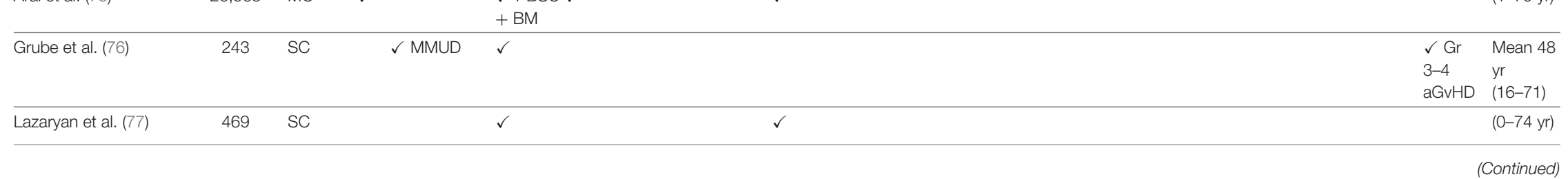


TABLE 2 | Continued

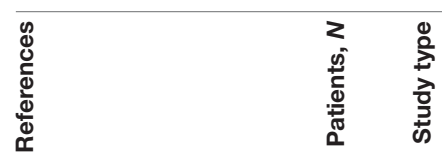

Risk factors

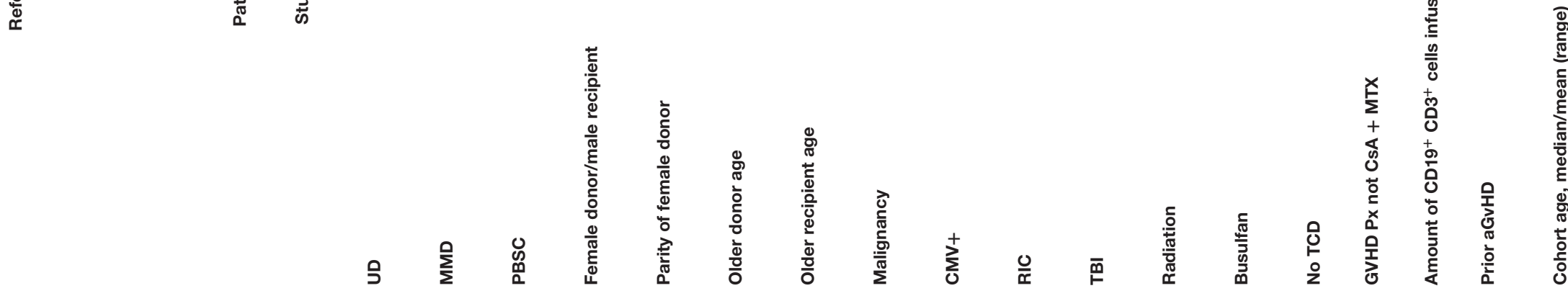

\begin{tabular}{|c|c|c|c|c|c|c|c|c|c|c|c|c|}
\hline Watkins et al. (78) & 442 & SC & & & $\checkmark$ & $\checkmark$ & & & & & & $\begin{array}{l}\text { Median } \\
12 \mathrm{yr} \\
(0.6-21)\end{array}$ \\
\hline Afram et al. (27) & 820 & $\mathrm{MC}$ & & $\begin{array}{l}\checkmark \text { severe } \\
\text { cGvHD }\end{array}$ & & $\checkmark$ & & & & & $\checkmark$ & $(1-70 \mathrm{yr})$ \\
\hline Qayed et al. (25) & 476 & MC & & & $\checkmark$ & $\begin{array}{l}\checkmark \geq 13 \\
y r\end{array}$ & & & & & & $(1-17 \mathrm{yr})$ \\
\hline Cuvelier et al. (14) & 243 & $\mathrm{MC}$ & $\checkmark$ & & & $\begin{array}{l}\checkmark \geq 13 \\
y r\end{array}$ & & & & $\checkmark$ & $\begin{array}{l}\checkmark \mathrm{Gr} \\
2-4 \\
\text { aGvHD }\end{array}$ & $\begin{array}{l}(0.2-18 \\
y r)\end{array}$ \\
\hline Kok et al. (79) & 98 & SC & & & & & & & & $\checkmark$ & & NR \\
\hline $\begin{array}{l}\text { For sclerotic cGvHD: } \\
\text { Martires et al. (80) }\end{array}$ & 206 & SC & & & & & $\checkmark$ & $\checkmark$ & $\checkmark$ & & $\checkmark$ & NR \\
\hline Inamoto et al. (81) & 977 & $\mathrm{SC}$ & & & & & & $\checkmark$ & $\checkmark$ & & $\checkmark$ & $\begin{array}{l}\text { Median } \\
48 \mathrm{yr} \\
(0-78)\end{array}$ \\
\hline
\end{tabular}

$\checkmark$, associated with the risk of CGVHD; A, adult; BOS, bronchiolitis obliterans syndrome; Ad, adolescent patients; CMV+, cytomegalovirus seropositivity; Gr, grade; MC, multicentre; MMD, mismatched donor; MMUD, mismatched unrelated donor; NR, not reported; P, paediatric; PBSC, peripheral blood stem cell; RIC, reduced-intensity conditioning; SC, single centre; TBI, total body irradiation; TCD, T-cell depletion; UD, unrelated donor; yr, years. 
TABLE 3 | Summary of risk factors for higher NRM and lower OS in patients with cGVHD identified in studies.

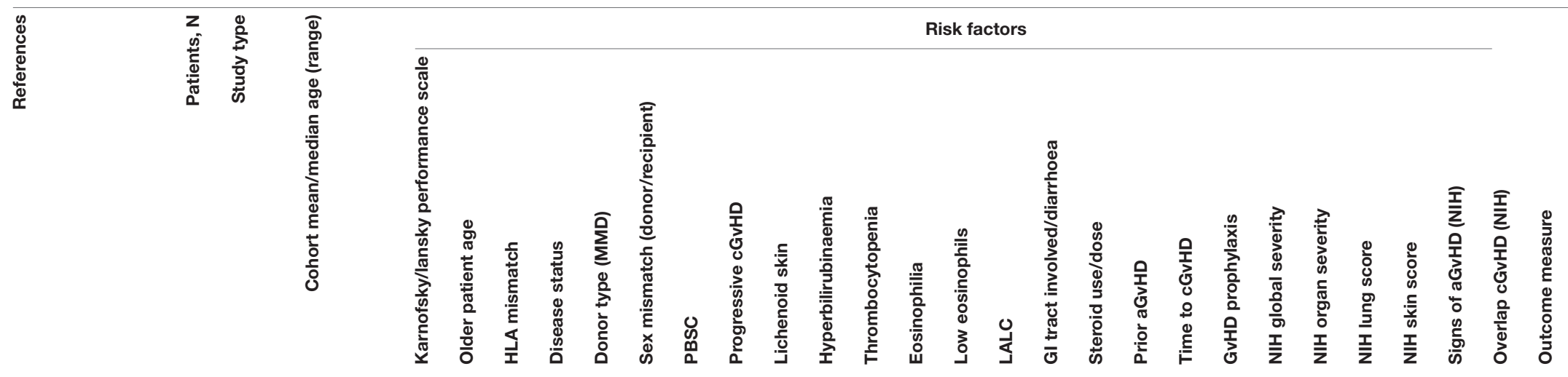

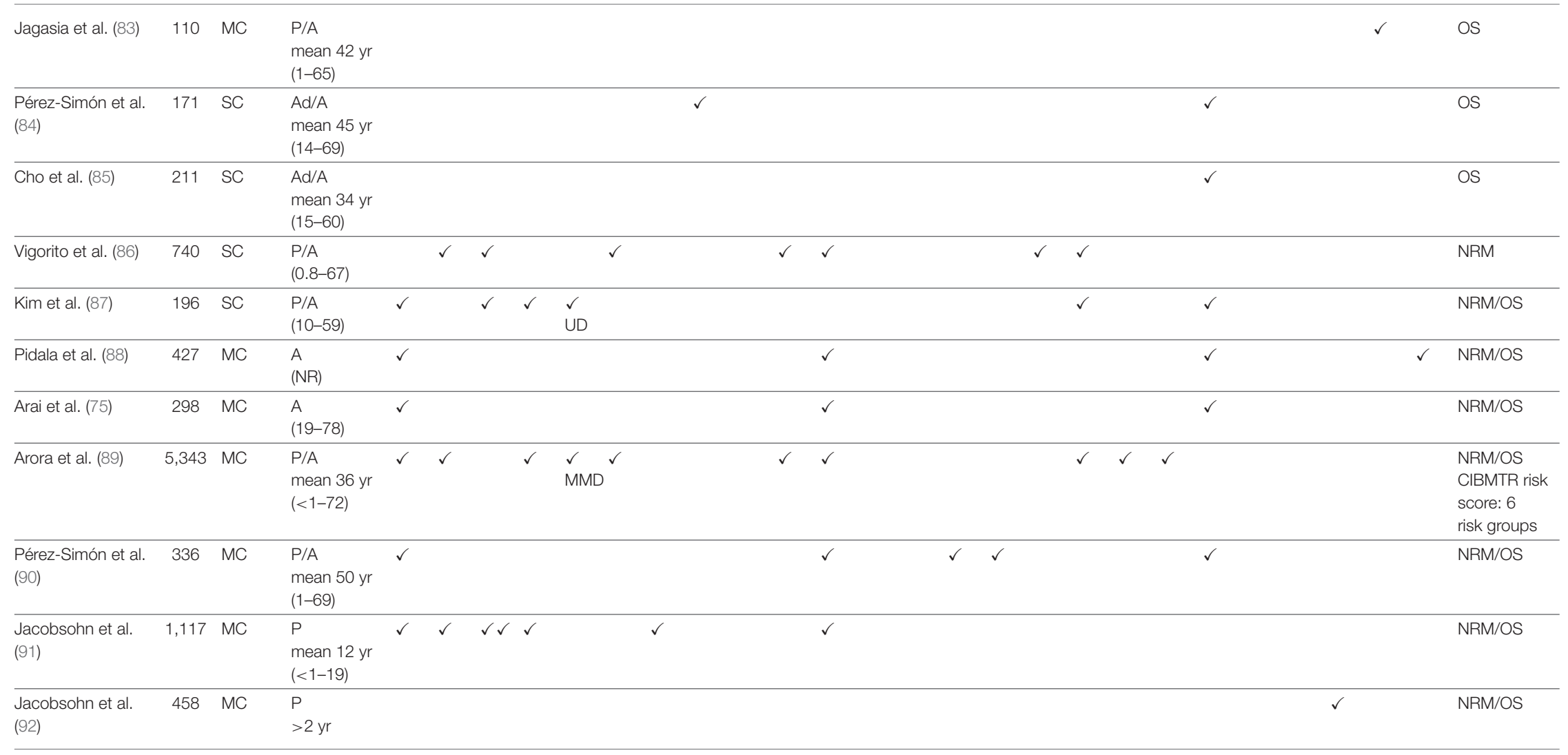


TABLE 3 | Continued

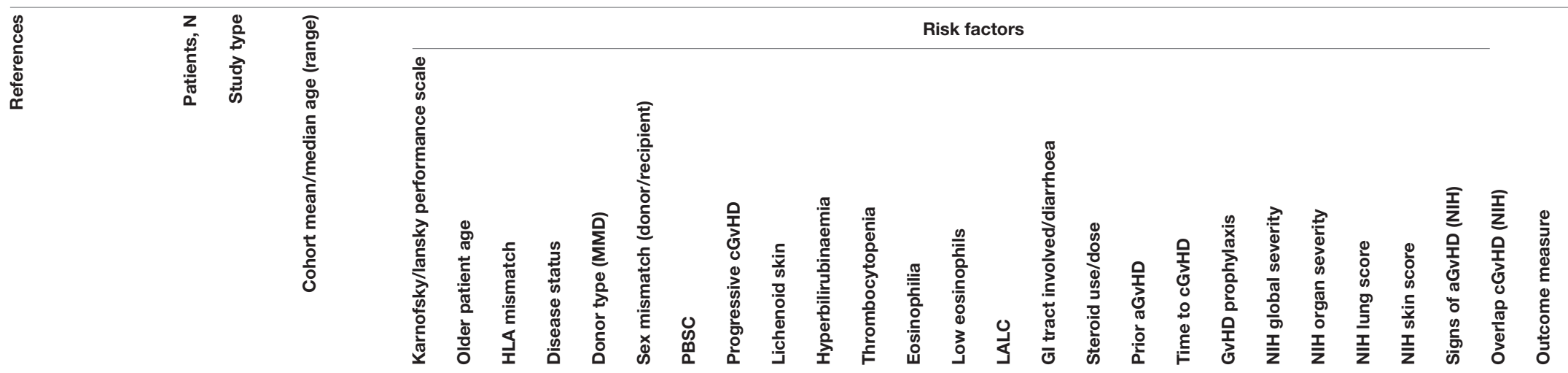

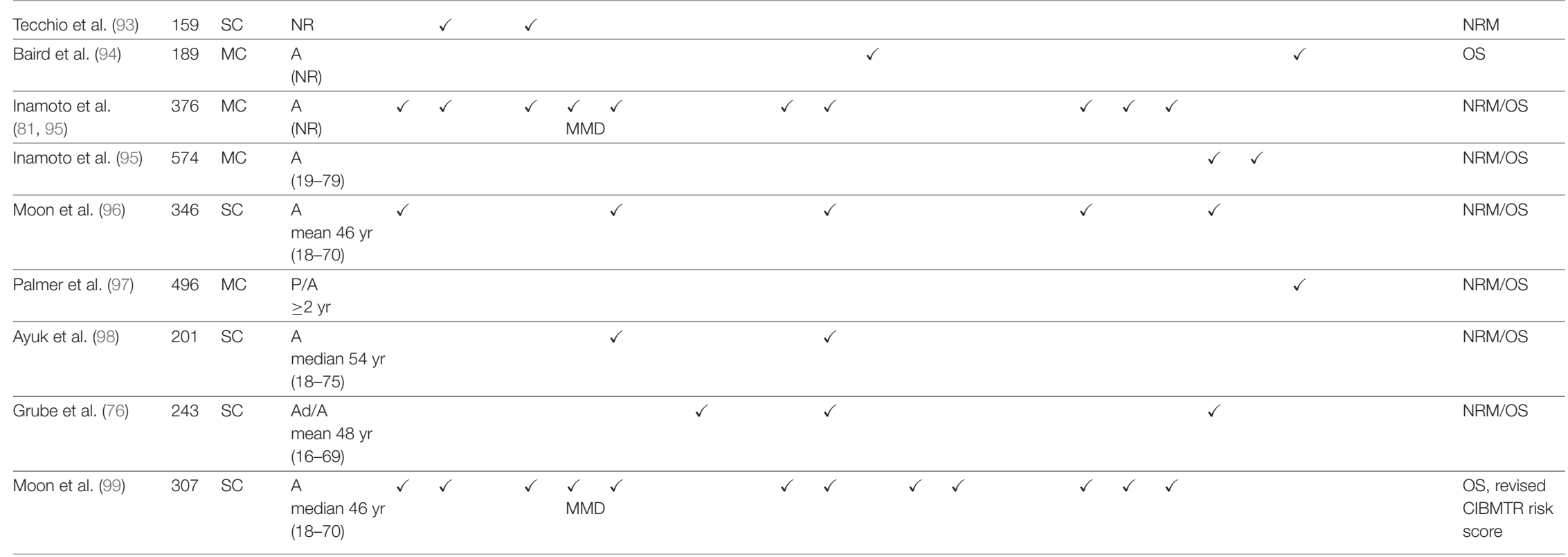

A, adult; Ad, adolescent; aGvHD, acute graft- vs.-host disease; CGvHD, chronic graft- vs. -host disease; CIBMTR, Centre for International Blood and Marrow Transplant Research; Gl, gastrointestinal; HLA, human leukocyte antigen; LALC, lower absolute lymphocyte count; MC, multicentre; MMD, mismatched donor; NIH, National Institutes for Health; NR, not reported; NRM, non-relapse mortality; OS, overall survival; P, paediatric; PBSC, peripheral blood stem cell; SC, single centre; UD, unrelated donor; yr, year. 
By far the most powerful predictor for the development of cGvHD seems the severity of aGvHD $(17,24,83)$. A lower incidence and severity of aGvHD and cGvHD has been associated with the use of ex vivo or in vivo T-cell depletion (TCD). However, use of TCD poses a risk of graft failure, infection and relapse (12); further data in paediatric HSCT for ALL are needed.

\section{Prognostic Factors Associated With Higher NRM and/or Poorer OS}

Regarding prognostic factors at the onset of $\mathrm{cGvHD}$ that are associated with increased mortality, the development, validation and the revision of the NIH consensus criteria for diagnosis and staging of $\operatorname{cGvHD}(5,6)$ have moved the field forward substantially (see Supplementary Material). In children, Cuvelier et al. reported on the feasibility and reliability of the $\mathrm{NIH}$ consensus criteria and concluded that further refinement was needed (14). The NIH global severity score of cGvHD has been validated in various adult studies, but less so in children $(84,85,87,90)$ and adolescents (76). In a large paediatric Centre for International Blood and Marrow Transplant Research (CIBMTR) study including 1,117 patients, Jacobsohn et al. found the following variables to be associated with higher NRM in a multivariate analysis: mismatched unrelated donor (MMUD), PBSC as the stem cell source, Karnofsky/Lansky performance score $<80$, and platelet count $<100 \times 10^{9} / \mathrm{L}$. Regarding worse OS, the study reported age $>10$ years, an MMUD, advanced disease at transplantation, Karnofsky/Lansky score $<80$; and platelet count $<100 \times 10^{9} / \mathrm{L}$ as significant risk factors (70). Additional risk factors associated with poor prognosis are direct progression from aGvHD to $\mathrm{cGvHD}$ and organ-specific aspects such as lung and gastrointestinal tract involvement and hyperbilirubinaemia (76) (Table 3).

Prior to publication of the NIH consensus criteria, a CIBMTR cGvHD risk score had been developed $(89,100)$. Studies in adults reported on improved prognostic stratification when combining the CIBMTR cGvHD score with the NIH criteria $(95,101)$.

To address the question of risk factors for $\mathrm{CGvHD}$ in paediatric patients, we studied retrospective data on 358 paediatric patients who underwent HSCT between 1980 and 2012 at the St. Anna Children's Hospital, Vienna, and who survived relapsefree beyond day +100 . We identified in multivariate analyses older donor age ( $>5$ years), prior aGvHD of grade $2-4$, and a female donor for a male recipient as risk factors for the development of cGvHD. Overall mortality was significantly higher for patients $>10$ years old and for those with moderateto-severe global severity score, while sclerotic cGvHD was independently associated with a lower risk of death (A. Lawitschka, unpublished data).

Within the NIH 2020 initiative a summary has been provided about the major advances in understanding of the aetiopathology of cGvHD and future efforts $(11,102,103)$. The field is moving toward clinical studies targeting prevention strategies that decrease the risk of morbid cGvHD such as moderate-tosevere $\mathrm{cGvHD}$ without an increased risk of relapse or infection. Regardless of the incidence of cGvHD, morbid forms of cGvHD like fasciitis and lung GvHD lead to excess long-term morbidity and a future aim is to avoid these. Therefore, it is important to evaluate risk factors for the development and the outcome of $\mathrm{cGvHD}$ and to predict the highly morbid forms.

The $2020 \mathrm{NIH}$ cGVHD consensus group agreed on the need for adoption of primary study endpoints measuring survival without moderate-to-severe cGvHD, such as cGvHDfree and relapse-free survival (CRFS). This remains challenging as studies need a minimum of 1 year of follow-up to assess relevant endpoints of cGvHD (12). In this regard, an important consideration for paediatric studies may be that endpoints should be tailored to non-malignant and malignant primary diseases separately because patient and HSCT characteristics, GvHD prophylaxis and treatment modalities differ distinctly between those patient groups (104).

\section{NIH-Defined Diagnosis, Organ Scoring and Staging of CGvHD}

The 2005 NIH Consensus Conference proposed new criteria for diagnosing and scoring the severity of cGvHD in clinical trials (6). The $2014 \mathrm{NIH}$ consensus maintained the prior framework but revised the criteria and provided guidelines for cGvHD definition, endpoint reporting and trial design. The main revisions were made for the subcategory of overlap cGvHD and the distinction between active disease and past tissue damage (5). Recently, a joint task force added some specifications to the NIH consensus criteria, with focus in associated manifestations and steroid sensitivity (105).

The 2014 NIH consensus criteria include clinical symptoms in 8 organs, laboratory findings and pulmonary function tests. Each organ is graded from 0 to 3 ; the overall severity is classified as mild, moderate or severe depending on the number of affected organs and the involvement severity. Symptoms can be stratified as diagnostic, distinctive and in common with aGvHD (5).

Patients who are lacking diagnostic signs of cGvHD require histological confirmation if new systemic immunosuppressive treatment is to be introduced, especially in the case of treatment failure. Exclusion of differential diagnoses such as infection is required (105). The most commonly affected organ is the skin, followed by the eyes $(14,73)$. Patients may show other immune-mediated manifestations also (termed "other, associated" manifestations), which should be evaluated although they do not contribute to grading. Regarding the type of onset of $\mathrm{cGvHD}$, the following definitions are applied: progressive (progression from aGvHD without resolution), quiescent (prior aGvHD with resolution), and de novo (without any history of aGvHD) (105).

\section{Applying and Adapting the NIH Criteria to Paediatric Patients}

Originally, the NIH consensus criteria were not validated in patients under 18 years of age. Lee et al. attempted to implement the 2005 criteria in paediatric patients (73). Furthermore, a paediatric adaption has been developed by Lawitschka et al. (1), which has been revised for clinical use within the paediatric transplant centres of the German-Austrian-Swiss Consensus Group (www.GVHD.de), but as yet is not validated. In 2019, Cuvelier et al. (14) reported important data from a prospective multi-institutional study on biomarkers in cGvHD in 302 
paediatric patients for which the 2014 NIH criteria were not only applied but also reviewed by a study adjudication committee. Although $28 \%$ of cGvHD cases were reclassified, the authors reported that the application of NIH criteria was feasible and reliable in a paediatric population. In that study cohort, the incidence of late acute and classic cGvHD was similar ( 25 vs. $21 \%$, respectively), which underlines the relationship between aGvHD and cGvHD; in fact, very few children have true de novo cGvHD and aGvHD of grade 2-4 is one of the main risk factors for developing cGvHD (see Table 2). The NIH criteria have also been adjusted for paediatric patients for the diagnosis and staging of pulmonary GvHD (14).

\section{Treatment for Paediatric cGvHD}

\section{First-Line Classic Immunosuppressive Therapy}

In mild cGvHD, patients may only require topical treatment depending on the organs involved and the risk of relapse of the underlying disease (106). In multiorgan involvement at cGvHD onset, moderate-to-severe or/and high-risk cGvHD (see section Risk Factors for the Development of cGvHD and Prevention Strategies on risk factors) immunosuppressive treatment is necessary. The recommended first-line immunosuppressive treatment comprises a corticosteroid (prednisone $1 \mathrm{mg} / \mathrm{kg} /$ day) with or without a calcineurin inhibitor (CNI) $(107,108)$, with topical therapy wherever possible; this applies to moderate and severe cGvHD at onset also (109). The addition of a CNI to corticosteroid therapy does not increase the response rate but allows for a reduction in corticosteroid dosing that can reduce long-term side effects. Koc et al. compared in a randomised study prednisone vs. prednisone plus cyclosporine in patients with cGvHD ( $n=307$; age $0.9-57.1$ years) without thrombocytopenia and reported similar outcomes for both study groups, with the exception that steroid-associated toxicity was lower with prednisone plus cyclosporine (110).

Recently, rituximab was evaluated as a part of the first-line therapy of cGvHD. In a phase 2 , prospective trial ( $n=24$ adults) it was added to a corticosteroid and CNI for newly diagnosed cGvHD (111). The overall response rate (ORR) at 1 year was $83 \%$ and the 1-year cumulative incidence of NRM was $14 \%$. In two other studies on rituximab as the frontline therapy of $\mathrm{cGvHD}$ $(112,113)$, the cumulative incidence of cGvHD resolution at 3 years was $71-77 \%$ and the rate of NRM was $15-19 \%$.

The efficacy of rituximab-based first-line treatment of cGvHD needs further investigation. In this regard, paediatric data are lacking. There is an ongoing clinical trial on the use of itacitinib and extracorporeal photopheresis (ECP) in adult patients (NCT04446182) as well as ibrutinib in patients over 12 years old (NCT02959944) as frontline cGvHD treatment.

For a risk-adapted, individualised approach to cGvHD management, not only the risk of relapse and infectious complications but additionally details of the pharmacological immunosuppression at onset of $\mathrm{cGvHD}$ may be considered (the intensity of any ongoing immunosuppression or time since termination of immunosuppression). Furthermore, the risk factors for $\mathrm{cGvHD}$ associated with poor prognosis (i.e., lung involvement, gastrointestinal involvement, hyperbilirubinaemia, thrombocytopenia and progressive onset) and the patient's general condition (Karnofsky/Lansky score) (91) may be of help to calibrate the intensity of first-line treatment.

Particularly for paediatric patients, the toxicity of long-term steroid therapy causes significant future problems (see Table 4) (114-138), such as effects on the musculoskeletal system resulting in growth and developmental retardation $(117,139)$. Therefore, the addition of an effective steroid-sparing agent and topical therapy is of crucial importance for long-term patient outcome.

\section{Topical Treatment and Ancillary Care}

In general, topical treatment and ancillary care for cGvHD is less toxic than systemic therapy and can improve response, thereby facilitating systemic dose reduction with the aim to apply systemic immunosuppression at the lowest effective dose for the shortest possible duration. This approach allows for minimisation of treatment-related side effects, and, in case of high risk of relapse or infection, it may spare systemic immunosuppression saving the protective GvL effect. The latter aspect is supported by consensus opinion predominantly, and controlled data are scarce in this regard (140-142).

Ample topical treatment of cGvHD is important in mild cGvHD as systemic immunosuppression may not be required, while in moderate-to-severe $\mathrm{cGvHD}$, topical treatment may hasten local responses in addition to systemic therapy. In patients with mixed responses (i.e., who have a response in one organ yet stable disease/progression in another organ) remaining symptoms may be addressed by topical treatment.

Of note, topical treatment in children bares two caveats: firstly, systemic levels of topical agents must be considered in infants because they have a larger surface area to body weight ratio than older patients and, secondly, the parents' assistance and compliance must be gained. In Table 5 (106, 135, 139-143, 158167) we provide selected organ-specific modalities of topical treatment and ancillary care for use in daily clinical practice, providing paediatric data where possible. For more detail, we refer readers to comprehensive publications by Dignan et al., Wolff et al., and Carpenter et al. (108, 142, 143).

\section{Steroid Refractoriness}

Treatment of cGvHD aims to reduce symptoms, control activity of disease manifestations, improve OS and quality of life, and prevent impairment and tissue damage. Untreated cGvHD leads to disability and death. Steroids as first-line cGvHD therapy led to a complete response (CR) in $30-50 \%$ of patients, which may indicate that the remaining $50-70 \%$ have steroid-refractory or steroid-dependent disease. Therapy is usually long-lasting. The median duration of systemic cGvHD treatment was 28.7 months in one study of paediatric and adult patients (86). Among patients with $\mathrm{cGvHD}$, approximately $50 \%$ discontinue systemic treatment within 7 years, $10 \%$ require continued systemic treatment beyond 7 years, and 40\% experience recurrent malignancy or NRM (158).

In 2018, the following definitions of steroid-refractory and steroid-dependent cGvHD were suggested by the European Society of Blood and Marrow Transplantation (EBMT)-NIHCIBMTR Task Force: (105). 
TABLE 4 | The main side effects of commonly used agents for cGvHD, other than infection risk.

\begin{tabular}{|c|c|c|c|c|c|c|c|}
\hline \multirow[t]{2}{*}{ Therapy } & \multicolumn{7}{|c|}{ Side effect } \\
\hline & Blood & Cardiovascular & Visceral & Mobility & Neurological & Hormonal & Other \\
\hline Steroids (114-117) & Leucocytosis & $\begin{array}{l}\text { Hypertension, } \\
\text { metabolic syndrome, } \\
\text { thrombosis }\end{array}$ & Peptic ulcer & $\begin{array}{l}\text { Myopathy, avascular } \\
\text { bone necrosis }\end{array}$ & $\begin{array}{l}\text { Depression, } \\
\text { behavioural changes } \\
\text { (264), sexual } \\
\text { dysfunction }\end{array}$ & $\begin{array}{l}\text { Insulin resistance, } \\
\text { hyperglycaemia }\end{array}$ & $\begin{array}{l}\text { Striae, weight gain, } \\
\text { hirsutism, glaucoma, } \\
\text { cataract, fatigue }\end{array}$ \\
\hline $\begin{array}{l}\text { Mycophenolate mofetil } \\
(118-122)\end{array}$ & & & $\begin{array}{l}\text { Gl toxicity, nausea } \\
\text { diarrhoea, abdominal } \\
\text { discomfort, hepatitis }\end{array}$ & & Peripheral neuropathy & & $\begin{array}{l}\text { Increased risk of skin } \\
\text { cancer, fatigue }\end{array}$ \\
\hline $\begin{array}{l}\text { Calcineurin Inhibitors } \\
\text { (114) }\end{array}$ & $\begin{array}{l}\text { Anaemia, } \\
\text { thrombo-cytopenia }\end{array}$ & $\begin{array}{l}\text { Hypertension, } \\
\text { transplant-related } \\
\text { microangiopathy }\end{array}$ & $\begin{array}{l}\text { Acute and chronic } \\
\text { nephropathy, tubular } \\
\text { dysfunction } \\
\text { (hyperkalaemia, } \\
\text { hyponatraemia, } \\
\text { hypomagnesaemia, } \\
\text { hypercalciuria, and } \\
\text { hyperuricaemia) }\end{array}$ & $\begin{array}{l}\text { Peripheral neuropathy } \\
\text { (264) }\end{array}$ & $\begin{array}{l}\text { Central neuropathy, } \\
\text { tremor, psychosis, } \\
\text { PRES, seizures (264) }\end{array}$ & $\begin{array}{l}\text { Impaired glucose } \\
\text { tolerance, diabetes }\end{array}$ & $\begin{array}{l}\text { Hirsutism, increased } \\
\text { risk of skin cancer, } \\
\text { fatigue }\end{array}$ \\
\hline Sirolimus $(114,123)$ & Pancytopenia & $\begin{array}{l}\text { Hypertension, } \\
\text { hyperlipidaemia, } \\
\text { peripheral oedema }\end{array}$ & $\begin{array}{l}\text { Renal insufficiency, } \\
\text { proteinuria, colitis, } \\
\text { pancreatitis }\end{array}$ & $\begin{array}{l}\text { Avascular bone } \\
\text { necrosis }\end{array}$ & & & Pneumonitis, fatigue \\
\hline Imatinib $(124,125)$ & Leukopenia & Peripheral oedema & $\begin{array}{l}\text { Nausea Abdominal } \\
\text { discomfort }\end{array}$ & $\begin{array}{l}\text { Muscle spasms } \\
\text { Stiffness }\end{array}$ & Sexual dysfunction & & Oral ulcers, fatigue \\
\hline $\begin{array}{l}\text { Rituximab } \\
(111,113,125-128)\end{array}$ & $\begin{array}{l}\text { B-cell aplasia, hypo- or } \\
\text { a-gammaglobulinaemia }\end{array}$ & & & & Depression & & Fatigue \\
\hline Ibrutinib (129) & Low platelets, bleeding & $\begin{array}{l}\text { Hypertension, cardiac } \\
\text { arrhythmia }\end{array}$ & Nausea & $\begin{array}{l}\text { Muscle spasms, } \\
\text { peripheral neuropathy }\end{array}$ & Peripheral neuropathy & & $\begin{array}{l}\text { Oral ulcers }(137,138) \text {, } \\
\text { fatigue }\end{array}$ \\
\hline Ruxolitinib (130-132) & Pancytopenia, bleeding & $\begin{array}{l}\text { Hypertension, } \\
\text { hyperlipidaemia }\end{array}$ & Hepatitis, Gl bleeding & & Dizziness, headaches & & Weight gain, fatigue \\
\hline ECP (133-135) & & $\begin{array}{l}\text { Vascular access } \\
\text { complications, } \\
\text { thrombosis }\end{array}$ & & & & & \\
\hline
\end{tabular}

This summary lists the most common or most severe persistent side effects of therapeutic regimens. For a full list of side effects for each agent, please refer to the most recent product information. cGiHD, chronic graft- vs. -host disease; ECP, extracorporeal photopheresis; Gl, gastrointestinal; PRES, posterior reversible encephalopathy syndrome (114-122). 
TABLE 5 | Topical treatment and ancillary care for cGVHD.

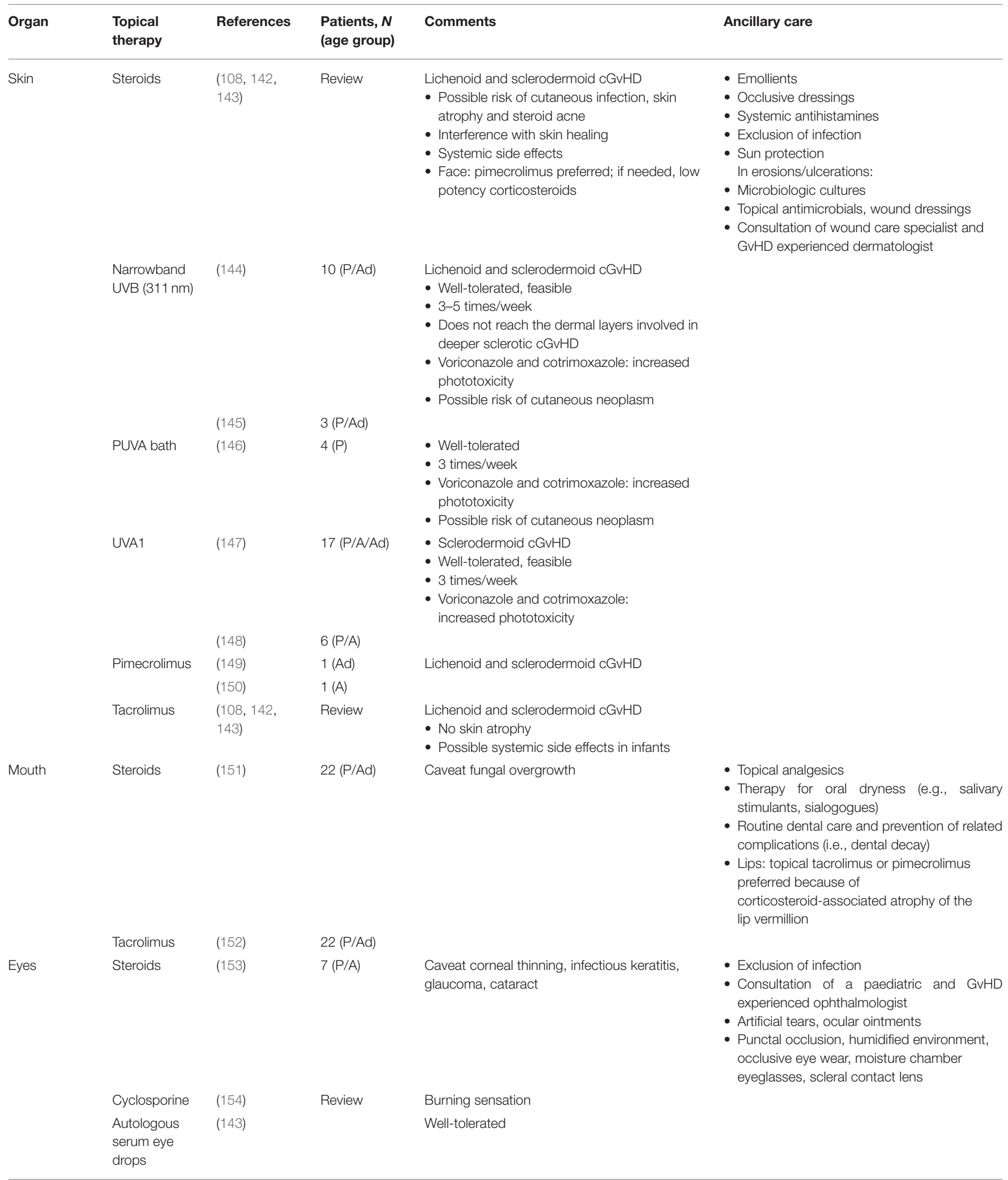


TABLE 5 | Continued

\begin{tabular}{|c|c|c|c|c|c|}
\hline Organ & $\begin{array}{l}\text { Topical } \\
\text { therapy }\end{array}$ & References & $\begin{array}{l}\text { Patients, } N \\
\text { (age group) }\end{array}$ & Comments & Ancillary care \\
\hline \multirow[t]{2}{*}{$\begin{array}{l}\text { Vulva and } \\
\text { vagina }\end{array}$} & Steroids & $(155)$ & $33(\mathrm{P} / \mathrm{A})$ & Caveat fungal overgrowth & $\begin{array}{l}\text { - Exclusion of coexisting infection } \\
\text { - Water-based or silicone lubricants } \\
\text { - Early gynaecology consultation } \\
\text { - Avoid glycerin, paraben, fragrance and other } \\
\text { additive products }\end{array}$ \\
\hline & Oestrogen & & & & \\
\hline \multirow[t]{2}{*}{$\begin{array}{l}\text { Gl tract and } \\
\text { liver }\end{array}$} & Steroids & $(156)$ & $15(\mathrm{P} / \mathrm{A})$ & & $\begin{array}{l}\text { - Exclusion of coexisting infection or } \\
\text { gastroesophageal reflux } \\
\text { - Avoidance of hepatotoxins } \\
\text { - Dietary modification } \\
\text { - Enzyme supplementation for pancreatic } \\
\text { insufficiency } \\
\text { - Gastroesophageal reflux management } \\
\text { - Ursodeoxycholic acid }\end{array}$ \\
\hline & & $(157)$ & $33(\mathrm{P} / \mathrm{A})$ & & \\
\hline Lung & Steroids & $\begin{array}{l}(108,142, \\
143)\end{array}$ & Review & & $\begin{array}{l}\text { - Exclusion of coexisting infection } \\
\text { - Fluticasone, azithromycin and montelukast } \\
\text { (FAM) } \\
\text { - To enhance mucociliary clearance: inhalation } \\
\text { with hypertonic saline 3-6\% } \\
\text { - Optimal supportive care } \\
\text { - Immunoglobulin substitution } \\
\text { - Pulmonary rehabilitation }\end{array}$ \\
\hline
\end{tabular}

Inhaled

bronchodilators

A, adults; Ad, adolescents; cGvHD, chronic graft- vs.-host-disease; Gl, gastrointestinal; P, paediatric; PUVA, Psoralen ultraviolet light A; UVB, ultraviolet light B.

- Steroid-refractory cGvHD (SR-GvHD): progression of cGvHD despite prednisolone $\geq 1 \mathrm{mg} / \mathrm{kg} /$ day for $1-2$ weeks, or stable cGvHD without improvement for 1-2 months while on prednisolone $\geq 0.5 \mathrm{mg} / \mathrm{kg} / \mathrm{day}$

- Steroid-dependent cGvHD: two unsuccessful attempts, separated by at least 8 weeks in time, to taper steroids.

The incidence of SR-cGvHD is difficult to estimate. A prospective study by Martin et al. in adults (159) showed that $>20 \%$ of the patients achieve $\mathrm{CR}$ or partial response (PR) to first line treatment based mostly on prednisone with or without calcineurin inhibitors with no secondary systemic treatment or recurrent malignancy at 1 year after the initial cGvHD treatment. This indicates a great need to search for and design new first-line treatment regimens.

\section{Second- and Late-Line Therapy for cGvHD}

So far there is no consensus regarding second and later lines of treatment for SR-cGvHD. There are numerous drugs and cellular therapy options that may be considered in this group of patients. Most of them were studied in retrospective analyses or small groups of patients, and there are very few prospective clinical trials regarding paediatric populations with $\mathrm{cGvHD}$.

Paediatric data on the use of immunosuppressive and immunomodulating drugs in the treatment of $\mathrm{cGvHD}$ are summarised in Table 6 (62, 119, 120, 124, 126, 130, 133, 136, 160205).
Second-line therapy should include agents with high efficacy and a good safety profile. In ALL patients, it is also important to spare the GvL effect. It is known that ECP preserves the antiviral and anti-leukaemic effect (206) and has a very low incidence of side effects. TKIs enhance the antileukaemic effect and are highly effective in SR-cGvHD but some studies reported a high incidence of infectious complications. Anyway, classical immunosuppressive agents like high-dose steroids, mycophenolate mofetil, rituximab, methotrexate, cyclophosphamide, pentostatin and mTOR inhibitors still find their place in SR-cGvHD management. Some of therapies are more effective than others for specific cGvHD manifestations, which also should be taken into account when selecting second and later lines of therapy (Table 6).

\section{New and Emerging Therapies}

In recent years various novel agents have been tested in the treatment of cGvHD. Among them tyrosine kinase inhibitors (TKIs) found their place in the therapy of SR-cGvHD and were approved by FDA in this indication. We discuss them below.

Belumosudil, a selective ROCK2 inhibitor, has been shown to be effective in recipients over 12 years of age with persistent cGvHD who failed 2-5 prior systemic lines of treatment and was approved by FDA in this age group (198). It decreases production of IL-17 and IL-21, which are pro-inflammatory cytokines and mediators of autoimmune disorders like rheumatoid arthritis and systemic lupus erythematosus. In a phase II clinical trial of 65 participants with predominantly severe cGvHD complete 
TABLE 6 | Immunosuppressive and immunomodulatory agents used in the treatment of paediatric cGVHD.

\begin{tabular}{|c|c|c|c|}
\hline Therapeutic agent & Mechanism of action & Response & Comments \\
\hline $\begin{array}{l}\text { Mycophenolate mofetil } \\
\text { (MMF) }\end{array}$ & $\begin{array}{l}\text { Depletes guanosine nucleotides in } \mathrm{T} \text { and } \mathrm{B} \\
\text { lymphocytes leading to inhibition of their } \\
\text { proliferation (119) }\end{array}$ & $\begin{array}{l}\text { ORR } 60 \% \text { in a study of } 15 \text { paediatric patients } \\
3-16 \text { years (220). Best responses in Gl tract } \\
(60 \% \text { CR), mouth ( } 33 \% \text { CR) and } \\
\text { non-sclerodermatous skin involvement ( } 43 \% \\
\text { CR). ORR } 69 \% \text { in a prospective study of } \\
\text { imatinib + MMF for } 13 \text { paediatric patients (age } \\
5-20 \text { years) with sclerotic / fibrotic SR-cGvHD } \\
\text { (160) }\end{array}$ & $\begin{array}{l}\text { No benefit was found from adding MMF to } \\
\text { first-line treatment for cGvHD (120) }\end{array}$ \\
\hline Rituximab & $\begin{array}{l}\text { Humanised chimeric monoclonal anti-CD20 } \\
\text { antibody that induces killing of CD20 }{ }^{+} \text {cells by } \\
\text { direct and indirect mechanisms }(126)\end{array}$ & $\begin{array}{l}\text { ORR } 86.4 \% \text { in } 37 \text { patients (age } 8-57 \text { years): } \\
8 / 37 \text { CR, 24/37 PR. The responses were better } \\
\text { for skin, oral cavity and musculoskeletal } \\
\text { involvement (161) }\end{array}$ & $\begin{array}{l}\text { Attention must be paid to anti-infectious } \\
\text { prophylaxis. }\end{array}$ \\
\hline Methotrexate & $\begin{array}{l}\text { Multiple actions: (1) suppresses many } \\
\text { inflammatory and immune reactions; (2) } \\
\text { induces T-cell apoptosis; (3) increases the } \\
\text { expression of long non-coding RNA p21, which } \\
\text { regulates many immune and inflammatory } \\
\text { processes; (4) modulates signalling pathways }\end{array}$ & $\begin{array}{l}\text { Meta-analysis by Nassar et al. (163) of } 125 \\
\text { patients (age 2-60 years): ORR } 77.6 \% \text {, CR } \\
49.6 \%, \text { PR } 28 \% \text {. Best responses were } \\
\text { achieved in skin ( } 77 \% \text { ) and liver ( } 72 \%) ; 2 \text { out of } \\
2 \text { patients with pulmonary involvement } \\
\text { responded. }\end{array}$ & $\begin{array}{l}\text { Grade III-IV haematologic toxicities observed in } \\
17.6 \% . \\
\text { Methotrexate is one of the most cost-effective } \\
\text { drugs used in the treatment of SR-cGVHD (164) }\end{array}$ \\
\hline
\end{tabular}

Tacrolimus Calcineurin phosphatase inhibitor (inhibits T-lymphocyte signal transduction and IL-2 transcription) $(165,228)$.

Cyclophosphamide Alkylating agent

mTOR inhibitor Inhibits mTOR, a kinase regulating mRNA (sirolimus, everolimus) translation and protein synthesis; stops cytotoxic T-cell proliferation and dendritic cell activity; promotes generation of $\mathrm{T}_{\text {regs; }}$; and has antifibrotic, antineoplastic and antiviral effects (170)

Pentostatin Inhibitor of adenosine deaminase which is active mainly in lymphoid system cells, especially $\mathrm{T}$ cells.

Belumosudil

Selective Rho-associated coiled-coil-containing protein kinase 2 (ROCK2) inhibitor, decrease of IL-17 and IL-21

ORR 46\% in combination with MMF for refractory cGvHD in 26 patients (7 patients under 20 years old) (166)

ORR 53\% in 13 patients (age 28-67) with SR-cGvHD (CR 1/13, PR 6/13) (168)

ORR $48.6 \%$ in 138 patients (7 patients under 20 years old) at 6 months when used with prednisone as frontline cGvHD therapy (171)

ORR $53 \%$ in paediatric phase 2 trial of pentostatin for SR-cGvHD in 51 children, median age 9,8 years (175). ORR 55\% in a prospective phase 2 trial (174) of effect (175)

58 patients (age 5-64 years) - the response rate was better among patients $<33$ years old vs. $>33$ years old (77 vs. $37.5 \%$ ).

Best ORR $74-77 \%$ in 65 patients aged $>12$ years with persistent cGvHD after 2 to 5 prior systemic treatment lines (198)

Bortezomib

Reversible proteasome inhibitor. Inhibits T cells and prevents activation of dendritic cells that mediate antigen presentation and cytokine transcription

Pomalidomide

Derivative of thalidomide (4,000-fold greater inhibition of TNF- $\alpha$ than thalidomide)
ORR $80 \%$ (10\% CR, 70\% PR) in 22 adults receiving bortezomib+prednisone for initial therapy (199) successful discontinuation of steroids in 2 of 3 paediatric patients with skin GVHD (200) ORR $67 \%$ in 24 adults with SR-cGvHD at 6 months (201)

ORR $54 \%$ in 13 adults with SR-cGvHD (only PR) (202)

Best ORR 40\% in a retrospective study of 15 adults (209) ORR 44\% (PR) in a phase I study of 16 adults with SR-cGvHD (203)
79\% treatment failure in 39 patients treated with tacrolimus after first-line treatment failure (CsA + prednisone) (167)

Very few retrospective studies. Three of three adults with cGvHD showed response in liver and oral cavity (169)

ORR 63-81\% in SR-cGvHD in adult studies (172, 173)

Main adverse events include renal toxicities (when used with CNIs), hyperlipidaemia, cytopenia and thrombotic microangiopathy.

Toxicity requiring drug discontinuation occurred in $25 \%$.

The drug had a significant steroid-sparing

Overall median time to response was 5 weeks (range, 4-66)

$38 \%$ of subjects had $\geq 1$ SAE; the most common was pneumonia (7\%), nausea, diarrhoea, asthenia.

Main side effects: nausea, diarrhoea, thrombocytopenia, peripheral neuropathy

\section{Lack of paediatric data}

The most frequent adverse events:

lymphopenia, infection, and fatigue, muscle cramps, tremors, neuropathy.

May cause cutaneous inflammation early after HSCT

Lack of paediatric data

Serious infectious complications in 20\%

(mostly pulmonary) costimulatory receptors CD80 and CD86 on antigen presenting cells and counteracts the costimulatory signal mediated by the ligand CD28 > T cell activation inhibitor 
TABLE 6 | Continued

\begin{tabular}{|c|c|c|c|}
\hline Therapeutic agent & Mechanism of action & Response & Comments \\
\hline Tocilizumab & IL-6 receptor inhibitor & $\begin{array}{l}\text { ORR } 70 \%(\mathrm{PR}) \text { in a retrospective study of } 11 \\
\text { adults with severe SR-cGvHD (204) } \\
\text { 3/4 paediatric patients with refractory cGvHD } \\
\text { decreased NIH overall Grade by one (205) }\end{array}$ & Neutropenia, infectious complications \\
\hline Imatinib & $\begin{array}{l}\text { Tyrosine kinase inhibitor; inhibits BCR-ABL1 } \\
\text { fusion protein and inhibits other tyrosine } \\
\text { kinases of the PDGFR and TGF- } \beta \text { pathways } \\
\text { which play a role in fibrosis. }\end{array}$ & $\begin{array}{l}\text { ORR } 79 \% \text { ( } 37 / 42 \% \text { CR/PR) in refractory } \\
\text { cGvHD with fibrotic features ( } 19 \text { patients, age } \\
\text { 10-62 years) (124) } \\
\text { ORR } 76.9 \% \text { in } 13 \text { paediatric patients with } \\
\text { bronchiolitis obliterans (136) } \\
36 \% \text { PR ( } \geq 25 \% \text { improvement) in range of } \\
\text { motion of joints limited by skin fibrosis ( } 20 \\
\text { patients, age } 7-60 \text { years) (62). }\end{array}$ & Oedema and fluid disturbances \\
\hline Ibrutinib & $\begin{array}{l}\text { Tyrosine kinase inhibitor. Inhibits Bruton's } \\
\text { tyrosine kinase which promotes B cell survival } \\
\text { and IL-2-inducible T cell kinase which is } \\
\text { involved in the selective activation of T cells. }\end{array}$ & $\begin{array}{l}\text { ORR } 85 \% \text { (PR) at } 6 \text { months in } 14 \text { paediatric } \\
\text { patients (median age } 13,5 \text { years) with cGvHD } \\
\text { who completed the study ( } 8 / 22 \text { stopped } \\
\text { ibrutinib by } 3 \text { months due to side effects or } \\
\text { death) (129) ORR } 41.1 \% \text { at } 48 \text { weeks in a } \\
\text { prospective study of } 193 \text { patients }>12 \text { years } \\
\text { old in the first-line treatment (177) }\end{array}$ & $\begin{array}{l}\text { FDA approval for adults with refractory cGvHD } \\
\text {-ORR } 67 \% \text { in a study by Miklos et al. (176) } \\
\text { High incidence of infections, bleeding disorder } \\
\text { and hepatotoxicity. } \\
\text { Paediatric pharmacokinetic studies are needec }\end{array}$ \\
\hline Ruxolitinib & $\begin{array}{l}\text { Selective JAK1/JAK2 inhibitor. JAK signalling } \\
\text { plays a role in B-cell development and } \\
\text { activation (178) and dendritic cell differentiation } \\
\text { and migration (179). Ruxolitinib decreases } \\
\text { T-cell proliferation and activation and reduces } \\
\text { cytokine release (180). Data from murine } \\
\text { models suggest that ruxolitinib does not inhibit } \\
\text { GVL activity (181). }\end{array}$ & ORR $70-91 \%$ & $\begin{array}{l}\text { High incidence of infection. Phase } 3 \text { REACH3 } \\
\text { study: (197) significantly greater ORR } \\
\text { compared to best available therapy ( } 49.7 \text { vs. } \\
25.6 \%) \text { at week } 24 \text {. The most common } \\
\text { adverse events were anaemia }(29.1 \%) \text {, } \\
\text { thrombocytopenia ( } 21.2 \%) \text {, hypertension } \\
(15.8 \%) \text {, and pyrexia (15.8\%). }\end{array}$ \\
\hline
\end{tabular}

\section{Ruxolitinib for cGvHD in paediatric patients}

\begin{tabular}{|c|c|c|c|}
\hline References & $N$ & Age range (years) & Response \\
\hline Mozo et al. (182) & 19 & $2-16$ & ORR 91\%, CR 8.3\% \\
\hline Yang et al. (183) & 36 & $3-17$ & ORR $80.6 \%$, CR $27.7 \%$ \\
\hline Wang et al. (130) & 20 & $5-26$ & ORR 70\%, CR 10\% \\
\hline Moiseev et al. (184) & 17 & $2-17$ & ORR 81\%, CR 20\% \\
\hline Uygun et al. (185) & 29 & $0.3-17$ & ORR $80 \%$ \\
\hline $\begin{array}{l}\text { Gonzalez Vicent et al. } \\
\text { (186) }\end{array}$ & 9 & $0.5-18$ & ORR 89\% \\
\hline $\begin{array}{l}\text { Escamilla Gomez et al. } \\
\text { (196) }\end{array}$ & 56 (7 patients < 14 years old) & $0-73$ & Best ORR 57,1\% \\
\hline Zeiser et al. (197) & 330 & $12+$ & $\begin{array}{l}\text { REACH 3-Phase III randomised study } \\
\text { (NCT03112603) } \\
\text { Best ORR 49,7\% }\end{array}$ \\
\hline
\end{tabular}

\section{ECP for the second-line}

$N$

Age range (yrs)

Corticoid sparing

ORR (\%)

treatment of cGvHD

References

\begin{tabular}{|c|c|c|c|c|}
\hline Salvaneschi et al. (187) & 14 & $5.4-18.1$ & Yes & 64 \\
\hline Seaton et al. (188) & 28 & $18-51$ & No & 36 \\
\hline Couriel et al. (189) & 71 & $5-70$ & Yes & 61 \\
\hline Kanold et al. (133) & 27 & $5-18$ & No & 73 \\
\hline Perseghin et al. (190) & 12 & $9-17$ & NA & 80 \\
\hline Dignan et al. (191) & 82 & $14.1-69.5$ & Yes & 79 \\
\hline Hautmann et al. (192) & 32 & $6-67$ & No & 44 \\
\hline Berger et al. (193) & 10 & $7-18.5$ & Yes & 40 \\
\hline Perotti et al. (194) & 23 & Mean 11.8 & Yes & 69.5 \\
\hline Messina et al. (195) & 44 & $0.3-20.5$ & Yes & 73 \\
\hline
\end{tabular}

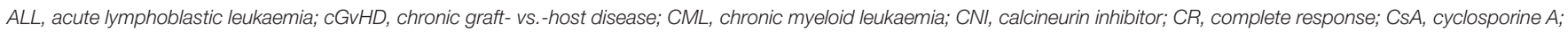

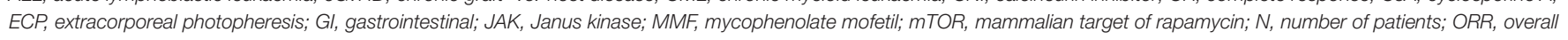
response rate; PDGFR, platelet-derived growth factor receptor; PR, partial response; SR, steroid refractory; TGF $\beta$, tumour growth factor $\beta$. 
resolution was observed in $6 \%$ of patients and partial response in $69 \%$, with a duration of response for a median of 50 weeks.

Bortezomib is a reversible proteasome inhibitor and has an inhibitory effect on B cells and plasma cells (207). It showed efficacy in murine models of cGvHD with maintained graft vs. tumour effect (208). Its efficacy in the initial therapy of cGvHD (together with prednisone) was evaluated in a study of 22 adults and showed $80 \%$ ORR (199). Paediatric data on its use in cGvHD treatment are very scarce.

Pomalidomide is a thalidomide derivative with 4,000-fold greater inhibition of TNF-alpha, which was originally used in the treatment of multiple myeloma. It has been evaluated in several adult studies for the treatment of SR-cGvHD with 54-67\% ORR observed $(201,202)$. Paediatric data are lacking.

Abatacept, a costimulatory signal blocker which inhibits $\mathrm{T}$ cell activation, has been also evaluated in small cohorts of adult patients with SR-cGvHD and showed 40-44\% ORR. As for pomalidomide, paediatric data are missing $(203,209)$.

Tocilizumab, a humanised IgG1 interleukin 6 (IL6)-receptor antibody, has shown efficacy in aGvHD and cGvHD. IL6 plays a significant role in the initiation of the inflammatory response, leads to increased immunoglobulin production by $B$ cells and decreased differentiation of $\mathrm{T}_{\text {regs }}$ (210). It was investigated in a retrospective adult study showing ORR of $70 \%$, as well as in a retrospective paediatric case series (204, 205). Infections were the primary adverse events associated with tocilizumab administration.

\section{Tyrosine Kinase Inhibitors}

TKIs are considered promising drugs in the treatment of SRcGvHD. Tyrosine kinases play a role in cell processes such as differentiation, proliferation, anti-apoptosis, and B- and Tcell signalling. TKIs have the potency to block B- and T-cell activation and to inhibit the transcription of genes encoding pro-inflammatory cytokines (211). They have been used in the treatment of haematological malignancies including acute leukaemia, B-cell lymphoma, chronic lymphocytic leukaemia and chronic myeloid leukaemia (CML). Their inhibitory effect on B and $\mathrm{T}$ cells led to their use in preclinical and clinical trials of cGvHD treatment. The use of imatinib, ibrutinib and ruxolitinib for $c G v H D$ treatment in paediatric patients is summarised in Table 6.

In a mouse model of $\mathrm{CGvHD}$, it was shown that animals lacking BTK in B cells or IL-2-inducible kinase in T cells did not develop cGvHD. In addition, activation of $\mathrm{T}$ and $\mathrm{B}$ cells from patients with active cGvHD was inhibited by ibrutinib blockade of BTK and IL-2-inducible kinase. Based on these preclinical data, the first clinical trials with ibrutinib in cGvHD were designed (212). In 2017, ibrutinib became the only drug approved by US Food and Drug Administration (FDA) for the treatment of SR-cGvHD in adults; this approval was based of the study data by Miklos et al. (176). There are ongoing clinical trials on the use of ibrutinib for $\mathrm{cGvHD}$, including in paediatric patients (NCT02959944).

Ruxolitinib was approved by the FDA in 2019 for salvage therapy in patients with aGvHD. Several retrospective studies have evaluated ruxolitinib in the treatment of SR-cGvHD in adults, with a $85.4 \%$ ORR observed in one multicentre retrospective survey (131). There was also a low recurrence rate of the underlying malignancy. Ruxolitinib has been evaluated also in paediatric patients with cGvHD, with a 70-91\% ORR observed (see Table 6). The favourable results of the phase 3, randomised, multicentre study $\mathrm{REACH} 3$, which investigated the efficacy of ruxolitinib in SR-cGvHD patients $\geq 12$ years of age as add-on therapy to steroids and in comparison to best available therapy, formed the basis for the FDA approval of ruxolitinib in September 2021. Prospective clinical trials and pharmacokinetic studies of ruxolitinib in paediatric patients are currently ongoing [REACH 4 in aGvHD and REACH 5 in cGvHD (132)].

\section{Immunomodulatory Interventions Extracorporeal Photopheresis}

ECP is an immunotherapy using the recipient's leukocytes to modulate inflammatory immune dysregulation in persons with cGvHD (213). The main technique fundaments of ECP are comprehensively outlined in Figure 1. This technique was approved by both the FDA and European Medicines Agency (EMA) for T-cell cutaneous lymphoma treatment (216). In the post HSCT setting, ECP can be applied both for the treatment of acute and chronic SR-GvHD (217).

The exact working mechanisms of ECP are incompletely understood but its effects might be considered on different levels, as outlined below.

Firstly, ECP might have a mechanical effect (irrespective of the disease for which it is applied) driven by the movement of blood through plastic tubing. Changes in monocyte and dendritic cell differentiation and maturation have been documented when blood is processed over plastic, probably via activated platelet signalling (213). Additionally, 8-MOP and exposure to UVA induces cross-linking damage to DNA in leukocytes, which induces apoptosis. The uptake of apoptotic cells by activated dendritic cells leads to changes in dendritic cells and a switch to a more tolerogenic phenotype $(217,218)$. This change in dendritic cell morphology and function has been demonstrated in several different diseases and likely represents the primary effect of ECP $(213,214,217)$.

Other effects of ECP occur downstream and reflect the disease process that is being treated, the age of the patient and extent of organ damage. Importantly, ECP can induce changes not only in cells in the inoculum which are directly exposed to 8-MOP and UVA but also in cells that are not directly harvested, suggesting that the immunomodulatory effects of ECP propagate beyond directly treated cells. ECP has been shown to induce a switch from a Th1- to Th2-type response with immunomodulatory cytokines in $\operatorname{GvHD}(213,215)$. A switch from proinflammatory to anti-inflammatory cytokine production (with a decrease in IFN- $\gamma$, TNF- $\alpha$, and IL- 2 secretion and an increase in TGF$\beta$ serum levels) as well as increase in $\mathrm{T}_{\text {reg }}$ numbers has been described $(214,216)$. Additionally, some authors have postulated that ECP impacts on B-lymphocyte homeostasis, with a decrease in $\mathrm{CD} 19^{+} / \mathrm{CD} 21^{-}$B-lymphocyte subsets, where others have described the possible expansion of $\mathrm{CD}^{+}$memory cells and differentiation of monocytes to immature antigen-presenting 


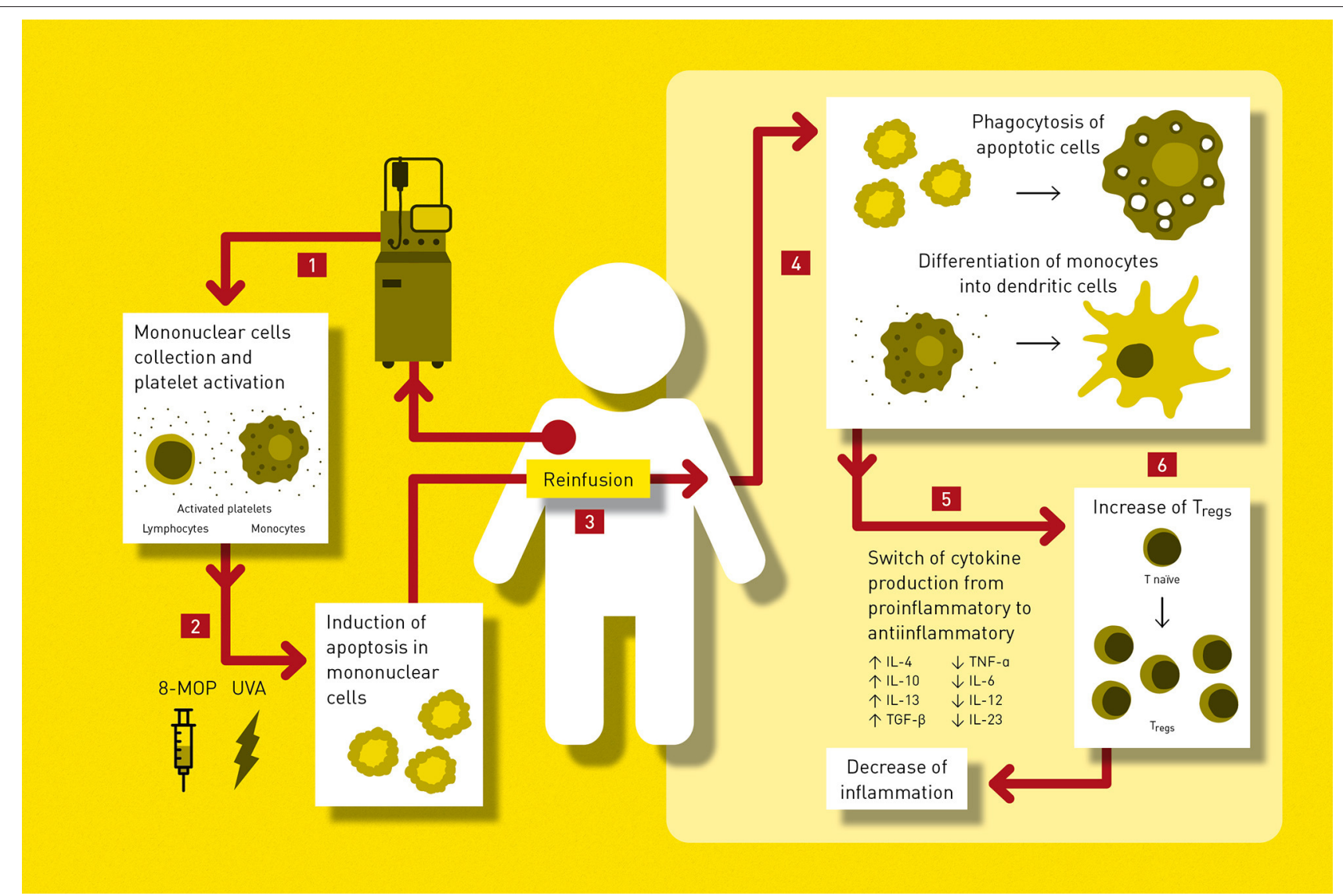

FIGURE 1 | Proposed procedure of ECP and its hypothesised mechanism of action. 1. Collection of mononuclear cells (MNC) during leukapheresis from the peripheral blood and activation of platelets by the plastic surfaces of the tubing system. 2. Ex vivo incubation of leukapheretic product with a photosensitizing agent 8-methoxypsoralen (8-MOP) followed by ultraviolet-A light (UVA) irradiation which initiates apoptosis in MNC including lymphocytes. 3. Reinfusion of the ECP product. 4. Process of apoptosis continues in ECP exposed cells for days resulting to phagocytosis by antigen presenting cells (APC). Activated platelets engage with monocytes promoting their differentiation into dendritic cells (DC). 5. The internalisation of apoptotic cells decrease the inflammatory reaction of phagocytes, induces antigen specific immunotolerance and lower production of proinflamatory cytokines while increasing antiinflamatory cytokines production (213, 214). ECP- induced DC initiate T-cell tolerance with an increase of Th2 cytokines including IL-4, IL-10, IL-13 and TGF- $\beta$, while production of Th1 cytokines is suppressed (215). 6 . APC promote generation of regulatory T-cells ( $\left.T_{\text {regs }}\right)$ (216). MNC, mononuclear cells; 8-MOP, 8-methoxypsoralen; UVA, ultraviolet A light; APC, antigen presenting cells; DC, dendritic cells; $T_{\text {regs }}$, regulatory $\mathrm{T}$-cells.

cells $(219,220)$. Therefore, the immune modulatory effect of ECP appears to be a complex response to the whole procedure, as depicted in Figure 1.

In contrast to conventional immunosuppression, ECP is safe and has limited side effects, confined mainly to risks associated with use of an indwelling central venous catheter (including infection), hypotension and photosensitivity related to 8-MOP exposure (215). In small children, the leukapheresis procedure itself may be technically challenging $(215,221)$.

Currently, there are three techniques in use for ECP: the in-line method ("closed" system), the off-line method ("open" system) and so-called mini-ECP which we briefly describe in Figure 2.

Importantly, ECP is not associated with an increased risk of infectious complications, likely because it spares antigenspecific activity against novel and recall antigens. Further benefits are the potential preservation of the GvL effect and-in contrast to systemic immunosuppressive treatment-the absence of metabolic or toxic side effects $(222,223)$.

Abu-Dalle et al. published a systematic review of the literature in 2014 including 9 studies (1 randomised trial) of ECP for cGvHD in 323 patients aged 1.4-67 years. In a pooled analysis, the ORR for cGvHD overall was $64 \%$ (95\% confidence interval [CI], 47-79\%) and the proportion of patients with CR in various organs was $26 \%(95 \% \mathrm{CI}$, $5-55 \%)$. The ORR for skin manifestations was $71 \%(95 \%$ CI, $57-84 \%)$, for gut it was $62 \%$ (95\% CI, 21-94\%), for liver it was $58 \%(95 \% \mathrm{CI}, 27-86 \%)$, for oral mucosa it was $63 \%$ (95\% CI, 43-81\%), for the musculoskeletal system it was $45 \%(95 \% \mathrm{CI}, 18-74 \%)$ and for the lung it was $15 \%$ (95\% CI, 0-50\%) (224). The majority of reported paediatric data are predominantly derived from non-randomised, singlecentre or retrospective studies and are summarised in Table 6. Treatment schedules and durations of ECP for paediatric cGvHD 


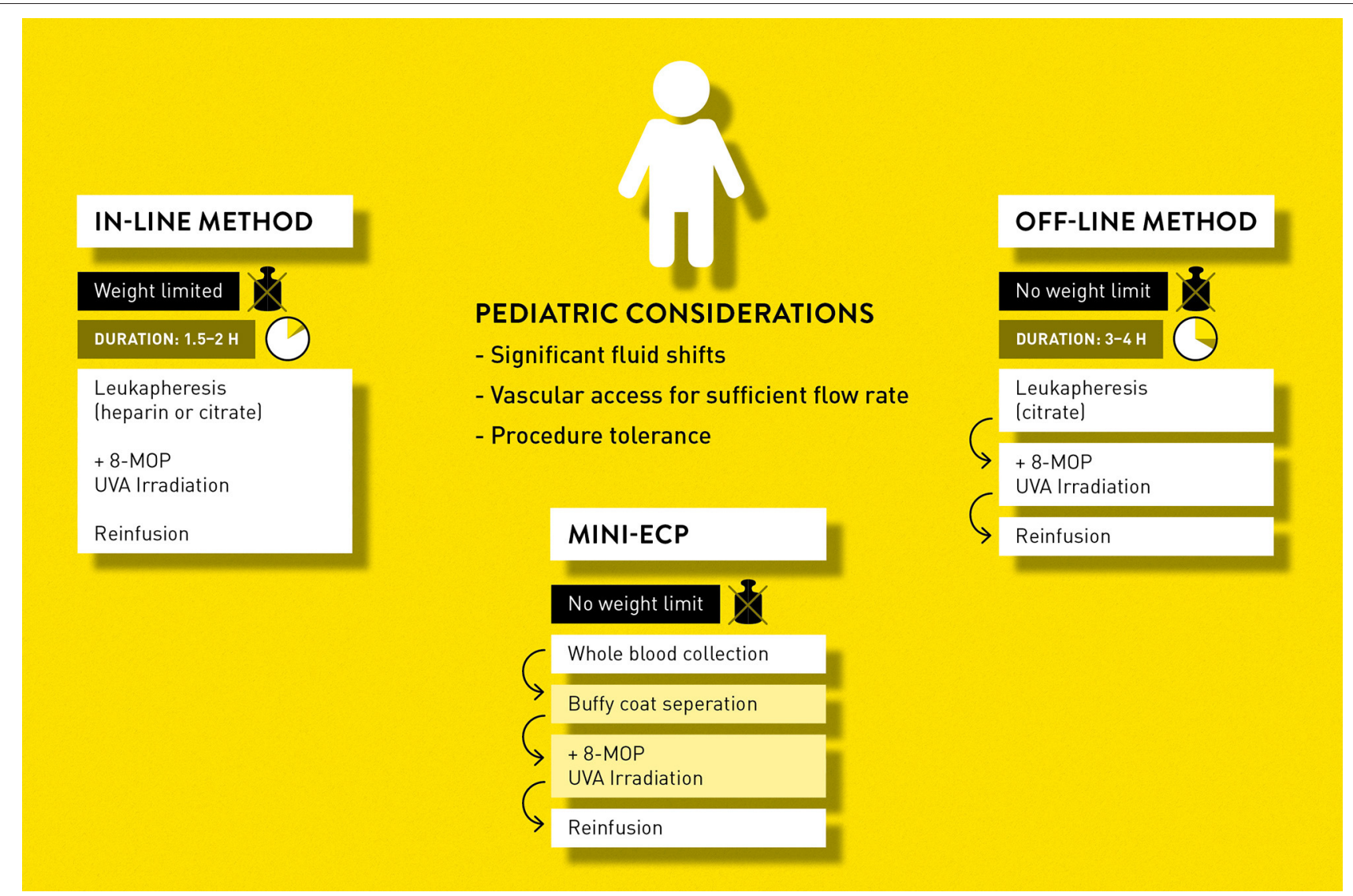

FIGURE 2 | Different approaches to extracorporeal photopheresis.

management vary but most often involve two procedures applied every other week. The optimal approach has not been established yet.

The benefits of ECP include reduction in the need for conventional immune suppression, with corresponding reduction in the risk of infection, secondary malignancies and adverse effects attributable to those conventional immunosuppressive therapies. For example, patients reducing or ceasing glucocorticoids may have normalisation of blood pressure and blood glucose. Based on its efficacy and the excellent safety profile, several expert groups have reached the consensus that ECP has an established place as second-line or adjuvant therapy in cGvHD (216).

In 2013-2014, the Paediatric Diseases Working Party (PDWP) of the EBMT conducted a survey on the use of ECP in paediatric GvHD treatment in routine clinical practice; 52 EBMT centres responded (19\%). Results of the analysis revealed that the majority of centres used ECP as an "add on" treatment during various lines of GvHD therapy in patients with a high risk of relapse or infection (81\%) or with comorbidities $(88 \%)$. Of note, $85 \%$ of responding centres agreed that, in children, a nonmalignant disease and no need of GvL may be an indication for early implementation of ECP within a multimodal GvHD treatment schedule (Lawitschka et al., unpublished results).
The NIH 2020 initiative set the stage for future GvHD research projects including the further evaluation of ECP within a preemptive therapeutic setting for well-defined forms of highly morbid cGvHD, since ECP does not increase risk of relapse or infection. The expert group recommended the evaluation of ECP as a first-line therapeutic agent, applying rigorous biomarker panels pre- and post-intervention. Databases including biobanks should be analysed for a predictive biomarker of response to ECP $(12,13,225,226)$.

\section{Mesenchymal Stromal Cells}

Mesenchymal stromal cells (MSCs) are a heterogeneous precursor cell population with some degree of pluripotency. Potential usefulness for treatment of GvHD was suggested early on as MSCs can modulate immune responses (227). Tissue regeneration properties were also noted.

According to current hypotheses, MSCs are injected as a "prodrug." They do not begin to secrete relevant mediators until they are immersed in an environment with certain cytokines, specifically IFN $\gamma(228,229)$, which is not a dominant mediator in cGvHD (230).

Clinical outcomes of studies provide conclusions that are limited only for the specific MSC product applied and clinical situation for which they were studied. In meta-analysis by Tarifa 
et al. infusion of MSCs (of variable provenance, variable dose, schedule, etc.) was associated with reduced cGvHD incidence (relative risk, $0.64 ; 95 \% \mathrm{CI}, 0.47-0.88 ; I^{2}=0 \%$ ) and a trend toward lower incidence of extensive cGvHD (relative risk, 0.50; 95\% CI, $0.25-0.10 ; p=0.05$ ), both in adults and children (231). Fisher et al. came to essentially similar conclusions (232) as does the meta-analysis by Wang et al. (233), albeit restricted to children.

Outcomes were reported in several case series comprising fewer than 100 patients and MSCs of various provenance and dose. While they may appear overall satisfactory, it is very important to bear in mind that all of these studies lack control groups, which could have answered the question of attributability of the improvement to the MSC infusion, i.e., could have distinguished between "improvement" and "response."

Alternatively, proving the hypothesis that prophylactic infusion of MSCs might be able to prevent cGvHD is hampered by the poor predictability of (severe) cGvHD and its relatively low prevalence. Work by Lazarus et al., reports a high frequency of cGvHD (of $61 \%$ in patients surviving to day 90, almost a quarter of whom had severe cGvHD) which does not suggest a prophylactic benefit (234). In that study, MSCs were coadministered with the graft. A later double-blinded trial of umbilical cord blood MSCs (235) investigated this issue further. In a 1:1 randomised assignment, 124 haploidentical transplanted patients received umbilical cord blood MSCs or control (saline). Although the treatment schedule itself is described in somewhat vague terms, a signal indicating efficacy is reported. Whether dose, schedule (especially timing relative to the transplantation), source of MSCs or any other quality attribute of the MSCs is responsible remains elusive. The promising data certainly encourage further exploration of the issue.

To summarise, the role of MSCs in cGvHD treatment is unclear. For a specific preparation of umbilical cord blood MSC efficacy was demonstrated in a prophylactic setting in haploidentical transplantation, which begs confirmation.

\section{Real-World Response Evaluation}

The appropriate assessment of cGvHD treatment response is essential for making optimal therapeutic decisions and, thus, for optimising final outcomes of cGvHD treatment. The $2014 \mathrm{NIH}$ consensus criteria on diagnosis and grading include definitions of overall and organ-specific therapeutic response in cGvHD for use in clinical trials (135).

The NIH consensus project recommends that clinicians assess organ-specific response for the skin, mouth, liver, upper and lower gastrointestinal tract, oesophagus, lung, eye, and joint/fascia (236).

Three general categories of overall response are proposed:

- CR: resolution of all manifestations in each organ

- PR: improvement in at least 1 organ or site without progression in any other organ

- lack of response: unchanged, mixed response, or progression

Regarding timepoints for assessment, response should not be assessed earlier than 8 weeks after induction of treatment. Subsequent measurements should be made at regular intervals, for example every 3 months, and whenever a new systemic immunosuppressive treatment is started or the patient stops treatment $(1,236)$. Generally, a measure of success in cGvHD treatment is the complete discontinuation of therapy or complete disease control on unimodal immunosuppressive treatment at a low dose.

\section{Tapering Systemic Immunosuppressive Treatment}

There is no "gold standard" for tapering schedules of cGvHD treatment because randomised prospective trials are lacking. Therefore, expert-based recommendations compensate for the lack of evidence-based data.

The choice to taper treatment should be patient specific and may start with the agent that is either less well-tolerated by the patient or that has more toxic side effects. The schedule of taper may best be guided by the organ pattern and severity of cGvHD as well as the patient's individual risk of poor outcomes of cGvHD, concomitant comorbidities and infectious complications. In paediatric patients, tapering should usually start with steroids because of the broad spectrum of possible adverse effects with these agents and to allow for best possible growth and development of the child.

Generally, drugs should be withdrawn gradually, one at a time, after gaining an objective clinical response to therapy. In our opinion, regular clinical examinations in shorter intervals, such as once or twice weekly in moderate-to-severe cGvHD, are important. Discussions and shared management decisions within a multidisciplinary team are strongly recommended. We have summarised different published approaches to tapering in Table $7(106,139,141,237)$.

If cGvHD exacerbation occurs during the taper, other contributing causes, especially infections, must be excluded followed by a swift dose escalation. In the event of unresponsiveness or progression of cGvHD after 4 weeks, a new agent should be introduced. The same applies after two unsuccessful attempts to taper therapy. Ineffective treatment should be tapered and discontinued after successful induction of the new treatment to avoid unnecessary immunosuppression.

However, management of paediatric cGvHD requires continuous recalibration of immunosuppressive treatment in order to avoid over- or undertreatment. Usually, in paediatric patients the treatment intensity decreases over time and a specific threshold can be set individually for each patient by repetitive attempts to decrease treatment intensity.

\section{Anti-infectious Prophylaxis}

It is important to recognise that the complete management of cGvHD includes optimal supportive care. During cGvHD, patients are immunocompromised due to both immunosuppressive medication and immune dysregulation by $c$ GvHD itself. The prolonged use of immunosuppressants in $\mathrm{cGvHD}$ is common (with only $18 \%$ of patients being off immunosuppressive therapy after 2 years in a combined paediatric/adult study) and is associated with an increased incidence of infection and mortality (238). cGvHD is a risk factor for bacterial, fungal and viral infections (239-241) and increased TRM $(240,242)$. 
TABLE 7 | Summary of recommended approaches for the taper of immunosuppressive agents used in the treatment of cGvHD (review of recent literature).

\begin{tabular}{|c|c|c|c|}
\hline References & Timing of taper initiation & Approach to taper & $\begin{array}{l}\text { Approach to dose increase in the } \\
\text { event of cGvHD relapse or } \\
\text { exacerbation }\end{array}$ \\
\hline $\begin{array}{l}\text { Sarantopoulos et al. } \\
(141)\end{array}$ & $\begin{array}{l}\text { After } 3-4 \text { weeks of the initial } \\
\text { prednisone dose. }\end{array}$ & Not specified & Not specified \\
\hline Wolff et al. (139) & $\begin{array}{l}\text { As soon as disease control has been } \\
\text { achieved. }\end{array}$ & Not specified & $\begin{array}{l}\text { If cGvHD flares during steroid taper, } \\
\text { increasing the dose by } 1 \text { or } 2 \text { taper } \\
\text { steps may be enough to control } \\
\text { symptoms. }\end{array}$ \\
\hline Jacobsohn (106) & $\begin{array}{l}\text { After } 2 \text { weeks of the initial prednisone } \\
\text { dose. }\end{array}$ & $\begin{array}{l}\text { Taper to alternate-day prednisone by } \\
1-2 \text { months. }\end{array}$ & Not specified \\
\hline $\begin{array}{l}\text { Flowers and Martin } \\
\text { (237) }\end{array}$ & $\begin{array}{l}\text { As soon as clinical improvement is } \\
\text { achieved. }\end{array}$ & $\begin{array}{l}20-30 \% \text { dose reduction every } 2 \\
\text { weeks, with smaller absolute } \\
\text { decrements toward the end of the } \\
\text { taper schedule; the prednisone dose } \\
\text { is reduced to } 0.1 \mathrm{mg} / \mathrm{kg} \text { every other } \\
\text { day within } 22 \text { weeks; it equates to } \\
\text { adrenal replacement therapy and is } \\
\text { continued for at least } 4 \text { weeks. }\end{array}$ & $\begin{array}{l}\text { 2-log increase in dose with daily } \\
\text { administration for } 2-4 \text { weeks, } \\
\text { followed by resumption of } \\
\text { alternate-day administration which is } \\
\text { continued for at least } 3 \text { months } \\
\text { before next attempt of taper. }\end{array}$ \\
\hline
\end{tabular}

cGvHD, chronic graft vs. host disease.

Therefore, prophylaxis against multiple types of infection is indispensable to minimise the risk of life-threatening infections (243). The $2014 \mathrm{NIH}$ consensus project included recommendations on ancillary therapy and supportive care in cGvHD, including the strength of each recommendation (143). Recently, paediatric expert recommendations stemming from workshops of the EBMT PDWP were published regarding the prevention of infections in patients after HSCT (244).

\section{Antibacterial Prophylaxis}

In patients with cGvHD, the risk of infections caused by encapsulated bacteria is more than double that in those without cGvHD (245).

Prolonged antibiotic prophylaxis is recommended only for preventing infection with $S$. pneumoniae among cGvHD patients receiving active cGvHD treatment (level A-III) (243, 245, 246). Oral phenoxymethylpenicillin has been shown to prevent encapsulated bacterial infection and, thus, may be suitable (level A-III) $(243,245)$. However, it is recommended to make a choice of antibiotic agent according to local antibiotic susceptibility data $(243,246)$.

\section{Pneumocystis Jirovecii Prophylaxis}

In general, patients with active cGvHD taking immunosuppressive treatment (especially multimodal treatment including steroids) and/or with neutropenia and/or with $\mathrm{CD}^{+} \mathrm{T}$ cells $<200 \times 10^{9} / \mathrm{L}$ may be at risk of Pneumocystis jirovecii infection, taking into account that the initially HIVderived $\mathrm{CD} 4^{+}$T-cell threshold has been not evaluated in the cGvHD setting and Pneumocystis jirovecii infections have been observed in patients above the proposed threshold. For prophylaxis against Pneumocystis jiroveci interstitial pneumonia, trimethoprim/sulfamethoxazole is recommended (level A-I) (7).

\section{Antifungal Prophylaxis (Systemic and Topical)}

If tolerated, a mould-active azole is recommended for prophylaxis in patients undergoing treatment for cGvHD (level A-I) $(7,243)$. Suitable agents include posaconazole and voriconazole (level A-I) or itraconazole with regular monitoring of plasma levels (level B-II) (243). If there is a history of invasive aspergillosis, secondary prophylaxis using antimycotics that are active against Aspergillus (level B-I) including weekly or biweekly liposomal amphotericin B should be administered $(7,247)$.

\section{Antiviral Prophylaxis}

In at-risk patients, the stringent monitoring of cytomegalovirus (CMV) levels by quantitative polymerase chain reaction (qPCR) should be continued throughout the period of cGvHD (level B-I) to enable pre-emptive treatment or maintenance of prophylactic management if needed $(89,243)$. Due to the high risk of posttransplant lymphoproliferative disease, it also is reasonable to monitor patients with $\mathrm{cGvHD}$ on $\mathrm{T}$ cell suppressive agents (i.e., a CNI, mycophenolate mofetil, or ruxolitinib) for Epstein-Barr virus reactivation by qPCR $(243,248)$.

In patients who are seropositive for herpes simplex virus or varicella zoster virus, acyclovir is recommended to prevent reactivation (level B-II) (7).

\section{Toxoplasmosis Prophylaxis}

In patients who were seropositive for toxoplasma pre transplant, there is a risk of reactivation during cGvHD treatment. Regular monitoring by qPCR is recommended. Of note, Pneumocystis jirovecii prophylaxis with trimethoprim/sulfamethoxazole potentially may be protective against toxoplasmosis because the majority of post-transplant cases occur in patients not receiving this prophylactic medication (243).

\section{Tuberculosis Prophylaxis}

If there is a history of tuberculosis, secondary prophylaxis using isoniazid should be used (level C-III) (7). 


\section{Intravenous Immunoglobulin}

Substitution of polyvalent immunoglobulins either intravenously or subcutaneous is recommended in the presence of IgG deficiency (below $400 \mathrm{mg} / \mathrm{dL}$ ) post transplant, post rituximab treatment and in patients with recurrent infections $(7,244)$. Immunoglobulin substitution does not inhibit the immune response to inactivated vaccines. For live virus vaccines, vaccination should be delayed until the patient is immunocompetent (at least 24 months post HSCT).

\section{Vaccination of Patients and Close Contacts}

There are data on vaccination responses in children after HSCT but very limited data are available specifically in children with cGvHD. A prospective study by Meisel et al. reported on the safety and immunogenicity of a heptavalent pneumococcal conjugate vaccine (7vPCV) administered to 53 children. Patients were immunised with 3 consecutive doses (at monthly intervals) starting 6-9 months after HSCT (249). Ten of the 53 patients had been on systemic immunosuppressive treatment, while patients with uncontrolled cGvHD were excluded. There were indications that the responses to $7 \mathrm{vPCV}$ in patients with active cGvHD were suboptimal, with low B cells and low IgG being risk factors for a suboptimal response $(249,250)$. Data from a combined paediatric/adult cohort where pneumococcal conjugate vaccination was triggered by milestones in immunity $\left(\mathrm{CD} 4^{+}\right.$cells $>200 \times 10^{6} / \mathrm{L}$ and $\left.\operatorname{IgG}>0.5 \mathrm{~g} / \mathrm{L}\right)$, show that $\mathrm{cGvHD}$ patients respond just as well as patients without cGvHD to vaccination but are vaccinated significantly later after transplant than patients without $\mathrm{cGvHD}$ (the median time 1.8 vs. 1.1 year post HSCT, respectively) (251).

Importantly, there is no evidence that inactivated vaccines induce or aggravate GvHD $(252,253)$ and, therefore, the start of vaccination (or revaccination) with a diphtheria, tetanus, acellular pertussis, polio, hepatitis B and Haemophilus influenzae type $\mathrm{B}$ combination vaccine (DTaP/IPV/HBV/Hib) and 13-valent pneumococcal conjugate (PCV13) vaccine is recommended 6 months after allogeneic HSCT for patients with and without cGvHD (7, 244, 254). Cordonnier et al. showed that a fourth dose of PCV13 increased antibody levels significantly in children and this has been implemented in the current EBMT recommendations (level A-ll) $(169,255)$. The additional effectiveness of the polysaccharide vaccine Pneumo23 is potentially limited in patients who suffer from cGVHD after HSCT $(244,255)$.

In view of the especially high risk of encapsulated bacterial infection in cGvHD, all patients with cGvHD should receive vaccination against Haemophilus influenzae (level B-1) and Streptococcus pneumoniae (level A-11) $(243,249,254)$. Conjugate vaccines, which also achieve good vaccination success in infants, are preferred $(7,254)$.

Serum tests are recommended to monitor response to vaccination in patients receiving immunosuppression to assess the immunologic response to vaccination and/or need for subsequent booster immunisation $(7,244,254)$.

Recommendations for optional and conditional vaccines can be found in the EBMT recommendations by Ifversen et al. (244).
Of the recommended inactivated vaccines, influenza vaccine can be given from 4 to 6 months post transplant and immunisation should be repeated on an annual basis $(7,243,244,253)$. However, it has been observed that a greater percentage of adults with $\mathrm{GGvHD}$ do not respond to the H1N1 vaccine in comparison to healthy individuals (256). This is of particular interest in the light of the coronavirus pandemic and mass vaccination with COVID-19 vaccine of all patients with ALL, where impaired responses have indeed also been observed to the COVID-19 vaccine. The recommendations are continuously updated but the EMA currently advises to give three doses of COVID-19 vaccine to all adult immunocompromised patients (recommendations published on 04/10/2021, https://www.ema.europa.eu/en/ news/comirnaty-spikevax-ema-recommendations-extra-dosesboosters) (257). As the vaccine has recently been EMAapproved for use in children over 5 years old it is likely that this recommendation will soon include children with ALL of 5 years and older, and after transplant regardless of cGvHD development (258). There are strong indications that patients with $\mathrm{B}$ cell depleting therapies impairing their antibody responses, are still able to mount adequate $\mathrm{T}$ cell responses against natural infection and COVID-19 vaccination $(259,260)$.

A strong recommendation is that live vaccines must not be administered in patients with cGvHD (level A-I) $(243,244,254)$.

Household contacts should also receive routine vaccinations plus the seasonal influenza vaccine (254) and the COVID-19 vaccine (see EBMT website, COVID-19 vaccines).

\section{PERSONALISED MANAGEMENT OF PAEDIATRIC cGVHD}

The $2020 \mathrm{NIH}$ initiative clearly set out all the unmet needs in paediatric $c \mathrm{GvHD}$ management and pointed out that future efforts must aim for prompt recognition and intervention to limit organ damage and significant morbidity $(11,12)$.

Nonetheless, despite the advances brought through and driven by the $2014 \mathrm{NIH}$ consensus conference, the diagnosis of paediatric cGvHD remains challenging in daily clinical practice since clinical onsets can be infection associated and insidious. Moreover, patients may present with clinical manifestations of cGvHD beyond the NIH-defined diagnostic and distinctive features. These are referred to as "associated cGvHD symptoms" and may consist of endothelial dysfunction and polyserositis, immune-mediated cytopenias, and atypical manifestations regarding the kidneys, the central and peripheral nervous system and others (226) (see supplemental cGvHD documentation form in Supplementary Material). However, standardised diagnostic criteria for associated manifestations are lacking and may be missed as being cGvHD associated. These atypical cGvHD manifestations are understudied in paediatric patients but may contribute significantly to morbidity and mortality and may share cGvHD pathophysiology (67). An additional challenge can be the differentiation of cGvHD manifestations from pre-existing toxicities and specific residual 
phenotypes of inborn errors appearing alongside paediatric cGvHD symptoms.

Another problem specific to cGvHD is the waxing and waning nature of the disease with high inter- and intraindividual heterogeneity. This impedes clinicians' decisions on when and how to best implement therapeutic agents, with the added difficulty of a lack of standardised recommendations, including taper schedules for treatments.

A further difficulty lies in how and when to best implement therapeutic approaches for the individual patient. Many research activities have provided new pathophysiological insights allowing for therapeutic approaches that may more accurately target involved pathways. However, substantially fewer data are available on how the various pathways intersect and how they apply to the various phenotypes of cGvHD. Of note, single-target inhibitors may have a beneficial or detrimental effect at different phases of immune cell development and immune dysfunction. In this regard the results of a randomised phase 2 trial evaluating the response of pomalidomide in 34 adult patients with moderate to severe cGvHD may serve as an example: authors reported that the use of pomalidomide early after HSCT may cause cutaneous inflammation in contrast to the treatment responses observed in late sclerotic cGvHD (201).

Another difficulty is that the rather promising results from early studies of these agents are yet to be confirmed in large prospective studies, and our understanding of drug interactions in children is currently incomplete. The FDA approval of ruxolitinib as the first agent for SR-cGvHD in patients over the age of 12 years in September 2021 will likely change the cGvHD field, but paediatric data from large prospective trials are missing. There is an ongoing REACH 5 trial evaluating ruxolitinib in patients under the age of 18 years with moderate to severe cGvHD.

Moreover, with respect to difficulties in the clinical management of paediatric cGvHD, a plethora of potential infections and drug-induced toxicities make a patientspecific approach of crucial importance. In this regard, the $2020 \mathrm{NIH}$ initiative has emphasised the benefit of applying immunomodulatory agents as opposed to broad immunosuppressive agents (225).

A comprehensive review on the management of cGvHD in children was provided by Jacobsohn (106), but since that publication major advances, as outlined in detail within this manuscript, have been made and an update is pending. Recently, an individualised and patient-centred cGVHD management offering continuing care embedded in a multidisciplinary team has been described $(103,141)$. To fill this gap regarding paediatric cGVHD patients was the central aim of this manuscript.

In consideration of the unmet needs as outlined above, coupled with the debilitating morbidity of the disease, we have developed a model for a personalised approach for the management of paediatric cGvHD. This model integrates published evidence, expert opinions, clinicians' experience and patient-specific considerations.

\section{Holistic View of Paediatric cGvHD and Associated Manifestations (The See-Saw of cGvHD)}

We propose that clinicians take a holistic view of paediatric cGVHD interpreting classical cGvHD, atypical cGvHD and other manifestations not only in the context of allo/auto-immunity after HSCT but rather as a kind of chronic graft dysfunction. This chronic graft dysfunction of the transplanted immune system involves multiple layers and effectors of the innate and adaptive aberrant immune system (30) which interfere with functional tolerance; chronic inflammation mediated by GvHD and/or infections play a central role.

Figure 3 illustrates the possible insidious onset of cGvHD and the complex interplay with functional correlates. With better insight, the individualised clinical management of paediatric cGvHD and enhanced early intervention may be supported.

\section{Risk of ALL Relapse}

The association between cGvHD and leukaemic disease control has long been debated and study results are contradictory. A study of Boyiadzis et al. performed in cohort of 7,489 patients with leukaemia including 599 paediatric patients with ALL demonstrated a protective effect of $\mathrm{cGvHD}$ against late relapse only for patients with CML (4). Moreover, the presence of cGvHD was associated with significantly higher TRM and worse OS across all diseases studied. Kato et al. described a cohort of 1,030 paediatric patients with ALL in which CGvHD was not found to reduce the risk of post-transplant relapse (3). However, most recently, Yeshurun et al. studied the impact of the GvL effect on survival in 5,215 patients with ALL. In this study were 1,619 paediatric patients and 2,593 adults in CR1/CR2 as well as 1,003 patients with advanced ALL (i.e., CR3 or greater or active disease) (261). The study demonstrated that, both for patients in CR1/CR2 and for patients with advanced ALL, development of cGvHD was associated with a lower risk of relapse.

Thus, it is important to identify the setting in which cGvHD would be most beneficial for leukaemia control by means of developing better cGvHD prevention and therapies in order to improve leukaemia- and event-free survival (4). In addition, it is important to monitor as precisely as possible the post-transplant ALL status of patients during the treatment of $\mathrm{cGvHD}$ and to assure early detection of impending relapse and early therapeutic intervention where possible.

\section{Monitoring of ALL Status}

All subjects with active cGvHD undergoing immunosuppressive treatment should be systematically screened for ALL relapse based on physical examination and results of routine haematological tests, post-transplant haematopoietic chimerism and minimal residual disease (MRD) level. In patients on distinct immunosuppressive treatment for cGvHD, MRD monitoring should be prolonged, especially in those patients who demonstrate a high- or very-high risk score for posttransplant ALL relapse, as proposed by Bader et al. (262). To date, no general recommendation can be given on the best methods or frequency of MRD monitoring in patients with active cGvHD but careful and meticulous execution of the 


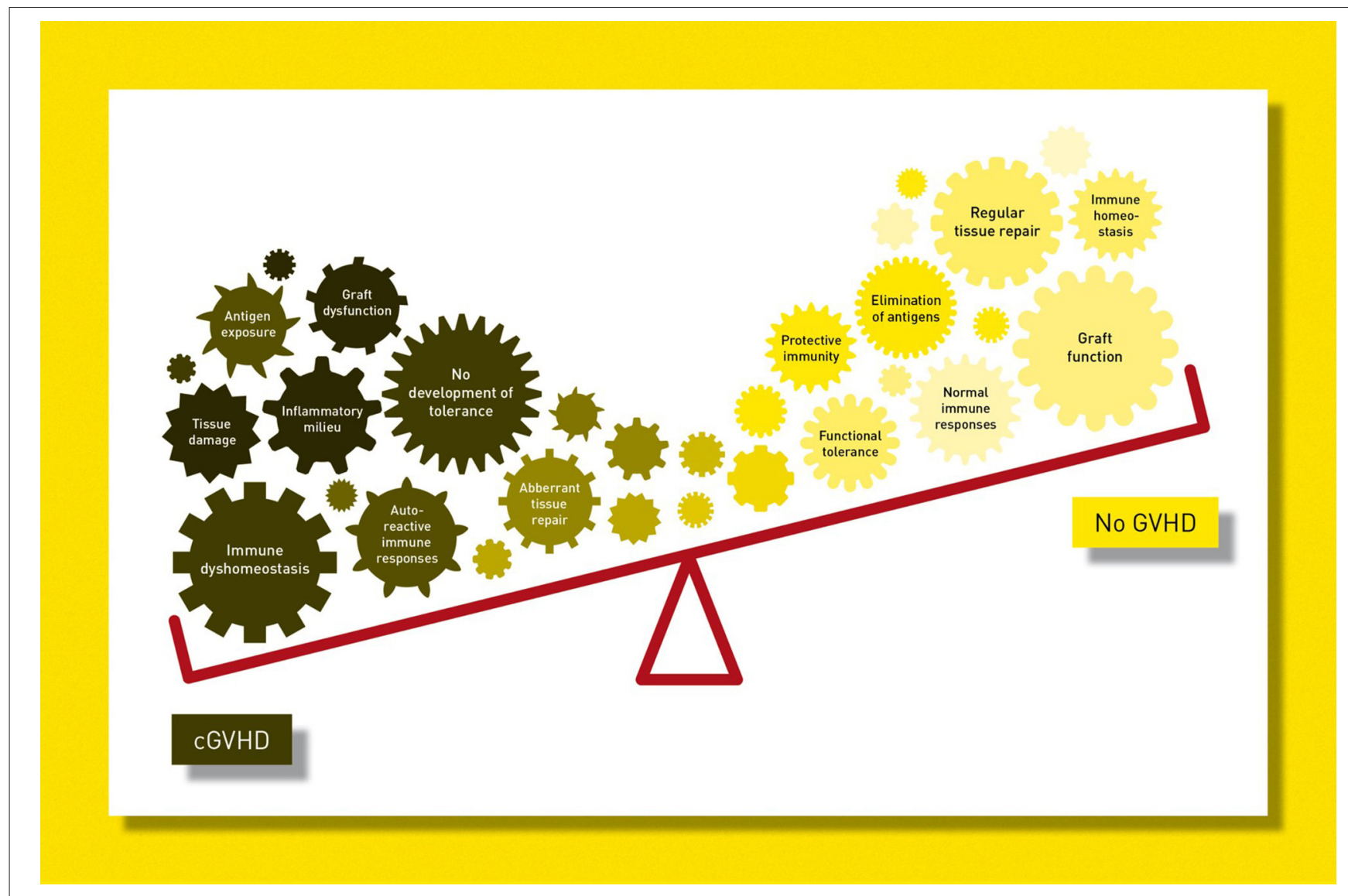

FIGURE 3 | The see-saw of cGvHD.

above-mentioned approaches should allow the timely detection of any leukaemia relapses in these patients.

\section{cGvHD-Related Immune Impairment and Risk of Infection}

Murine studies in combination with biomarker studies have demonstrated a role for $\mathrm{T}$ cells as well as $\mathrm{B}$ cells in cGvHD. Increased percentages of peripheral naïve

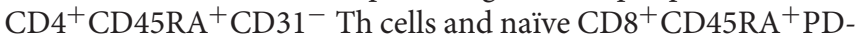
$1^{+}$cytotoxic $\mathrm{T}$ cells as well as activated $\mathrm{T}$ cells $\left(\mathrm{CD} 3^{+} \mathrm{CD} 69^{+}\right)$ were observed in children with cGvHD compared with patients without cGvHD post HSCT (67). Increased levels of T cells have been observed also in severe compared to moderate cGvHD in children and adolescents (45).

However, GvHD biomarker studies suggest that the hallmark of cGvHD-related immune dysregulation is a profoundly disturbed B-cell profile, with low numbers of transitional memory B cells and lack of differentiation to the switched memory B cell phenotype (56). The most severe cGvHD disease in children and adolescents correlated significantly with a distorted B cell profile consisting of increased CD $19^{+} \mathrm{CD} 21^{\text {low }} \mathrm{B}$ cells along with an increased $\mathrm{CD} 19^{+} \mathrm{CD} 21^{\text {low }}$ to $\mathrm{CD} 19^{+} \mathrm{CD} 27^{+}$ $\mathrm{B}$ cell ratio (45). Elevated percentages of CD21 $1^{\text {low }} \mathrm{B}$ cells have been shown to correlate with the occurrence of severe infections
(56). In a third of adult cGvHD patients, this perturbed B cell differentiation leads to significant hypogammaglobulinaemia (57). Conversely, hypergammaglobulinaemia can occur in a subgroup of patients with cGvHD and is associated with the occurrence of allo/autoantibodies, targeting various tissues. Bacterial infections are common in cGvHD and may be the result of dysgammaglobulinaemia aggravated by a degree of functional asplenia (263).

Skin cGvHD was demonstrated to be a specific risk factor for late Staphylococcus aureus bacteraemia in a paediatric cohort receiving $\mathrm{BM}$ transplants, probably as a result of skin barrier breakthrough (264).

Both aGvHD and cGvHD are risk factors for viral infection and reactivation in paediatric transplant patients, with the highest cumulative incidence for $\operatorname{CMV}(265,266)$. Other pathogens for which risks of infection/reactivation are increased by GvHD include Epstein-Barr virus, adenovirus, BK virus and varicella zoster virus, as well as respiratory infections. Even varicella zoster virus can be fatal in patients with active GvHD on immunosuppressive therapy (267).

A continued risk of invasive fungal infection exists in patients with $\mathrm{cGvHD}$ and also paediatric patients who receive highdose steroids post HSCT (268-270). For patients who develop pulmonary aspergillosis post HSCT yet who continue to need 


\begin{tabular}{|c|c|c|c|}
\hline Current comorbidities & \multirow{5}{*}{\multicolumn{2}{|c|}{$\begin{array}{l}\text { cGVHD at onset } \\
\text { Mucocutaneous / GI-liver / lung / fascia } \\
\text { Morbid forms: eyes, lungs } \\
\text { Progressive sclerosis / fibrosis } \\
\text { Overlap cGVHD }\end{array}$}} & cGVHD at current \\
\hline Risk of & & & Steroid-resistant \\
\hline - Relapse & & & Steroid-dependent \\
\hline - Infection & & & Steroid-intolerant \\
\hline - Cytopenia & & & \\
\hline - Mixed chimerism & \multicolumn{2}{|c|}{ Progressive onset } & Mucocutaneous / GI-liver / lung / \\
\hline Poor Karnofsky / Lansky score $(\leq 80)$ & \multicolumn{2}{|c|}{ Low platelets* } & fascia \\
\hline Status of immune reconstitution: & \multicolumn{2}{|c|}{ Hyperbilirubinaemia } & Morbid forms: eyes, lungs \\
\hline - $\quad \mathrm{T}$ cell compartment & \multicolumn{2}{|c|}{ prior aGVHD grade $2-4$} & Progressive sclerosis /fibrosis \\
\hline - B cell compartment & \multicolumn{2}{|c|}{ PBSC-HSCT } & Speed of progression \\
\hline - Immunuglobulines & \multicolumn{2}{|c|}{ MMD-HSCT } & Liver: hepatitis-like-type / \\
\hline - $\quad$ Autoantibody positivity & \multicolumn{2}{|c|}{$\begin{array}{l}\text { TBI-containing conditioning } \\
\text { Age }>12 \text { years at } \mathrm{HSCT}\end{array}$} & cholestatic type \\
\hline Venous access & \multicolumn{2}{|c|}{$\begin{array}{l}\text { IST } \text { at onset: } \\
\text { - } \quad \text { Tapering level } \\
\text { - } \quad \text { Therapeutic level }\end{array}$} & Comments \\
\hline $\begin{array}{l}\text { History of comorbidities } \\
\text { Heavily pre-treated } \\
\text { Comorbidties of primary disease } \\
\text { History of } \\
\text { - } \quad \text { Toxicity } \\
\text { - Infections } \\
\text { - Autoimmune disease } \\
\text { Osteonecrosis/Osteoporosis }\end{array}$ & \multicolumn{2}{|c|}{$\begin{array}{l}\text { History of acute GVHD } \\
\text { aGVHD organ and grade } \\
\text { aGVHD overall grade } \\
\text { Steroid-resistant aGVHD } \\
\text { Other refractory treatments }\end{array}$} & \\
\hline \multicolumn{2}{|l|}{ Patient-specific considerations } & \multicolumn{2}{|c|}{ Treatment-specific considerations } \\
\hline \multicolumn{2}{|l|}{ Psychosocial / socio-economic aspe } & \\
\hline \multicolumn{2}{|l|}{ - Compliance / adherence } & \multicolumn{2}{|c|}{ Steroid sparing approach } \\
\hline \multicolumn{2}{|l|}{ - Language barrier } & \multicolumn{2}{|c|}{ T-reg enhancing approach } \\
\hline \multirow{2}{*}{\multicolumn{2}{|c|}{$\begin{array}{l}\text { - Psychosocial integration: schooling/education, } \\
\text { family, friends }\end{array}$}} & \multirow{4}{*}{\multicolumn{2}{|c|}{$\begin{array}{l}\text { Topical treatment / ancillary care } \\
\text { Initial weekly assessment } \\
\text { Possibility of trial enrollment } \\
\text { Discussion within multidisciplinary team }\end{array}$}} \\
\hline & & & \\
\hline Distance to Transplant Center & & & \\
\hline \multicolumn{2}{|l|}{ Patient acceptability } & & \\
\hline \multicolumn{2}{|c|}{$\begin{array}{l}\text { Patient counselling: } \\
\text { avoid additional tissue inciting events (e.g. trauma, } \\
\text { operation, infection, sun exposure, etc.) }\end{array}$} & \multicolumn{2}{|c|}{$\begin{array}{l}\text { Do not change more than } 1 \text { at once } \\
\text { Do not combine }>3 \text { systemic IST agents at the same time } \\
\text { Age }+ \text { individual adjusted formula }\end{array}$} \\
\hline
\end{tabular}

FIGURE 4 | Individualised risk assessment and aggregated considerations (cheque as appropriate). *Platelets < 100 Gil. Gl, gastrointestinal tract; PBSC, peripheral blood stem cells; HSCT, hematopoietic stem cell transplantation; MMD, mismatched donor; TBI, total body irradiation; IST, immunosuppressive therapy.

immunosuppressive treatment, the risk of mortality is high, with reports varying from $50-70 \%(268-270)$.

\section{Infections in Association With Specific Treatment Options}

Treatments for cGvHD are often combined making it near impossible to ascertain the risk of infection associated with each separate drug, with the exception of rituximab which in known to cause hypogammaglobulinaemia that directly correlates to increased risks of bacterial and viral infections (271). Most secondary agents are given on a backdrop of some level of steroids. With regards to the newer small molecule therapies, in a study of 22 paediatric patients on ibrutinib for $c \mathrm{GvHD}$, severe bacterial infection $(n=2)$, Epstein-Barr virus reactivations $(n=1)$, and no fungal infections were seen (129). However, data from lymphoma treatment with ibrutinib provide a warning regarding the risk of Pneumocystis jirovecii pneumonia and fungal infections (including Aspergillus) (272).

Patients with bronchiolitis obliterans syndrome may be at particularly high risk of opportunistic infections when treated with ruxolitinib (273). In an adolescent/adult cohort receiving ruxolitinib/steroid treatment for bronchiolitis obliterans syndrome, a serious infection of grade 2 or higher occurred in 
$47 \%$ of patients, with two thirds of these being fungal infections (273). The myelosuppressive side effects of ruxolitinib result in neutropenia; moreover, its mechanism of action of widely blocking innate and specific immune intracellular cytokine signalling makes $c \mathrm{GvHD}$ patients receiving this therapy more prone to developing all types of infection (especially viral infections but also candida, fungal and mycobacterial infections) $(186,273,274)$.

Of all treatments for $\mathrm{CGvHD}$ discussed above, ECP appears to be associated with the lowest rate of infection (275).

\section{cGvHD-Related Organ Toxicity and the Risk of Complications and Late Effects}

Both the highly inflammatory state and immune dysregulation seen in CGvHD and the side effects of medications can damage organ systems. This can lead to new organ dysfunctions that will require new medical interventions over time. The long-term toxicities and complications of paediatric $\mathrm{cGvHD}$ are the result of a complex interplay of symptoms and dysfunctions which impact on physical functioning and quality of life, with inferior outcomes associated with severe cGvHD (2). A summary of the main treatment-related toxicities is shown in Table 4.

The long-term consequences of these late complications in children are possibly: (i) an impairment of future developmental potential within a growing organ system (276), and (ii) an increase in morbidity of chronic health conditions occurring throughout life (277). The occurrence and patterns of late toxicity and complications associated with cGvHD and its treatment depend on the intensity of conditioning (especially TBI-based conditioning) and patient age at transplant $(278,279)$ and at beginning of complications. These complications contribute to late comorbidities (280). Nearly any organ might be affected by them, including the development of secondary malignancies $(15,281,282)$. As the life expectancy of paediatric patients post HSCT continues to increase, these chronic health conditions are a significant burden in the population of transplant survivors.

\section{Proposal for the Personalised Management of Paediatric CGvHD From the Clinicians' Viewpoint A Checklist for Individualised Risk Evaluation With Aggregated Considerations}

As intervention and treatment decisions in daily clinical practice are both clinician and patient specific, we summarise here the most important aspects including evaluation of the individual's risk and prognostic indicators as well as an assessment of aggregated considerations. The evaluation of individual risk and prognostic indicators covers details of GvHD and immune reconstitution, the primary disease and relapse risk, comorbidities and infectious complications. Aggregated considerations cover details of the patient's individual psychosocial and socio-economic circumstances and take into account their personal tolerance and preferences. To capture all these details, we created a comprehensive colour-coded checklist for routine clinical use (Figure 4). This walk-through checklist will provide the clinician with a summary of the patient's status and should be used at baseline and each timepoint of clinical evaluation, helping the clinician to identify various co-existing aspects at one glance.

The rationale behind this approach is to better identify the appropriate time point for the most appropriate treatment approach in a patient-centred manner, keeping in mind that prevention of severe cGvHD is of utmost importance (11).

\section{A Treatment Algorithm for Paediatric cGvHD Patients at High Risk of Relapse}

The desirable therapeutic approach to managing paediatric cGvHD patients at high risk of relapse would consist of a safe treatment with minimum short-and long-term adverse events, embedded within an evidence-based protocol and supported by reliable predictors of response. Currently, data are not available to support such a therapeutic approach and it is likely that therapeutic interventions will not benefit all patients. Therefore, we propose a treatment algorithm to inform the personalised management plans of high-risk patients, which we developed based on the literature and joint clinical experience (Figure 5). The algorithm uses representative paediatric patients with cGvHD following HSCT for ALL who are at high risk of relapse.

We recommend that, for patients at high risk of relapse, clinicians use both our checklist for risk evaluation and our treatment algorithm to inform personalised management plans. Given the variety of organ-specific cGvHD manifestations and comorbidities that patients may present with and various patient-specific considerations, we recommend that each patient's cGvHD management plan is discussed within a multidisciplinary team.

\section{DISCUSSION}

Similarly to adults, cGVHD in children presents as a complex multi-system disease with high interindividual heterogeneity and with a distinctly inconsistent intraindividual disease course. Given the debilitating consequences and the potentially lifethreatening nature of $\mathrm{cGvHD}$, recognition of the earliest signs and symptoms and an early timepoint of intervention are of utmost importance. The prevention of severe and highly morbid forms of paediatric CGvHD is a main goal of management (1113). Within the limits of this review, current knowledge has been summarised and gaps in knowledge have been identified. To facilitate the early recognition of this complex disease for the clinician, we have put forth a theory of a holistic view of paediatric $\mathrm{cGvHD}$ and its associated manifestations.

Improved understanding of the immunobiology of $c \mathrm{GvHD}$, more precise diagnosis by the application of various biomarkers, and the identification of new therapeutic targets is required. Beside this, the treatment choices of paediatric cGvHD-and especially SR-cGvHD-remain clinician and patient specific in daily clinical practice. As no standardised recommendations exist regarding when and how to modify treatment, and in light of a risk of relapse, infection and comorbidity, we developed an individualised cGvHD management plan aiming for the titration of immunosuppressive treatment according the current status of the patient. 


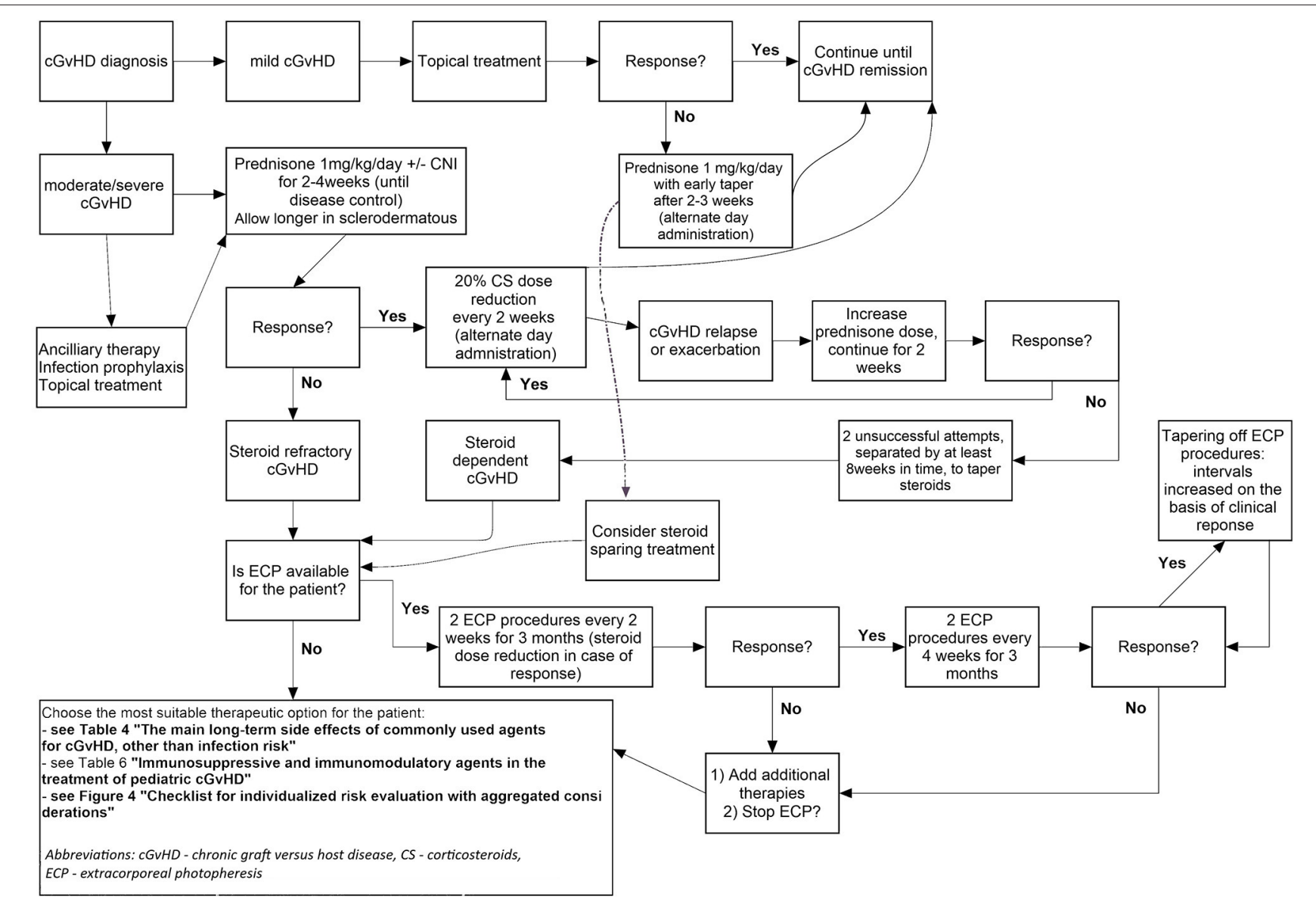

FIGURE 5 | Treatment algorithm for paediatric cGvHD patients at high risk of relapse.

We have proposed a walk-through checklist for individualised risk evaluation with aggregated considerations to provide the clinician with a summary of the patient's status. Ideally this checklist should be used at baseline and each timepoint of clinical evaluation, helping the clinician to identify various co-existing aspects at one glance during clinical follow up.

Moreover, using representative cases of paediatric cGvHD after HSCT for ALL, we have proposed a treatment algorithm for those patients at high risk of relapse. ECP with its GvL sparing and immunomodulatory effect and no serious side effects seems beneficial for this patient group, although standardised recommendations regarding the ECP treatment schedule in paediatric patients are lacking. The mode of vascular access, the benefit of earlier introduction of ECP after paediatric HSCT, and the broader use of mini ECP remain areas where further research is warranted.

Our proposed approach is mainly based on the literature and expert opinions and will require confirmation via well-designed studies. In lieu of the evidence-based data needed to inform individualised cGvHD management in paediatric patients, we hope our proposed approach that focuses on patients' individual needs will help clinicians to improve their clinical management of $\mathrm{cGvHD}$.

Evidence-based data from ongoing studies are eagerly awaited, especially regarding the recently FDA-approved treatment ruxolitinib, allowing more targeted treatment. The possible risk of infectious complications with ruxolitinib must be taken into account, again pointing out a possible advantage of ECP in this regard.

In conclusion, as a complex multiorgan disease with manifold pathogenetic pathways and the presentation of multiple manifestations over time, paediatric cGvHD requires optimal patient-adjusted management with flexible regimens chosen for specific clinical findings according to each patient's risk profile and circumstances.

\section{DATA AVAILABILITY STATEMENT}

The original contributions presented in the study are included in the article/Supplementary Material, further inquiries can be directed to the corresponding author.

\section{AUTHOR CONTRIBUTIONS}

AS-S, CL, TS, JW, J-HD, HB, and AL contributed to conception, design of the study, and wrote the first draft of the manuscript. AS-S, CL, TS, JW, J-HD, HB, AG, and AL wrote sections of the 
manuscript. All authors contributed to manuscript revision, read, and approved the submitted version.

\section{FUNDING}

This study received funding from the St. Anna Children's Cancer Research Institute, Vienna, Austria. The funders were not involved in the study design, collection, analysis, interpretation of data, the writing of this article, or the decision to submit it for publication.

\section{REFERENCES}

1. Wolff D, Lawitschka A. Chronic GvHD. In: Enric Carreras, Editor. The EBMT Handbook. Cham: Springer International Publishing (2019). p. 33146.

2. Inagaki J, Moritake H, Nishikawa T, Hyakuna N, Okada M, Suenobu SI, et al. Long-term morbidity and mortality in children with chronic graft-versushost disease classified by National Institutes of Health Consensus criteria after allogeneic hematopoietic stem cell transplantation. Biol Blood Marrow Transplant. (2015) 21:1973-80. doi: 10.1016/j.bbmt.2015.07.025

3. Kato M, Kurata M, Kanda J, Kato K, Tomizawa D, Kudo K, et al. Impact of graft-versus-host disease on relapse and survival after allogeneic stem cell transplantation for pediatric leukemia. Bone Marrow Transplant. (2019) 54:68-75. doi: 10.1038/s41409-018-0221-6

4. Boyiadzis M, Arora M, Klein JP, Hassebroek A, Hemmer M, UrbanoIspizua $\mathrm{A}$, et al. Impact of chronic graft-versus-host disease on late relapse and survival on 7,489 patients after myeloablative allogeneic hematopoietic cell transplantation for leukemia. Clin Cancer Res. (2015) 21:2020-8. doi: 10.1158/1078-0432.CCR-14-0586

5. Jagasia MH, Greinix HT, Arora M, Williams KM, Wolff D, Cowen EW, et al. National Institutes of Health Consensus Development project on criteria for clinical trials in chronic graft-versus-host disease: I. The 2014 diagnosis and staging working group report. Biol Blood Marrow Transplant. (2015) 21:389-401.el. doi: 10.1016/j.bbmt.2014.12.001

6. Filipovich AH, Weisdorf D, Pavletic S, Socie G, Wingard JR, Lee SJ, et al. National Institutes of Health Consensus Development project on criteria for clinical trials in chronic graft-versus-host disease: I. Diagnosis and staging working group report. Biol Blood Marrow Transplant. (2005) 11:94556. doi: 10.1016/j.bbmt.2005.09.004

7. Wolff D, Bertz H, Greinix H, Lawitschka A, Halter J, Holler E. The treatment of chronic graft-versus-host disease. Dtsch Arztebl Onl. (2011) 108:73240. doi: 10.3238 /arztebl.2011.0732

8. Cooke KR, Luznik L, Sarantopoulos S, Hakim FT, Jagasia M, Fowler DH, et al. The biology of chronic graft-versus-host disease: a task force report from the National Institutes of Health Consensus Development project on criteria for clinical trials in chronic graft-versus-host disease. Biol Blood Marrow Transplant. (2017) 23:211-34. doi: 10.1016/j.bbmt.2016.09.023

9. Zeiser R, Blazar BR. Pathophysiology of chronic graft-versushost disease and therapeutic targets. $N$ Engl J Med. (2017) 377:2565-79. doi: 10.1056/nejmra1703472

10. Saidu NEB, Bonini C, Dickinson A, Grce M, Inngjerdingen M, Koehl $\mathrm{U}$, et al. New approaches for the treatment of chronic graft-versushost disease: current status and future directions. Front Immunol. (2020) 11:578314. doi: 10.3389/fimmu.2020.578314

11. Kitko CL, Pidala J, Schoemans HM, Lawitschka A, Flowers ME, Cowen EW, et al. National Institutes of Health Consensus Development project on criteria for clinical trials in chronic graft-versus-host disease: IIa. The 2020 clinical implementation and early diagnosis working group report. Transplant Cell Ther. (2021) 27:545-57. doi: 10.1016/j.jtct.2021.03.033

12. Williams KM, Inamoto Y, Im A, Hamilton B, Koreth J, Arora M, et al. National Institutes of Health Consensus Development project on criteria for clinical trials in chronic graft-versus-host disease: I. The 2020 etiology

\section{ACKNOWLEDGMENTS}

Editorial support in the preparation of this manuscript was provided by Hannah Bridges of HB Health Comms Limited.

\section{SUPPLEMENTARY MATERIAL}

The Supplementary Material for this article can be found online at: https://www.frontiersin.org/articles/10.3389/fped. 2022.808103/full\#supplementary-material

and prevention working group report. Transplant Cell Ther. (2021) 27:45266. doi: 10.1016/j.jtct.2021.02.035

13. Pidala J, Kitko C, Lee SJ, Carpenter P, Cuvelier GDE, Holtan S, et al. National Institutes of Health Consensus Development project on criteria for clinical trials in chronic graft-versus-host disease: IIb. The 2020 preemptive therapy working group report. Transplant Cell Ther. (2021) 27:632-41. doi: 10.1016/j.jtct.2021.03.029

14. Cuvelier GDE, Nemecek ER, Wahlstrom JT, Kitko CL, Lewis VA, Schechter $\mathrm{T}$, et al. Benefits and challenges with diagnosing chronic and late acute GvHD in children using the NIH consensus criteria. Blood. (2019) 134:30416. doi: 10.1182/blood.2019000216

15. Lawitschka A, Peters C. Long-term effects of myeloablative allogeneic hematopoietic stem cell transplantation in pediatric patients with acute lymphoblastic leukemia. Curr Oncol Rep. (2018) 20:74. doi: 10.1007/s11912-018-0719-5

16. Cuvelier GDE, Li A, Drissler S, Kariminia A, Abdossamadi S, Rozmus J, et al. Age related differences in the biology of chronic graft-versus-host disease after hematopoietic stem cell transplantation. Front Immunol. (2020) 11:571884. doi: 10.3389/fimmu.2020.571884

17. Baird K, Cooke K, Schultz KR. Chronic graft-versus-host disease (GvHD) in children. (2010) 57:297-322. doi: 10.1016/j.pcl.2009.11.003

18. Bachier CR, Aggarwal SK, Hennegan K, Milgroom A, Francis K, Dehipawala $\mathrm{S}$, et al. Epidemiology and treatment of chronic graft-versus-host disease post-allogeneic hematopoietic cell transplantation: a us claims analysis. Transplant Cell Ther. (2021) 27:504.e1-6. doi: 10.1016/j.jtct.2020.12.027

19. Remberger M, Afram G, Sundin M, Uhlin M, Leblanc K, Björklund A, et al. High incidence of severe chronic GvHD after HSCT with sibling donors. A single center analysis. Bone Marrow Transplant. (2016) 51:151821. doi: 10.1038/bmt.2016.159

20. Wagner JE, Steinbuch M, Kernan NA, Broxmayer HE, Gluckman E. Allogeneic sibling umbilical-cord-blood transplantation in children with malignant and non-malignant disease. Lancet. (1995) 346:2149. doi: 10.1016/S0140-6736(95)91268-1

21. Rocha V, Wagner JE, Sobocinski KA, Klein JP, Zhang M-J, Horowitz MM, et al. Graft-versus-host disease in children who have received a cord-blood or bone marrow transplant from an hla-identical sibling. N Engl J Med. (2000) 342:1846-54. doi: 10.1056/nejm200006223422501

22. Gustafsson Jernberg Å, Remberger M, Ringdén O, Winiarski J. Graftversus-leukaemia effect in children: chronic GvHD has a significant impact on relapse and survival. Bone Marrow Transplant. (2003) 31:17581. doi: 10.1038/sj.bmt.1703808

23. Meisel R, Laws HJ, Balzer S, Bernbeck B, Kramm C, Schonberger S, et al. Comparable long-term survival after bone marrow versus peripheral blood progenitor cell transplantation from matched unrelated donors in children with hematologic malignancies. Biol Blood Marrow Transplant. (2007) 13:1338-45. doi: 10.1016/j.bbmt.2007.07.009

24. Zecca M, Prete A, Rondelli R, Lanino E, Balduzzi A, Messina C, et al. Chronic graft-versus-host disease in children: incidence, risk factors, and impact on outcome. Blood. (2002) 100:1192-200. doi: 10.1182/blood-2001-11-0059

25. Qayed M, Wang T, Hemmer MT, Spellman S, Arora M, Couriel D, et al. Influence of age on acute and chronic GvHD in children undergoing hla-identical sibling bone marrow transplantation for acute leukemia: 
implications for prophylaxis. Biol Blood Marrow Transplant. (2018) 24:5218. doi: 10.1016/j.bbmt.2017.11.004

26. Group SCTC. Allogeneic peripheral blood stem-cell compared with bone marrow transplantation in the management of hematologic malignancies: an individual patient data meta-analysis of nine randomized trials. J Clin Oncol. (2005) 23:5074-87. doi: 10.1200/JCO.2005.09.020

27. Afram G, Simón JaP, Remberger M, Caballero-Velázquez T, Martino R, Piñana JL, et al. Reduced intensity conditioning increases risk of severe cGvHD: identification of risk factors for $\mathrm{cGvHD}$ in a multicenter setting. Med Oncol. (2018) 35, 1-8. doi: 10.1007/s12032-018-1127-2

28. Perez-Simon JA, Diez-Campelo M, Martino R, Brunet S, Urbano A, Caballero MD, et al. Influence of the intensity of the conditioning regimen on the characteristics of acute and chronic graft-versus-host disease after allogeneic transplantation. Br J Haematol. (2005) 130:394403. doi: 10.1111/j.1365-2141.2005.05614.x

29. Ferrara JLM, Levine JE, Reddy P, Holler E. Graft-versus-host disease. Lancet. (2009) 373:1550-61. doi: 10.1016/S0140-6736(09)60237-3

30. Cutler CS, Koreth J, Ritz J. Mechanistic approaches for the prevention and treatment of chronic GvHD. Blood. (2017) 129:22-9. doi: 10.1182/blood-2016-08-686659

31. Rozmus J. Monogenic immune diseases provide insights into the mechanisms and treatment of chronic graft-versus-host disease. Front Immunol. (2021) 11:574569. doi: 10.3389/fimmu.2020.574569

32. Macdonald KPA, Blazar BR, Hill GR. Cytokine mediators of chronic graftversus-host disease. J Clin Invest. (2017) 127:2452-63. doi: 10.1172/JCI90593

33. Bleakley M, Heimfeld S, Loeb KR, Jones LA, Chaney C, Seropian S, et al. Outcomes of acute leukemia patients transplanted with naive $\mathrm{T}$ celldepleted stem cell grafts. J Clin Invest. (2015) 125:2677-89. doi: 10.1172/JCI 81229

34. Chen X, Vodanovic-Jankovic S, Johnson B, Keller M, Komorowski R, Drobyski WR. Absence of regulatory T-cell control of Th1 and Th17 cells is responsible for the autoimmune-mediated pathology in chronic graft-versushost disease. Blood. (2007) 110:3804-13. doi: 10.1182/blood-2007-05-091074

35. Gartlan KH, Markey KA, Varelias A, Bunting MD, Koyama M, Kuns $\mathrm{RD}$, et al. Tc17 cells are a proinflammatory, plastic lineage of pathogenic CD8+ T cells that induce GvHD without antileukemic effects. Blood. (2015) 126:1609-20. doi: 10.1182/blood-2015-01-622662

36. Serody JS, Hill GR. The il-17 differentiation pathway and its role in transplant outcome. Biol Blood Marrow Transplant. (2012) 18:S5661. doi: 10.1016/j.bbmt.2011.10.001

37. Flynn R, Du J, Veenstra RG, Reichenbach DK, Panoskaltsis-Mortari A, Taylor PA, et al. Increased t follicular helper cells and germinal center B cells are required for cGvHD and bronchiolitis obliterans. Blood. (2014) 123:3988-98. doi: 10.1182/blood-2014-03-562231

38. Sarantopoulos S, Stevenson KE, Kim HT, Cutler CS, Bhuiya NS, Schowalter M, et al. Altered B-cell homeostasis and excess baff in human chronic graft-versus-host disease. Blood. (2009) 113:3865-74. doi: 10.1182/blood-2008-09-177840

39. Mcmanigle W, Youssef A, Sarantopoulos S. B cells in chronic graft-versus-host disease. Hum Immunol. (2019) 80:3939. doi: 10.1016/j.humimm.2019.03.003

40. Markey KA, Schluter J, Gomes ALC, Littmann ER, Pickard AJ, Taylor BP, et al. The microbe-derived short-chain fatty acids butyrate and propionate are associated with protection from chronic GvHD. Blood. (2020) 136:1306. doi: 10.1182/blood.2019003369

41. Peled JU, Gomes ALC, Devlin SM, Littmann ER, Taur Y, Sung $\mathrm{AD}$, et al. Microbiota as predictor of mortality in allogeneic hematopoietic-cell transplantation. $N$ Engl $J$ Med. (2020) 382:822-34. doi: 10.1056/nejmoa1900623

42. Teshima T, Hill GR. The pathophysiology and treatment of graft-versushost disease: lessons learnt from animal models. Front Immunol. (2021) 12:715424. doi: 10.3389/fimmu.2021.715424

43. Paczesny S, Hakim FT, Pidala J, Cooke KR, Lathrop J, Griffith LM, et al. National Institutes of Health Consensus Development project on criteria for clinical trials in chronic graft-versus-host disease: III: the 2014 biomarker working group report. Biol Blood Marrow Transplant. (2015) 21:78092. doi: $10.1016 /$ j.bbmt.2015.01.003
44. Wolff D, Greinix H, Lee SJ, Gooley T, Paczesny S, Pavletic S, et al. Biomarkers in chronic graft-versus-host disease: quo vadis? Bone Marrow Transplant. (2018) 53:832-7. doi: 10.1038/s41409-018-0092-x

45. Lawitschka A, Gueclue ED, Januszko A, Körmöczi U, Rottal A, Fritsch G, et al. National institutes of health-defined chronic graft-vs.-host disease in pediatric hematopoietic stem cell transplantation patients correlates with parameters of long-term immune reconstitution. Front Immunol. (2019) 10:1879. doi: 10.3389/fimmu.2019.01879

46. Fujii H, Cuvelier G, She K, Aslanian S, Shimizu H, Kariminia A, et al. Biomarkers in newly diagnosed pediatric-extensive chronic graft-versushost disease: a report from the children's oncology group. Blood. (2008) 111:3276-85. doi: 10.1182/blood-2007-08-106286

47. Sarantopoulos S, Stevenson KE, Kim HT, Bhuiya NS, Cutler CS, Soiffer RJ, et al. High levels of B-cell activating factor in patients with active chronic graft-versus-host disease. Clin Cancer Res. (2007) 13:610714. doi: 10.1158/1078-0432.CCR-07-1290

48. Saliba RM, Sarantopoulos S, Kitko CL, Pawarode A, Goldstein SC, Magenau J, et al. B-cell activating factor (baff) plasma level at the time of chronic GvHD diagnosis is a potential predictor of non-relapse mortality. Bone Marrow Transplant. (2017) 52:1010-5. doi: 10.1038/bmt.2017.73

49. Zaid MA, Wu J, Wu C, Logan BR, Yu J, Cutler C, et al. Plasma biomarkers of risk for death in a multicenter phase 3 trial with uniform transplant characteristics post-allogeneic hct. Blood. (2017) 129:16270. doi: 10.1182/blood-2016-08-735324

50. Kitko CL, Levine JE, Storer BE, Chai X, Fox DA, Braun TM, et al. Plasma cxcl9 elevations correlate with chronic GvHD diagnosis. Blood. (2014) 123:786-93. doi: 10.1182/blood-2013-08-520072

51. Hakim FT, Memon S, Jin P, Imanguli MM, Wang H, Rehman $\mathrm{N}$, et al. Upregulation of IFN-inducible and damage-response pathways in chronic graft-versus-host disease. J Immunol. (2016) 197:3490-503. doi: 10.4049/jimmunol.1601054

52. Kariminia A, Holtan SG, Ivison S, Rozmus J, Hebert MJ, Martin PJ, et al. Heterogeneity of chronic graft-versus-host disease biomarkers: association with cxcl10 and cxcr3+ nk cells. Blood. (2016) 127:308291. doi: 10.1182/blood-2015-09-668251

53. Liu X, Yue Z, Yu J, Daguindau E, Kushekhar K, Zhang Q, et al. Proteomic characterization reveals that $\mathrm{mmp}-3$ correlates with bronchiolitis obliterans syndrome following allogeneic hematopoietic cell and lung transplantation. Am J Transplant. (2016) 16:2342-51. doi: 10.1111/ajt. 13750

54. Inamoto Y, Martin PJ, Paczesny S, Tabellini L, Momin AA, Mumaw CL, et al. Association of plasma CD163 concentration with de novo-onset chronic graft-versus-host disease. Biol Blood Marrow Transplant. (2017) 23:12506. doi: 10.1016/j.bbmt.2017.04.019

55. She K, Gilman AL, Aslanian S, Shimizu H, Krailo M, Chen Z, et al. Altered toll-like receptor 9 responses in circulating B cells at the onset of extensive chronic graft-versus-host disease. Biol Blood Marrow Transplant. (2007) 13:386-97. doi: 10.1016/j.bbmt.2006.12.441

56. Greinix HT, Pohlreich D, Kouba M, Körmöczi U, Lohmann I, Feldmann $\mathrm{K}$, et al. Elevated numbers of immature/transitional CD21- b lymphocytes and deficiency of memory CD27+ B cells identify patients with active chronic graft-versus-host disease. Biol Blood Marrow Transplant. (2008) 14:208-19. doi: 10.1016/j.bbmt.2007.10.009

57. Kuzmina Z, Greinix HT, Weigl R, Körmöczi U, Rottal A, Frantal S, et al. Significant differences in B-cell subpopulations characterize patients with chronic graft-versus-host disease-associated dysgammaglobulinemia. Blood. (2011) 117:2265-74. doi: 10.1182/blood-2010-07-295766

58. Zorn E, Kim HT, Lee SJ, Floyd BH, Litsa D, Arumugarajah S, et al. Reduced frequency of FOXP3 $+\mathrm{CD} 4+\mathrm{CD} 25+$ regulatory $\mathrm{T}$ cells in patients with chronic graft-versus-host disease. Blood. (2005) 106:290311. doi: 10.1182/blood-2005-03-1257

59. Forcade E, Paz K, Flynn R, Griesenauer B, Amet T, Li W, et al. An activated Th17-prone $\mathrm{T}$ cell subset involved in chronic graft-versushost disease sensitive to pharmacological inhibition. JCI Insight. (2017) 2:e92111. doi: 10.1172/jci.insight.92111

60. Forcade E, Kim HT, Cutler C, Wang K, Alho AC, Nikiforow $\mathrm{S}$, et al. Circulating $\mathrm{t}$ follicular helper cells with increased 
function during chronic graft-versus-host disease. Blood. (2016) 127:2489-97. doi: 10.1182/blood-2015-12-688895

61. Yu J, Storer BE, Kushekhar K, Abu Zaid M, Zhang Q, Gafken PR, et al. Biomarker panel for chronic graft-versus-host disease. J Clin Oncol. (2016) 34:2583-90. doi: 10.1200/JCO.2015.65.9615

62. Baird K, Comis LE, Joe GO, Steinberg SM, Hakim FT, Rose JJ, et al. Imatinib mesylate for the treatment of steroid-refractory sclerotic-type cutaneous chronic graft-versus-host disease. Biol Blood Marrow Transplant. (2015) 21:1083-90. doi: 10.1016/j.bbmt.2015.03.006

63. Du J, Flynn R, Paz K, Ren HG, Ogata Y, Zhang Q, et al. Murine chronic graftversus-host disease proteome profiling discovers ccl15 as a novel biomarker in patients. Blood. (2018) 131:1743-54. doi: 10.1182/blood-2017-08-800623

64. Adom D, Rowan C, Adeniyan T, Yang J, Paczesny S. Biomarkers for allogeneic hct outcomes. Front Immunol. (2020) 11:673. doi: $10.3389 /$ fimmu. 2020.00673

65. Malard F, Bossard C, Brissot E, Chevallier P, Guillaume T, Delaunay J, et al. Increased Th17/Treg ratio in chronic liver GvHD. Bone Marrow Transplant. (2014) 49:539-44. doi: 10.1038/bmt.2013.215

66. Alho AC, Kim HT, Chammas MJ, Reynolds CG, Matos TR, Forcade E, et al. Unbalanced recovery of regulatory and effector $\mathrm{T}$ cells after allogeneic stem cell transplantation contributes to chronic GvHD. Blood. (2016) 127:64657. doi: 10.1182/blood-2015-10-672345

67. Schultz KR, Kariminia A, Ng B, Abdossamadi S, Lauener M, Nemecek ER, et al. Immune profile differences between chronic GvHD and late acute GvHD: results of the able/pbmtc 1202 studies. Blood. (2020) 135:128798. doi: 10.1182/BLOOD.2019003186

68. Socié G, Schmoor C, Bethge WA, Ottinger HD, Stelljes M, Zander $\mathrm{AR}$, et al. Chronic graft-versus-host disease: long-term results from a randomized trial on graft-versus-host disease prophylaxis with or without anti-T-cell globulin ATG-fresenius. Blood. (2011) 117:637582. doi: 10.1182/blood-2011-01-329821

69. Diaz MA, Vicent MG, Gonzalez ME, Verdeguer A, De La Rubia J, Bargay J, et al. Risk assessment and outcome of chronic graftversus-host disease after allogeneic peripheral blood progenitor cell transplantation in pediatric patients. Bone Marrow Transplant. (2004) 34:433-8. doi: 10.1038/sj.bmt.1704589

70. Eapen M, Horowitz MM, Klein JP, Champlin RE, Loberiza FR, Ringdén $\mathrm{O}$, et al. Higher mortality after allogeneic peripheral-blood transplantation compared with bone marrow in children and adolescents: the histocompatibility and alternate stem cell source working committee of the international bone marrow transplant registry. J Clin Oncol. (2004) 22:4872-80. doi: 10.1200/JCO.2004.02.189

71. Ozawa S, Nakaseko C, Nishimura M, Maruta A, Cho R, Ohwada C, et al. Chronic graft-versus-host disease after allogeneic bone marrow transplantation from an unrelated donor: incidence, risk factors and association with relapse. A report from the Japan marrow donor program. Br J Haematol. (2007) 137:142-51. doi: 10.1111/j.1365-2141.2007.06543.x

72. Williams KM, Chien JW, Gladwin MT, Pavletic SZ. Bronchiolitis obliterans after allogeneic hematopoietic stem cell transplantation. J Am Med Assoc. (2009) 302:306-14. doi: 10.1001/jama.2009.1018

73. Lee JW, Lee DH, Jang PS, Yi MS, Chung NG, Cho B, et al. Prognostic implications of the NIH consensus criteria in children with chronic graft-versus-host disease. Yonsei Med J. (2011) 52:77986. doi: $10.3349 /$ ymj.2011.52.5.779

74. Kanda J, Nakasone H, Atsuta Y, Toubai T, Yokoyama H, Fukuda T, et al. Risk factors and organ involvement of chronic GvHD in Japan. Bone Marrow Transplant. (2014) 49:228-35. doi: 10.1038/bmt.2013.151

75. Arai S, Jagasia M, Storer B, Chai X, Pidala J, Cutler C, et al. Global and organ-specific chronic graft-versus-host disease severity according to the $2005 \mathrm{NIH}$ consensus criteria. Blood. (2011) 118:42429. doi: 10.1182/blood-2011-03-344390

76. Grube M, Holler E, Weber D, Holler B, Herr W, Wolff D. Risk factors and outcome of chronic graft-versus-host disease after allogeneic stem cell transplantation-results from a single-center observational study. Biol Blood Marrow Transplant. (2016) 22:1781-91. doi: 10.1016/j.bbmt.2016.06.020

77. Lazaryan A, Weisdorf DJ, Defor T, Brunstein CG, Macmillan ML, Bejanyan $\mathrm{N}$, et al. Risk factors for acute and chronic graft-versus-host disease after allogeneic hematopoietic cell transplantation with umbilical cord blood and matched sibling donors. Biol Blood Marrow Transplant. (2016) 22:13440. doi: 10.1016/j.bbmt.2015.09.008

78. Watkins BK, Horan J, Storer B, Martin PJ, Carpenter PA, Flowers MED. Recipient and donor age impact the risk of developing chronic GvHD in children after allogeneic hematopoietic transplant. Bone Marrow Transplant. (2017) 52:625-6. doi: 10.1038/bmt.2016.328

79. Kok LMC, Bungener L, De Bock GH, Biswana A, Van Der Wal G, Van Imhoff GW, et al. Risk factors associated with the development of moderate to severe chronic graft-versus-host disease after non-myeloablative conditioning allogeneic stem cell transplantation in patients with aml or mds. Hum Cell. (2020) 33:243-51. doi: 10.1007/s13577-019-00297-7

80. Martires KJ, Baird K, Steinberg SM, Grkovic L, Joe GO, Williams KM, et al. Sclerotic-type chronic GvHD of the skin: clinical risk factors, laboratory markers, and burden of disease. Blood. (2011) 118:42507. doi: 10.1182/blood-2011-04-350249

81. Inamoto $\mathrm{Y}$, Storer BE, Petersdorf EW, Nelson JL, Lee SJ, Carpenter $\mathrm{PA}$, et al. Incidence, risk factors, and outcomes of sclerosis in patients with chronic graft-versus-host disease. Blood. (2013) 121:5098-103. doi: 10.1182/blood-2012-10-464198

82. Flowers MED, Inamoto Y, Carpenter PA, Lee SJ, Kiem HP, Petersdorf $\mathrm{EW}$, et al. Comparative analysis of risk factors for acute graft-versushost disease and for chronic graft-versus-host disease according to National Institutes of Health consensus criteria. Blood. (2011) 117:32149. doi: 10.1182/blood-2010-08-302109

83. Jagasia M, Giglia J, Chinratanalab W, Dixon S, Chen H, Frangoul H, et al. Incidence and outcome of chronic graft-versus-host disease using National Institutes of Health Consensus criteria. Biol Blood Marrow Transplant. (2007) 13:1207-15. doi: 10.1016/j.bbmt.2007.07.001

84. Pérez-Simón JA, Encinas C, Silva F, Arcos MJ, Díez-Campelo M, SánchezGuijo FM, et al. Prognostic factors of chronic graft-versus-host disease following allogeneic peripheral blood stem cell transplantation: the National Institutes Health scale plus the type of onset can predict survival rates and the duration of immunosuppressive therapy. Biol Blood Marrow Transplant. (2008) 14:1163-71. doi: 10.1016/j.bbmt.2008.07.015

85. Cho BS, Min CK, Eom KS, Kim YJ, Kim HJ, Lee S, et al. Feasibility of NIH consensus criteria for chronic graft-versus-host disease. Leukemia. (2009) 23:78-84. doi: 10.1038/leu.2008.276

86. Vigorito AC, Campregher PV, Storer BE, Carpenter PA, Moravec CK, Kiem HP, et al. Evaluation of NIH consensus criteria for classification of late acute and chronic GvHD. Blood. (2009) 114:702-8. doi: 10.1182/blood-2009-03-208983

87. Kim DY, Lee JH, Lee JH, Kim SH, Lim SN, Kim SD, et al. Reevaluation of the National Institutes of Health criteria for classification and scoring of chronic GvHD. Bone Marrow Transplant. (2010) 45:117480. doi: $10.1038 /$ bmt. 2009.320

88. Pidala J, Vogelsang G, Martin P, Chai X, Storer B, Pavletic S, et al. Overlap subtype of chronic graft-versus-host disease is associated with an adverse prognosis, functional impairment, and inferior patient-reported outcomes: a chronic graft-versus-host disease consortium study. Haematologica. (2012) 97:451-8. doi: 10.3324/haematol.2011.055186

89. Arora M, Klein JP, Weisdorf DJ, Hassebroek A, Flowers MED, Cutler CS, et al. Chronic GvHD risk score: a center for international blood and marrow transplant research analysis. Blood. (2011) 117:6714-20. doi: 10.1182/blood-2010-12-323824

90. Pérez-Simón JA, Afram G, Martino R, Piñana JL, Caballero-Velazquez $\mathrm{T}$, Ringden $\mathrm{O}$, et al. Evaluation of prognostic factors among patients with chronic graft-versus-host disease. Haematologica. (2012) 97:118795. doi: 10.3324/haematol.2011.055244

91. Jacobsohn DA, Arora M, Klein JP, Hassebroek A, Flowers ME, Cutler CS, et al. Risk factors associated with increased nonrelapse mortality and with poor overall survival in children with chronic graft-versus-host disease. Blood. (2011) 118:4472-9. doi: 10.1182/blood-2011-04-349068

92. Jacobsohn DA, Kurland BF, Pidala J, Inamoto Y, Chai X, Palmer JM, et al. Correlation between NIH composite skin score, patient-reported skin score, and outcome: results from the chronic GvHD consortium. Blood. (2012) 120:2545-52. doi: 10.1182/blood-2012-04-424135

93. Tecchio C, Mosna F, Andreini A, Paoli L, Di Bella R, Sabata DD, et al. The National Institutes of Health criteria for classification and scoring of chronic 
graft versus host disease: long-term follow-up of a single center series. Leuk Lymphoma. (2013) 54:1020-7. doi: 10.3109/10428194.2012.733877

94. Baird K, Steinberg SM, Grkovic L, Pulanic D, Cowen EW, Mitchell SA, et al. National institutes of health chronic graft-versus-host disease staging in severely affected patients: organ and global scoring correlate with established indicators of disease severity and prognosis. Biol Blood Marrow Transplant. (2013) 19:632-9. doi: 10.1016/j.bbmt.2013.01.013

95. Inamoto Y, Kim DD, Storer BE, Moon JH, Lipton JH, Kuruvilla J, et al. To the editor: application of CIBMTR risk score to NIH chronic GvHD at individual centers. Blood. (2014) 123:453-5. doi: 10.1182/blood-2013-11-536581

96. Moon JH, Sohn SK, Lambie A, Ellis L, Hamad N, Uhm J, et al. Validation of National Institutes of Health Global Scoring System for chronic graft-versus-host disease (GvHD) according to overall and GvHD-specific survival. Biol Blood Marrow Transplant. (2014) 20:55663. doi: 10.1016/j.bbmt.2014.01.010

97. Palmer J, Williams K, Inamoto Y, Chai X, Martin PJ, Tomas LS, et al. Pulmonary symptoms measured by the National Institutes of Health Lung Score predict overall survival, nonrelapse mortality, and patientreported outcomes in chronic graft-versus-host disease. Biol Blood Marrow Transplant. (2014) 20:337-44. doi: 10.1016/j.bbmt.2013.11.025

98. Ayuk F, Veit R, Zabelina T, Bussmann L, Christopeit M, Alchalby H, et al. Prognostic factors for survival of patients with newly diagnosed chronic GvHD according to NIH criteria. Ann Hematol. (2015) 94:172732. doi: 10.1007/s00277-015-2452-6

99. Moon JH, Hamad N, Sohn SK, Uhm J, Alam N, Gupta V, et al. Improved prognostic stratification power of CIBMTR risk score with the addition of absolute lymphocyte and eosinophil counts at the onset of chronic GvHD. Ann Hematol. (2017) 96:805-15. doi: 10.1007/s00277-017-2939-4

100. Arora M, Hemmer MT, Ahn KW, Klein JP, Cutler CS, Urbano-Ispizua A, et al. Center for international blood and marrow transplant research chronic graft-versus-host disease risk score predicts mortality in an independent validation cohort. Biol Blood Marrow Transplant. (2015) 21:640-5. doi: 10.1016/j.bbmt.2014.10.022

101. Shapiro RM, Shin E, Law AD, Lam W, Michelis FV, Viswabandya A, et al. Combination of the centre for international blood and marrow transplant registry risk score and the global severity score enhances prognostic risk stratification in patients receiving frontline therapy for chronic graft-versus-host disease. Biol Blood Marrow Transplant. (2019) 25:1761-9. doi: 10.1016/j.bbmt.2019.05.029

102. Greinix HT, Eikema D-J, Koster L, Penack O, Yakoub-Agha I, Montoto $\mathrm{S}$, et al. Improved outcome of patients with graft-versus-host disease after allogeneic hematopoietic cell transplantation for hematologic malignancies over time: an EBMT mega-file study. Haematologica. (2021). doi: 10.3324/haematol.2020.265769. [Epub ahead of print].

103. Wolff D, Fatobene G, Rocha V, Kröger N, Flowers ME. Steroidrefractory chronic graft-versus-host disease: treatment options and patient management. Bone Marrow Transplant. (2021) 56:2079-87. doi: 10.1038/s41409-021-01389-5

104. Lawitschka A, Lucchini G, Strahm B, Dalle JH, Balduzzi A, Gibson B, et al. Pediatric acute graft-versus-host disease prophylaxis and treatment: surveyed real-life approach reveals dissimilarities compared to published recommendations. Transpl Int. (2020) 33:762-72. doi: 10.1111/tri.13601

105. Schoemans HM, Lee SJ, Ferrara JL, Wolff D, Levine JE, Schultz KR, et al. EBMT-NIH-CIBMTR task force position statement on standardized terminology \& guidance for graft-versus-host disease assessment. Bone Marrow Transplant. (2018) 53:1401-15. doi: 10.1038/s41409-018-0204-7

106. Jacobsohn DA. Optimal management of chronic graftversus-host disease in children: review. $\mathrm{Br} J$ Haematol. (2010) 150:278-92. $\quad$ doi: $\quad 10.1111 /$ j. $1365-2141.2010 .0$ 8247.x

107. Penack O, Marchetti M, Ruutu T, Aljurf M, Bacigalupo A, Bonifazi F, et al. Prophylaxis and management of graft versus host disease after stem-cell transplantation for haematological malignancies: updated consensus recommendations of the European Society for blood and marrow transplantation. Lancet Haematol. (2020) 7:e157-67. doi: 10.1016/S2352-3026(19)30256-X
108. Dignan FL, Clark A, Amrolia P, Cornish J, Jackson G, Mahendra P, et al. Diagnosis and management of acute graft-versus-host disease. Br J Haematol. (2012) 158:30-45. doi: 10.1111/j.1365-2141.2012.09129.x

109. Jamil MO, Mineishi S. State-of-the-art acute and chronic GvHD treatment. Int J Hematol. (2015) 101:452-66. doi: 10.1007/s12185-015-1785-1

110. Koc S, Leisenring W, Flowers MED, Anasetti C, Joachim Deeg H, Nash RA, et al. Therapy for chronic graft-versus-host disease: a randomized trial comparing cyclosporine plus prednisone versus prednisone alone. Blood. (2002) 100:48-51. doi: 10.1182/blood.V100.1.48

111. Malard F, Labopin M, Yakoub-Agha I, Chantepie S, Guillaume T, Blaise D, et al. Rituximab-based first-line treatment of cGvHD after allogeneic SCT: results of a phase 2 study. Blood. (2017) 130:218695. doi: 10.1182/blood-2017-05-786137

112. Sizemore C, Ridgeway M, Zhang X, Morris LE, Holland HK, Solh M, et al. Rituximab-based first line treatment for chronic GvHD following allogeneic transplant: single center analysis of 95 patients. Biol Blood Marrow Transplant. (2018) 24:S172-3. doi: 10.1016/j.bbmt.2017.12.121

113. Solomon SR, Sizemore CA, Ridgeway M, Zhang X, Brown S, Holland $\mathrm{HK}$, et al. Safety and efficacy of rituximab-based first line treatment of chronic GvHD. Bone Marrow Transplant. (2019) 54:1218-26. doi: 10.1038/s41409-018-0399-7

114. Zhang W, Egashira N, Masuda S. Recent topics on the mechanisms of immunosuppressive therapy-related neurotoxicities. Int J Mol Sci. (2019) 20:3210. doi: 10.3390/ijms20133210

115. Bergmann TK, Barraclough KA, Lee KJ, Staatz CE. Clinical pharmacokinetics and pharmacodynamics of prednisolone and prednisone in solid organ transplantation. Clin Pharmacokinet. (2012) 51:711-41. doi: 10.1007/s40262-012-0007-8

116. Staub Y, Suga Y, Ikawa Y, Tsubouchi K, Hashimoto M, Kawagishi A, et al. Detailed assessment and risk factor analysis of corticosteroid-induced psychiatric disorders in pediatric, adolescent, and young adult patients undergoing induction or consolidation therapy for hematologic malignancy. J Oncol Pharm Pract. (2020) 26:1041-51. doi: 10.1177/1078155219879992

117. Mcavoy S, Baker KS, Mulrooney D, Blaes A, Arora M, Burns LJ, et al. Corticosteroid dose as a risk factor for avascular necrosis of the bone after hematopoietic cell transplantation. Biol Blood Marrow Transplant. (2010) 16:1231-6. doi: 10.1016/j.bbmt.2010.03.008

118. Zimmerhackl LB, Wiesmayr S, Kirste G, Jungraithmayr T. Mycophenolate mofetil (cellcept) in pediatric renal transplantation. Transplant Proc. (2006) 38:2038-40. doi: 10.1016/j.transproceed.2006.06.042

119. Allison AC. Mechanisms of action of mycophenolate mofetil. Lupus. (2005) 14:2-8. doi: 10.1191/0961203305lu2109oa

120. Martin PJ, Storer BE, Rowley SD, Flowers MED, Lee SJ, Carpenter $\mathrm{PA}$, et al. Evaluation of mycophenolate mofetil for initial treatment of chronic graft-versus-host disease. Blood. (2009) 113:5074-82. doi: 10.1182/blood-2009-02-202937

121. Busca A, Saroglia EM, Lanino E, Manfredini L, Uderzo C, Nicolini B, et al. Mycophenolate mofetil (MMF) as therapy for refractory chronic GvHD (cGvHD) in children receiving bone marrow transplantation. Bone Marrow Transplant. (2000) 25:1067-71. doi: 10.1038/sj.bmt.1702410

122. Kawashima N, Iida M, Suzuki R, Fukuda T, Atsuta Y, Hashii Y, et al. Prophylaxis and treatment with mycophenolate mofetil in children with graft-versus-host disease undergoing allogeneic hematopoietic stem cell transplantation: a nationwide survey in Japan. Int J Hematol. (2019) 109:4918. doi: 10.1007/s12185-019-02601-5

123. Nguyen LS, Vautier M, Allenbach Y, Zahr N, Benveniste O, Funck-Brentano $\mathrm{C}$, et al. Sirolimus and mtor inhibitors: a review of side effects and specific management in solid organ transplantation. Drug Saf. (2019) 42:81325. doi: 10.1007/s40264-019-00810-9

124. Olivieri A, Locatelli F, Zecca M, Sanna A, Cimminiello M, Raimondi $\mathrm{R}$, et al. Imatinib for refractory chronic graft-versus-host disease with fibrotic features. Blood. (2009) 114:709-18. doi: 10.1182/blood-2009-02204156

125. Zaja F, Bacigalupo A, Patriarca F, Stanzani M, Van Lint MT, Filì C, et al. Treatment of refractory chronic GvHD with rituximab: a gitmo study. Bone Marrow Transplant. (2007) 40:273-7. doi: 10.1038/sj.bmt.1705725 
126. Cerny $\mathrm{T}$, Borisch B, Introna $\mathrm{M}$, Johnson $\mathrm{P}$, Rose AL. Mechanism of action of rituximab. Anticancer Drugs. (2002) 13:S3-10. doi: 10.1097/00001813-200211002-00002

127. Iijima K, Sako M, Nozu K. Rituximab for nephrotic syndrome in children. Clin Exp Nephrol. (2017) 21:193-202. doi: 10.1007/s10157-016-1313-5

128. Rao A, Kelly M, Musselman M, Ramadas J, Wilson D, Grossman W, et al. Safety, efficacy, and immune reconstitution after rituximab therapy in pediatric patients with chronic or refractory hematologic autoimmune cytopenias. Pediatr Blood Cancer. (2008) 50:822-5. doi: 10.1002/pbc.21264

129. Teusink-Cross A, Davies SM, Grimley MS, Chandra S, Flannery A, Dandoy $\mathrm{CE}$, et al. Ibrutinib for the treatment of chronic graft-vs-host disease in pediatric hematopoietic stem cell transplant patients: a single-center experience. PediatrTransplant. (2020) 24:e13692. doi: 10.1111/petr.13692

130. Wang YM, Teusink-Cross A, Elborai Y, Krupski MC, Nelson AS, Grimley MS, et al. Ruxolitinib for the treatment of chronic GvHD and overlap syndrome in children and young adults. Transplantation. (2021) 106:41219. doi: $10.1097 / \mathrm{tp} .0000000000003768$

131. Zeiser R, Burchert A, Lengerke C, Verbeek M, Maas-Bauer K, Metzelder SK, et al. Ruxolitinib in corticosteroid-refractory graft-versus-host disease after allogeneic stem cell transplantation: a multicenter survey. Leukemia. (2015) 29:2062-8. doi: 10.1038/leu.2015.212

132. Zeiser R, Polverelli N, Ram R, Hashmi SK, Chakraverty R, Flowers MED, et al. Ruxolitinib (rux) vs best available therapy (bat) in patients with steroid-refractory/steroid-dependent chronic graft-vs-host disease (cGvHD): primary findings from the phase 3, randomized reach3 study. Blood. (2020) 136:22-4. doi: 10.1182/blood-2020-137694

133. Kanold J, Merlin E, Halle P, Paillard C, Marabelle A, Rapatel C, et al. Photopheresis in pediatric graft-versus-host disease after allogeneic marrow transplantation: clinical practice guidelines based on field experience and review of the literature. Transfusion. (2007) 47:227689. doi: 10.1111/j.1537-2995.2007.01469.x

134. Winther-Jørgensen S, Nygaard M, Heilmann C, Ifversen M, Sørensen K, Müller K, et al. Feasibility of extracorporeal photopheresis in pediatric patients with graft-versus-host disease after hematopoietic stem cell transplantation. PediatrTransplant. (2019) 23:e13416. doi: 10.1111/petr.13416

135. Lawitschka A, Ball L, Peters C. Nonpharmacologic treatment of chronic graft-versus-host disease in children and adolescents. Biol Blood Marrow Transplant. (2012) 18:S74-81. doi: 10.1016/j.bbmt.2011.11.001

136. Faraci M, Ricci E, Bagnasco F, Pierri F, Giardino S, Girosi D, et al. Imatinib melylate as second-line treatment of bronchiolitis obliterans after allogenic hematopoietic stem cell transplantation in children. Pediatr Pulmonol. (2020) 55:631-7. doi: 10.1002/ppul.24652

137. Vigarios E, Beylot-Barry M, Jegou MH, Oberic L, Ysebaert L, Sibaud V. Dose-limiting stomatitis associated with ibrutinib therapy: a case series. $\mathrm{Br}$ J Haematol. (2019) 185:784-8. doi: 10.1111/bjh.15620

138. Thermos G, Tosios KI. Ibrutinib-associated oral ulcers. Oral Oncol. (2020) 100:104445. doi: 10.1016/j.oraloncology.2019.104445

139. Wolff D, Schleuning M, Von Harsdorf S, Bacher U, Gerbitz A, Stadler M, et al. Consensus conference on clinical practice in chronic GvHD: secondline treatment of chronic graft-versus-host disease. Biol Blood Marrow Transplant. (2011) 17:1-17. doi: 10.1016/j.bbmt.2010.05.011

140. Kim YJ, Lee GH, Kwong BY, Martires KJ. Evidence-based, skin-directed treatments for cutaneous chronic graft-versus-host disease. Cureus. (2019) 11:e6462. doi: 10.7759/cureus.6462

141. Sarantopoulos S, Cardones AR, Sullivan KM. How i treat refractory chronic graft-versus-host disease. Blood. (2019) 133:1191-200. doi: 10.1182/blood-2018-04-785899

142. Wolff D, Gerbitz A, Ayuk F, Kiani A, Hildebrandt GC, Vogelsang GB, et al. Consensus conference on clinical practice in chronic graft-versushost disease (GvHD): first-line and topical treatment of chronic GvHD. Biol Blood Marrow Transplant. (2010) 16:1611-28. doi: 10.1016/j.bbmt.2010. 06.015

143. Carpenter PA, Kitko CL, Elad S, Flowers MED, Gea-Banacloche JC, Halter JP, et al. National Institutes of Health Consensus Development project on criteria for clinical trials in chronic graft-versus-host disease: V. The 2014 ancillary therapy and supportive care working group report. Biol Blood Marrow Transplant. (2015) 21:1167-87. doi: 10.1016/j.bbmt.2015.03.024
144. Brazzelli V, Grasso V, Muzio F, Moggio E, Zecca M, Locatelli F, et al. Narrowband ultraviolet b phototherapy in the treatment of cutaneous graftversus-host disease in oncohaematological paediatric patients. Br J Dermatol. (2010) 162:404-9. doi: 10.1111/j.1365-2133.2009.09503.x

145. Enk CD, Elad S, Vexler A, Kapelushnik J, Gorodetsky R, Kirschbaum M. Chronic graft-versus-host disease treated with uvb phototherapy. Bone Marrow Transplant. (1998) 22:1179-83. doi: 10.1038/sj.bmt.1701460

146. Bonanomi S, Balduzzi A, Tagliabue A, Biagi E, Rovelli A, Corti P, et al. Bath puva therapy in pediatric patients with drug-resistant cutaneous graft-versus-host disease [1]. Bone Marrow Transplant. (2001) 28:6313. doi: 10.1038/sj.bmt.1703151

147. Pinton PC, Porta F, Izzi T, Venturini M, Capezzera R, Zane C, et al. Prospects for ultraviolet A1 phototherapy as a treatment for chronic cutaneous graftversus-host disease. Haematologica. (2003) 88:1169-75. doi: 10.3324/\%25x

148. Ständer H, Schiller M, Schwarz T. UVA1 therapy for sclerodermic graftversus-host disease of the skin. J Am Acad Dermatol. (2002) 46:799800. doi: $10.1067 / \mathrm{mjd} .2002 .121352$

149. Ziemer M, Gruhn B, Thiele JJ, Elsner P. Treatment of extensive chronic cutaneous graft-versus-host disease in an infant with topical pimecrolimus. J Am Acad Dermatol. (2004) 50:946-8. doi: 10.1016/j.jaad.200 4.02 .010

150. Schmook T, Kraft J, Benninghoff B, Nindl I, Roewert J, Ulrich C, et al. Treatment of cutaneous chronic graft-versus-host disease with topical pimecrolimus. Bone Marrow Transplant. (2005) 36:87-8. doi: 10.1038/sj.bmt. 1704998

151. Treister NS, Woo SB, O’holleran EW, Lehmann LE, Parsons SK, Guinan EC. Oral chronic graft-versus-host disease in pediatric patients after hematopoietic stem cell transplantation. Biol Blood Marrow Transplant. (2005) 11:721-31. doi: 10.1016/j.bbmt.2005. 06.002

152. Albert $\mathrm{MH}$, Becker $\mathrm{B}$, Schuster $\mathrm{FR}$, Klein B, Binder V, Adam $\mathrm{K}$, et al. Oral graft vs. host disease in children - treatment with topical tacrolimus ointment. PediatrTransplant. (2007) 11:306-9. doi: 10.1111/j.1399-3046.2006.00666.x

153. Robinson MR, Lee SS, Rubin BI, Wayne AS, Pavletic SZ, Bishop MR, et al. Topical corticosteroid therapy for cicatricial conjunctivitis associated with chronic graft-versus-host disease. Bone Marrow Transplant. (2004) 33:10315. doi: 10.1038/sj.bmt.1704453

154. Dietrich-Ntoukas T, Cursiefen C, Westekemper H, Eberwein P, Reinhard $\mathrm{T}$, Bertz $\mathrm{H}$, et al. Diagnosis and treatment of ocular chronic graftversus-host disease: report from the german-austrian-swiss consensus conference on clinical practice in chronic GvHD. Cornea. (2012) 31:299310. doi: 10.1097/ICO.0b013e318226bf97

155. Stratton P, Turner ML, Childs R, Barrett J, Bishop M, Wayne AS, et al. Vulvovaginal chronic graft-versus-host disease with allogeneic hematopoietic stem cell transplantation. Obstet Gynecol. (2007) 110:10419. doi: 10.1097/01.AOG.0000285998.75450.86

156. Iyer RV, Hahn T, Roy HN, Battiwalla M, Cooper M, Anderson B, et al. Long-term use of oral beclomethasone dipropionate for the treatment of gastrointestinal graft-versus-host disease. Biol Blood Marrow Transplant. (2005) 11:587-92. doi: 10.1016/j.bbmt.2005.04.008

157. Villanueva FN, Pérez-Simón JA, Silva FF, Caballero-Velázquez TT, SánchezGuijo FF, Cañizo CC, et al. Oral beclomethasone dipropionate for the treatment of gastrointestinal chronic graft-versus-host disease. Biol Blood Marrow Transplant. (2009) 15:1331-6. doi: 10.1016/j.bbmt.2009. 05.018

158. Martin PJ, Lee SJ, Przepiorka D, Horowitz MM, Koreth J, Vogelsang GB, et al. National Institutes of Health Consensus Development project on criteria for clinical trials in chronic graft-versus-host disease: VI. The 2014 clinical trial design working group report. Biol Blood Marrow Transplant. (2015) 21:1343-59. doi: 10.1016/j.bbmt.2015.05.004

159. Martin PJ, Storer BE, Inamoto Y, Flowers MED, Carpenter PA, Pidala $J$, et al. An endpoint associated with clinical benefit after initial treatment of chronic graft-versus-host disease. Blood. (2017) 130:3607. doi: 10.1182/blood-2017-03-775767

160. Choi JY, Kim H, Baek HJ, Kook H, Lee JM, Kim BK, et al. Open-label, multicenter phase ii study of combination therapy of imatinib mesylate and mycophenolate mofetil in pediatric patients with steroid-refractory 
sclerotic/fibrotic type chronic graft-versus-host disease. Transplant Cell Ther. (2021) 27:925 e1-7. doi: 10.1016/j.jtct.2021.07.019

161. Kim SJ, Lee JW, Jung CW, Min CK, Cho B, Shin HJ, et al. Weekly rituximab followed by monthly rituximab treatment for steroid-refractory chronic graft-versus-host disease: results from a prospective, multicenter, phase ii study. Haematologica. (2010) 95:1935-42. doi: 10.3324/haematol.2010.026104

162. Cronstein BN, Aune TM. Methotrexate and its mechanisms of action in inflammatory arthritis. Nat Rev Rheumatol. (2020) 16:145-54. doi: 10.1038/s41584-020-0373-9

163. Nassar A, Elgohary G, Elhassan T, Nurgat Z, Mohamed SY, Aljurf M. Methotrexate for the treatment of graft-versus-host disease after allogeneic hematopoietic stem cell transplantation. J Transplant. (2014) 2014:110. doi: $10.1155 / 2014 / 980301$

164. Yalniz FF, Murad MH, Lee SJ, Pavletic SZ, Khera N, Shah ND, et al. Steroid refractory chronic graft-versus-host disease: costeffectiveness analysis. Biol Blood Marrow Transplant. (2018) 24:1920-7. doi: 10.1016/j.bbmt.2018.03.008

165. Thomson AW, Bonham CA, Zeevi A. Mode of action of tacrolimus (fk506): molecular and cellular mechanisms. Ther Drug Monit. (1995) 17:58491. doi: 10.1097/00007691-199512000-00007

166. Mookerjee B, Altomonte V, Vogelsang G. Salvage therapy for refractory chronic graft-versus-host disease with mycophenolate mofetil and tacrolimus. Bone Marrow Transplant. (1999) 24:517-20. doi: 10.1038/sj.bmt.1701936

167. Carnevale-Schianca F, Martin P, Sullivan K, Flowers M, Gooley T, Anasetti $\mathrm{C}$, et al. Changing from cyclosporine to tacrolimus as salvage therapy for chronic graft-versus-host disease. Biol Blood Marrow Transplant. (2000) 6:613-20. doi: 10.1016/S1083-8791(00)70026-7

168. Fante MA, Holler B, Weber D, Angstwurm K, Bergler T, Holler E, et al. Cyclophosphamide for salvage therapy of chronic graft-versushost disease: a retrospective analysis. Ann Hematol. (2020) 99:218190. doi: 10.1007/s00277-020-04193-1

169. Mayer J, Krejci M, Doubek M, Pospisil Z, Brychtova Y, Tomiska $\mathrm{M}$, et al. Pulse cyclophosphamide for corticosteroid-refractory graft-versus-host disease. Bone Marrow Transplant. (2005) 35:699-705. doi: 10.1038/sj.bmt.1704829

170. Abouelnasr A, Roy J, Cohen S, Kiss T, Lachance S. Defining the role of sirolimus in the management of graft-versus-host disease: from prophylaxis to treatment. Biol Blood Marrow Transplant. (2013) 19:1221. doi: 10.1016/j.bbmt.2012.06.020

171. Carpenter PA, Logan BR, Lee SJ, Weisdorf DJ, Johnston L, Costa LJ, et al. A phase ii/iii randomized, multicenter trial of prednisone/sirolimus versus prednisone/ sirolimus/calcineurin inhibitor for the treatment of chronic graft-versus-host disease: BMT CTN 0801. Haematologica. (2018) 103:191524. doi: 10.3324/haematol.2018.195123

172. Jurado M, Vallejo C, Pérez-Simón JA, Brunet S, Ferra C, Balsalobre P, et al. Sirolimus as part of immunosuppressive therapy for refractory chronic graft-versus-host disease. Biol Blood Marrow Transplant. (2007) 13:7016. doi: 10.1016/j.bbmt.2007.02.003

173. Couriel DR, Saliba R, Escalón MP, Hsu Y, Ghosh S, Ippoliti C, et al. Sirolimus in combination with tacrolimus and corticosteroids for the treatment of resistant chronic graft-versus-host disease. Br J Haematol. (2005) 130:40917. doi: 10.1111/j.1365-2141.2005.05616.x

174. Jacobsohn DA, Chen AR, Zahurak M, Piantadosi S, Anders V, BolañosMeade J, et al. Phase II study of pentostatin in patients with corticosteroidrefractory chronic graft-versus-host disease. J Clin Oncol. (2007) 25:425561. doi: 10.1200/JCO.2007.10.8456

175. Jacobsohn DA, Gilman AL, Rademaker A, Browning B, Grimley M, Lehmann L, et al. Evaluation of pentostatin in corticosteroidrefractory chronic graft-versus-host disease in children: a pediatric blood and marrow transplant consortium study. Blood. (2009) 114:4354-60. doi: 10.1182/blood-2009-05-224840

176. Miklos D, Cutler CS, Arora M, Waller EK, Jagasia M, Pusic I, et al. Ibrutinib for chronic graft-versus-host disease after failure of prior therapy. Blood. (2017) 130:2243-50. doi: 10.1182/blood-2017-07-793786

177. Miklos DB, Jagasia MH, Greinix H, Ko B-S, Jacobsohn DA, Mokatrin A, et al. A randomized, double-blind phase iii study of ibrutinib versus placebo in combination with corticosteroids in patients with new onset chronic graft versus host disease. J Clin Oncol. (2017) 35:TPS7072TPS. doi: 10.1200/JCO.2017.35.15_suppl.TPS7072

178. Jackson SW, Jacobs HM, Arkatkar T, Dam EM, Scharping NE, Kolhatkar NS, et al. B cell IFN $-\gamma$ receptor signaling promotes autoimmune germinal centers via cell-intrinsic induction of BCL-6. J Exp Med. (2016) 213:73350. doi: 10.1084/jem.20151724

179. Heine A, Held SaE, Daecke SN, Wallner S, Yajnanarayana SP, Kurts C, et al. The jak-inhibitor ruxolitinib impairs dendritic cell function in vitro and in vivo. Blood. (2013) 122:1192-202. doi: 10.1182/blood-2013-03-484642

180. Spoerl S, Mathew NR, Bscheider M, Schmitt-Graeff A, Chen S, Mueller T, et al. Activity of therapeutic jak $1 / 2$ blockade in graft-versus-host disease. Blood. (2014) 123:3832-42. doi: 10.1182/blood-2013-12-543736

181. Choi J, Ziga ED, Ritchey J, Collins L, Prior JL, Cooper ML, et al. Ifn $\gamma \mathrm{r}$ signaling mediates alloreactive T-cell trafficking and GvHD. Blood. (2012) 120:4093-103. doi: 10.1182/blood-2012-01-403196

182. Mozo Y, Bueno D, Sisinni L, Fernández-Arroyo A, Rosich B, Martínez AP, et al. Ruxolitinib for steroid-refractory graft versus host disease in pediatric HSCT: high response rate and manageable toxicity. Pediatr Hematol Oncol. (2021) 38:331-45. doi: 10.1080/08880018.2020.1868637

183. Yang $\mathrm{W}$, Zhu G, Qin M, Li Z, Wang B, Yang J, et al. The effectiveness of ruxolitinib for acute/ chronic graft-versus-host disease in children: a retrospective study. Drug Des Devel Ther. (2021) 15:743-52. doi: 10.2147/DDDT.S287218

184. Moiseev IS, Morozova EV, Bykova TA, Paina OV, Smirnova AG, Dotsenko AA, et al. Long-term outcomes of ruxolitinib therapy in steroid-refractory graft-versus-host disease in children and adults. Bone Marrow Transplant. (2020) 55:1379-87. doi: 10.1038/s41409-020-0834-4

185. Uygun V, Karasu G, Daloglu H, Öztürkmen S, Kiliç SÇ, Yalçin K, et al. Ruxolitinib salvage therapy is effective for steroid-refractory graft-versushost disease in children: a single-center experience. Pediatr Blood Cancer. (2020) 67:e28190. doi: 10.1002/pbc.28190

186. González Vicent M, Molina B, González De Pablo J, Castillo A, Díaz MÁ. Ruxolitinib treatment for steroid refractory acute and chronic graft vs host disease in children: clinical and immunological results. Am J Hematol. (2019) 94:319-26. doi: 10.1002/ajh.25376

187. Salvaneschi L, Perotti C, Zecca M, Bernuzzi S, Viarengo G, Giorgiani G, et al. Extracorporeal photochemotherapy for treatment of acute and chronic GvHD in childhood. Transfusion. (2001) 41:1299-305. doi: 10.1046/j.1537-2995.2001.41101299.x

188. Seaton ED, Szydlo RM, Kanfer E, Apperley JF, Russell-Jones R. Influence of extracorporeal photopheresis on clinical and laboratory parameters in chronic graft-versus-host disease and analysis of predictors of response. Blood. (2003) 102:1217-23. doi: 10.1182/blood-2002-11-3351

189. Couriel DR, Hosing C, Saliba R, Shpall EJ, Anderlini P, Rhodes B, et al. Extracorporeal photochemotherapy for the treatment of steroid-resistant chronic GvHD. Blood. (2006) 107:3074-80. doi: 10.1182/blood-2005-09-3907

190. Perseghin P, Dassi M, Balduzzi A, Rovelli A, Bonanomi S, Uderzo C. Mononuclear cell collection in patients undergoing extra-corporeal photo-chemotherapy for acute and chronic graft-vs.-host-disease (GvHD): comparison between cobe spectra version 4.7 and 6.0 (autopbsc). J Clin Apher. (2002) 17:65-71. doi: 10.1002/jca.10021

191. Dignan FL, Greenblatt D, Cox M, Cavenagh J, Oakervee H, Apperley JF, et al. Efficacy of bimonthly extracorporeal photopheresis in refractory chronic mucocutaneous GvHD. Bone Marrow Transplant. (2012) 47:82430. doi: 10.1038/bmt.2011.186

192. Hautmann AH, Wolff D, Hahn J, Edinger M, Schirmer N, Ammer J, et al. Extracorporeal photopheresis in 62 patients with acute and chronic GvHD: results of treatment with the cobe spectra system. Bone Marrow Transplant. (2013) 48:439-45. doi: 10.1038/bmt.2012.156

193. Berger M, Pessolano R, Albiani R, Asaftei S, Barat V, Carraro F, et al. Extracorporeal photopheresis for steroid resistant graft versus host disease in pediatric patients. J Pediatr Hematol Oncol. (2007) 29:67887. doi: 10.1097/MPH.0b013e31814d66f5

194. Perotti C, Del Fante C, Tinelli C, Viarengo G, Scudeller L, Zecca $\mathrm{M}$, et al. Extracorporeal photochemotherapy in graft-versushost disease: a longitudinal study on factors influencing the 
response and survival in pediatric patients. Transfusion. (2010) 50:1359-69. doi: 10.1111/j.1537-2995.2009.02577.x

195. Messina C, Locatelli F, Lanino E, Uderzo C, Zacchello G, Cesaro S, et al. Extracorporeal photochemotherapy for paediatric patients with graft-versushost disease after haematopoietic stem cell transplantation. $\mathrm{Br} J$ Haematol. (2003) 122:118-27. doi: 10.1046/j.1365-2141.2003.04401.x

196. Escamilla Gomez V, Garcia-Gutierrez V, Lopez Corral L, Garcia Cadenas I, Perez Martinez A, Marquez Malaver FJ, et al. Ruxolitinib in refractory acute and chronic graft-versus-host disease: a multicenter survey study. Bone Marrow Transplant. (2020) 55:641-8. doi: 10.1038/s41409-019-0731-x

197. Zeiser R, Polverelli N, Ram R, Hashmi SK, Chakraverty R, Middeke JM, et al. Ruxolitinib for glucocorticoid-refractory chronic graft-versus-host disease. N Engl J Med. (2021) 385:228-38. doi: 10.1056/NEJMoa2033122

198. Cutler C, Lee SJ, Arai S, Rotta M, Zoghi B, Lazaryan A, et al. Belumosudil for chronic graft-versus-host disease after 2 or more prior lines of therapy: the rockstar study. Blood. (2021) 138:2278-89. doi: 10.1182/blood.2021012021

199. Herrera AF, Kim HT, Bindra B, Jones KT, Alyea EP 3rd, Armand P, et al. A phase ii study of bortezomib plus prednisone for initial therapy of chronic graft-versus-host disease. Biol Blood Marrow Transplant. (2014) 20:173743. doi: 10.1016/j.bbmt.2014.06.040

200. Shah D, Reichbach Douglas J, Ashy J, Suhrheinrich G, Ziga ED, Pillai AB, et al. A single institution experience of bortezomib for GvHD in a pediatric HSCT population. Blood. (2019) 134:5680. doi: 10.1182/blood-2019-1 25884

201. Curtis LM, Ostojic A, Venzon DJ, Holtzman NG, Pirsl F, Kuzmina ZJ, et al. A randomized phase 2 trial of pomalidomide in subjects failing prior therapy for chronic graft-versus-host disease. Blood. (2021) 137:896907. doi: 10.1182/blood.2020006892

202. Pusic I, Rettig MP, Dipersio JF, Bauer S, Mcfarland K, Gale RP, et al. Phase-1/2 study of pomalidomide in chronic GvHD. Bone Marrow Transplant. (2016) 51:612-4. doi: 10.1038/bmt.2015.298

203. Nahas MR, Soiffer RJ, Kim HT, Alyea EP, 3rd, Arnason J, Joyce R, et al. Phase 1 clinical trial evaluating abatacept in patients with steroidrefractory chronic graft-versus-host disease. Blood. (2018) 131:283645. doi: 10.1182/blood-2017-05-780239

204. Kattner AS, Holler E, Holler B, Klobuch S, Weber D, Martinovic D, et al. Il6-receptor antibody tocilizumab as salvage therapy in severe chronic graft-versus-host disease after allogeneic hematopoietic stem cell transplantation: a retrospective analysis. Ann Hematol. (2020) 99:84753. doi: 10.1007/s00277-020-03968-w

205. Beebe KL, Miller HK, Ngwube A, Salzberg D, Stahlecker J, Mcnulty A, et al. Tocilizumab in the treatment of pediatric chronic GvHD. Biol Blood Marrow Transplant. (2018) 24:S207. doi: 10.1016/j.bbmt.201 7.12.174

206. Ni M, Wang L, Hückelhoven A, Sellner L, Neuber B, Hoffmann $\mathrm{J}-\mathrm{M}$, et al. No inhibition of anti-viral and anti-leukemia effects by extracorporeal photopheresis therapy. Blood. (2018) 132:3399. doi: 10.1182/blood-2018-99-113277

207. Mulder A, Heidt S, Vergunst M, Roelen DL, Claas FHJ. Proteasome inhibition profoundly affects activated human B cells. Transplant J. (2013) 95:1331-7.

208. Pai CC, Chen M, Mirsoian A, Grossenbacher SK, Tellez J, Ames E, et al. Treatment of chronic graft-versus-host disease with bortezomib. Blood. (2014) 124:1677-88. doi: 10.1182/blood-2014-02-554279

209. Wertheimer T, Dohse M, Afram G, Weber D, Heidenreich M, Holler B, et al. Abatacept as salvage therapy in chronic graftversus-host disease-a retrospective analysis. Ann Hematol. (2021) 100:779-87. doi: 10.1007/s00277-021-04434-x

210. Sheppard M, Laskou F, Stapleton PP, Hadavi S, Dasgupta B. Tocilizumab (actemra). Hum Vaccin Immunother. (2017) 13:1972-88. doi: 10.1080/21645515.2017.1316909

211. Pal Singh S, Dammeijer F, Hendriks RW. Role of bruton's tyrosine kinase in B cells and malignancies. Mol Cancer. (2018) 17, 1-23. doi: 10.1186/s12943-018-0779-z

212. Zeiser R, Blazar BR. Preclinical models of acute and chronic graft-versus-host disease: how predictive are they for a successful clinical translation? Blood. (2016) 127:3117-26. doi: 10.1182/blood-2016-02-699082
213. Vieyra P, Wolf P. Extracorporeal photopheresis: a case of immunotherapy ahead of its time. Transfus Med Hemoth. (2020) 47:226-35. doi: 10.1159/000508479

214. Lamioni A, Parisi F, Isacchi G, Giorda E, Di Cesare S, Landolfo A, et al. The immunological effects of extracorporeal photopheresis unraveled: induction of tolerogenic dendritic cells in vitro and regulatory $\mathrm{T}$ cells in vivo. Transplantation. (2005) 79:846-50. doi: 10.1097/01.TP.0000157278.02848.C7

215. Desimone RA, Schwartz J, Schneiderman J. Extracorporeal photopheresis in pediatric patients: practical and technical considerations. J Clin Apher. (2017) 32:543-52. doi: 10.1002/jca.21534

216. Drexler B, Buser A, Infanti L, Stehle G, Halter J, Holbro A. Extracorporeal photopheresis in graft-versus-host disease. Transfus Med Hemoth. (2020) 47:214-25. doi: $10.1159 / 000508169$

217. Cho A, Jantschitsch C, Knobler R. Extracorporeal photopheresis-an overview. Front Med. (2018) 5:236. doi: 10.3389/fmed.2018.00236

218. Durazzo TS, Tigelaar RE, Filler R, Hayday A, Girardi M, Edelson RL. Induction of monocyte-to-dendritic cell maturation by extracorporeal photochemotherapy: initiation via direct platelet signaling. Transf Apher Sci. (2014) 50:370-8. doi: 10.1016/j.transci.2013.11.008

219. Rutella S, Danese S, Leone G. Tolerogenic dendritic cells: cytokine modulation comes of age. Blood. (2006) 108:143540. doi: 10.1182/blood-2006-03-006403

220. Spisek R, Gasova Z, Bartunkova J. Maturation state of dendritic cells during the extracorporeal photopheresis and its relevance for the treatment of chronic graft-versus-host disease. Transfusion. (2006) 46:5565. doi: 10.1111/j.1537-2995.2005.00670.x

221. Sniecinski I, Seghatchian J. Factual reflections and recommendations on extracorporeal photopheresis in pediatrics. Transf Apher Sci. (2017) 56:11822. doi: 10.1016/j.transci.2017.03.013

222. Sestili S, Eder S, Belhocine R, Dulery R, Battipaglia G, Brissot E, et al. Extracorporeal photopheresis as first-line strategy in the treatment of acute graft-versus-host disease after hematopoietic stem cell transplantation: a single-center experience. Cytotherapy. (2020) 22:445-9. doi: 10.1016/j.jcyt.2020.03.003

223. Perfetti P, Carlier P, Strada P, Gualandi F, Occhini D, Van Lint MT, et al. Extracorporeal photopheresis for the treatment of steroid refractory acute GvHD. Bone Marrow Transplant. (2008) 42:609-17. doi: 10.1038/bmt.2008.221

224. Abu-Dalle I, Reljic T, Nishihori T, Antar A, Bazarbachi A, Djulbegovic $B$, et al. Extracorporeal photopheresis in steroid-refractory acute or chronic graft-versus-host disease: results of a systematic review of prospective studies. Biol Blood Marrow Transplant. (2014) 20:167786. doi: 10.1016/j.bbmt.2014.05.017

225. Defilipp Z, Couriel DR, Lazaryan A, Bhatt VR, Buxbaum NP, Alousi AM, et al. National Institutes of Health Consensus Development project on criteria for clinical trials in chronic graft-versus-host disease: III. The 2020 treatment of chronic GvHD report. Transplant Cell Ther. (2021) 27:72937. doi: 10.1016/j.jtct.2021.05.004

226. Wolff D, Radojcic V, Lafyatis R, Cinar R, Rosenstein RK, Cowen EW, et al. National Institutes of Health Consensus Development project on criteria for clinical trials in chronic graft-versus-host disease: IV. The 2020 highly morbid forms report. Transplant Cell Ther. (2021) 27:81735. doi: 10.1016/j.jtct.2021.06.001

227. Klyushnenkova E, Mosca JD, Zernetkina V, Majumdar MK, Beggs KJ, Simonetti DW, et al. T cell responses to allogeneic human mesenchymal stem cells: immunogenicity, tolerance, and suppression. J Biomed Sci. (2005) 12:47-57. doi: 10.1007/s11373-004-8183-7

228. Polchert D, Sobinsky J, Douglas GW, Kidd M, Moadsiri A, Reina E, et al. Ifn$\gamma$ activation of mesenchymal stem cells for treatment and prevention of graft versus host disease. Eur J Immunol. (2008) 38:1745-55. doi: 10.1002/eji.2007 38129

229. Siegel G, Schäfer R, Dazzi F. The immunosuppressive properties of mesenchymal stem cells. Transplantation. (2009) 87:S459. doi: 10.1097/TP.0b013e3181a285b0

230. Lucchini G, Introna M, Dander E, Rovelli A, Balduzzi A, Bonanomi S, et al. Platelet-lysate-expanded mesenchymal stromal cells as a salvage therapy for 
severe resistant graft-versus-host disease in a pediatric population. Biol Blood Marrow Transplant. (2010) 16:1293-301. doi: 10.1016/j.bbmt.2010.03.017

231. Morata-Tarifa C, Macías-Sánchez MDM, Gutiérrez-Pizarraya A, SanchezPernaute R. Mesenchymal stromal cells for the prophylaxis and treatment of graft-versus-host disease-a meta-analysis. Stem Cell Res Ther. (2020) 11:64. doi: 10.1186/s13287-020-01592-z

232. Fisher SA, Cutler A, Doree C, Brunskill SJ, Stanworth SJ, Navarrete C, et al. Mesenchymal stromal cells as treatment or prophylaxis for acute or chronic graft-versus-host disease in haematopoietic stem cell transplant (HSCT) recipients with a haematological condition. Cochrane Database Syst Rev. (2019) 1:CD009768. doi: 10.1002/14651858.CD009768.pub2

233. Wang L, Zhu CY, Ma DX, Gu ZY, Xu CC, Wang FY, et al. Efficacy and safety of mesenchymal stromal cells for the prophylaxis of chronic graft-versushost disease after allogeneic hematopoietic stem cell transplantation: a metaanalysis of randomized controlled trials. Ann Hematol. (2018) 97:194150. doi: $10.1007 / \mathrm{s} 00277-018-3384-8$

234. Lazarus HM, Haynesworth SE, Gerson SL, Rosenthal NS, Caplan AI. Ex vivo expansion and subsequent infusion of human bone marrow-derived stromal progenitor cells (mesenchymal progenitor cells): implications for therapeutic use. Bone Marrow Transplant. (1995) 16:557-64.

235. Gao L, Zhang Y, Hu B, Liu J, Kong P, Lou S, et al. Phase ii multicenter, randomized, double-blind controlled study of efficacy and safety of umbilical cord-derived mesenchymal stromal cells in the prophylaxis of chronic graftversus-host disease after hla-haploidentical stem-cell transplantation. J Clin Oncol. (2016) 34:2843-50. doi: 10.1200/JCO.2015.65.3642

236. Lee SJ, Wolff D, Kitko C, Koreth J, Inamoto Y, Jagasia M, et al. Measuring therapeutic response in chronic graft-versus-host disease. National Institutes of Health Consensus Development project on criteria for clinical trials in chronic graft-versus-host disease: IV. The 2014 response criteria working group report. Biol Blood Marrow Transplant. (2015) 21:98499. doi: 10.1016/j.bbmt.2015.02.025

237. Flowers MED, Martin PJ. How we treat chronic graft-versus-host disease. Blood. (2015) 125:606-15. doi: 10.1182/blood-2014-08-551994

238. Arora M, Burns LJ, Davies SM, Macmillan ML, Defor TE, Miller WJ, et al. Chronic graft-versus-host disease: a prospective cohort study. Biol Blood Marrow Transplant. (2003) 9:38-45. doi: 10.1053/bbmt.2003.50003

239. Robin M, Porcher R, De Castro Araujo R, De Latour RP, Devergie A, Rocha V, et al. Risk factors for late infections after allogeneic hematopoietic stem cell transplantation from a matched related donor. Biol Blood Marrow Transplant. (2007) 13:1304-12. doi: 10.1016/j.bbmt.2007.07.007

240. Norkin M, Shaw BE, Brazauskas R, Tecca HR, Leather HL, GeaBanacloche J, et al. Characteristics of late fatal infections after allogeneic hematopoietic cell transplantation. Biol Blood Marrow Transplant. (2019) 25:362-8. doi: 10.1016/j.bbmt.2018.09.031

241. Srinivasan A, Wang C, Srivastava DK, Burnette K, Shenep JL, Leung W, et al. Timeline, epidemiology, and risk factors for bacterial, fungal, and viral infections in children and adolescents after allogeneic hematopoietic stem cell transplantation. Biol Blood Marrow Transplant. (2013) 19:94101. doi: 10.1016/j.bbmt.2012.08.012

242. Atsuta Y, Suzuki R, Yamamoto K, Terakura S, Iida H, Kohno A, et al. Risk and prognostic factors for Japanese patients with chronic graft-versus-host disease after bone marrow transplantation. Bone Marrow Transplant. (2006) 37:289-96. doi: 10.1038/sj.bmt.1705247

243. Dignan FL, Scarisbrick JJ, Cornish J, Clark A, Amrolia P, Jackson G, et al. Organ-specific management and supportive care in chronic graft-versus-host disease. Br J Haematol. (2012) 158:62-78. doi: 10.1111/j.1365-2141.2012.09131.x

244. Ifversen M, Meisel R, Sedlacek P, Kalwak K, Sisinni L, Hutt D, et al. Supportive care during pediatric hematopoietic stem cell transplantation: prevention of infections. A report from workshops on supportive care of the paediatric diseases working party (PDWP) of the European Society for blood and marrow transplantation (EBMT). Front Pediatr. (2021) 9:705179. doi: 10.3389/fped.2021.705179

245. Engelhard D, Akova M, Boeckh MJ, Freifeld A, Sepkowitz K, Viscoli C, et al. Bacterial infection prevention after hematopoietic cell transplantation. Bone Marrow Transplant. (2009) 44:467-70. doi: 10.1038/bmt.2009.257

246. Tomblyn M, Chiller T, Einsele H, Gress R, Sepkowitz K, Storek $\mathrm{J}$, et al. Guidelines for preventing infectious complications among hematopoietic cell transplantation recipients: a global perspective. Biol Blood Marrow Transplant. (2009) 15:1143-238. doi: 10.1016/j.bbmt.2009. 06.019

247. El Cheikh J, Castagna L, Wang L, Esterni B, Faucher C, Furst S, et al. Once-weekly liposomal amphotericin $\mathrm{b}$ for prophylaxis of invasive fungal infection after graft-versus-host disease in allogeneic hematopoietic stem cell transplantation: a comparative retrospective single-center study. Hemat Oncol Stem Cell Ther. (2010) 3:167-73. doi: 10.5144/1658-3876.2010.167

248. Omar H, Hägglund H, Gustafsson-Jernberg Å, Leblanc K, Mattsson J, Remberger $\mathrm{M}$, et al. Targeted monitoring of patients at high risk of post-transplant lymphoproliferative disease by quantitative epstein-barr virus polymerase chain reaction. Transplant Infect Dis. (2009) 11:3939. doi: 10.1111/j.1399-3062.2009.00410.x

249. Meisel R, Kuypers L, Dirksen U, Schubert R, Gruhn B, Strauss G, et al. Pneumococcal conjugate vaccine provides early protective antibody responses in children after related and unrelated allogeneic hematopoietic stem cell transplantation. Blood. (2007) 109:2322-6. doi: 10.1182/blood-2006-06-032284

250. Sattler C, Hoffmann P, Herzberg PY, Weber D, Holler B, Fehn U, et al. Primary vaccination in adult patients after allogeneic hematopoietic stem cell transplantation - a single center retrospective efficacy analysis. Vaccine. (2021) 39:4742-50. doi: 10.1016/j.vaccine.2021.04.052

251. Pao M, Papadopoulos EB, Chou J, Glenn H, Castro-Malaspina H, Jakubowski $\mathrm{AA}$, et al. Response to pneumococcal (PNCRM7) and haemophilus influenzae conjugate vaccines (HIB) in pediatric and adult recipients of an allogeneic hematopoietic cell transplantation (ALLOHCT). Biol Blood Marrow Transplant. (2008) 14:1022-30. doi: 10.1016/j.bbmt.2008.06.012

252. Cordonnier C, Einarsdottir S, Cesaro S, Di Blasi R, Mikulska M, Rieger C, et al. Vaccination of haemopoietic stem cell transplant recipients: guidelines of the 2017 european conference on infections in leukaemia (ECIL 7). Lancet Infect Dis. (2019) 19:e200-12. doi: 10.1016/S1473-3099(18)30600-5

253. De La Cámara R. Vaccinations. In: Enric Carreras, Editor. The EBMT handbook. Cham: Springer International Publishing (2019). p. 207-20.

254. Hilgendorf I, Freund M, Jilg W, Einsele H, Gea-Banacloche J, Greinix $\mathrm{H}$, et al. Vaccination of allogeneic haematopoietic stem cell transplant recipients: report from the international consensus conference on clinical practice in chronic GvHD. Vaccine. (2011) 29:2825-33. doi: 10.1016/j.vaccine.2011.02.018

255. Cordonnier C, Ljungman P, Juergens C, Maertens J, Selleslag D, Sundaraiyer $\mathrm{V}$, et al. Immunogenicity, safety, and tolerability of 13-valent pneumococcal conjugate vaccine followed by 23 -valent pneumococcal polysaccharide vaccine in recipients of allogeneic hematopoietic stem cell transplant aged $\geq 2$ years: an open-label study. Clin Infect Dis. (2015) 61:31323. doi: $10.1093 / \mathrm{cid} / \mathrm{civ} 287$

256. Roll D, Ammer J, Holler B, Salzberger B, Schweiger B, Jilg W, et al. Vaccination against pandemic H1N1 (2009) in patients after allogeneic hematopoietic stem cell transplantation: a retrospective analysis. Infection. (2012) 40:153-61. doi: 10.1007/s15010-011-0206-5

257. Agency EM. Comirnaty and Spikevax: EMA Recommendations on Extra Doses and Boosters. Amsterdam (2021).

258. Mushtaq MU, Shahzad M, Chaudhary SG, Luder M, Ahmed N, Abdelhakim $\mathrm{H}$, et al. Impact of SARS-Cov-2 in hematopoietic stem cell transplantation and chimeric antigen receptor $\mathrm{T}$ cell therapy recipients. Transplant Cell Ther. (2021) 27:796 e1-7. doi: 10.1016/j.jtct.2021.07.005

259. Meir J, Abid MA, Abid MB. State of the car-t: risk of infections with chimeric antigen receptor T-cell therapy and determinants of SARS-Cov-2 vaccine responses. Transplant Cell Ther. (2021) 27:97387. doi: 10.1016/j.jtct.2021.09.016

260. Parvathaneni K, Torres-Rodriguez K, Meng W, Hwang WT, Frey N, Naji A, et al. SARS-Cov-2 spike-specific T-cell responses in patients with B-cell depletion who received chimeric antigen receptor T-cell treatments. JAMA Oncol. (2021) 8:164-7. doi: 10.1001/jamaoncol.2021.6030

261. Yeshurun M, Weisdorf D, Rowe JM, Tallman MS, Zhang MJ, Wang HL, et al. The impact of the graft-versus-leukemia effect on survival in acute lymphoblastic leukemia. Blood Adv. (2019) 3:670-80. doi: 10.1182/bloodadvances.2018027003

262. Bader P, Salzmann-Manrique E, Balduzzi A, Dalle JH, Woolfrey AE, Bar $\mathrm{M}$, et al. More precisely defining risk peri-hct in pediatric all: pre- vs 
post-mrd measures, serial positivity, and risk modeling. Blood Adv. (2019) 3:3393-405. doi: 10.1182/bloodadvances.2019000449

263. Picardi M, Selleri C, Rotoli B. Spleen sizing by ultrasound scan and risk of pneumococcal infection in patients with chronic GvHD: preliminary observations. Bone Marrow Transplant. (1999) 24:1737. doi: 10.1038/sj.bmt.1701861

264. Mihu CN, Schaub J, Kesh S, Jakubowski A, Sepkowitz K, Pamer $\mathrm{EG}$, et al. Risk factors for late staphylococcus aureus bacteremia after allogeneic hematopoietic stem cell transplantation: a single-institution, nested case-controlled study. Biol Blood Marrow Transplant. (2008) 14:142933. doi: 10.1016/j.bbmt.2008.09.005

265. Czyzewski K, Dziedzic M, Salamonowicz M, Fraczkiewicz J, ZajacSpychala O, Zaucha-Prazmo A, et al. Epidemiology, outcome and risk factors analysis of viral infections in children and adolescents undergoing hematopoietic cell transplantation: antiviral drugs do notprevent epstein-barr virus reactivation. Infect Drug Resist. (2019) 12:3893902. doi: 10.2147/IDR.S224291

266. Verdeguer A, De Heredia CD, González M, Martínez AM, FernándezNavarro JM, Pérez-Hurtado JM, et al. Observational prospective study of viral infections in children undergoing allogeneic hematopoietic cell transplantation: a 3-year getmon experience. Bone Marrow Transplant. (2011) 46:119-24. doi: 10.1038/bmt.2010.52

267. Peritz DC, Duncan C, Kurek K, Perez-Atayde AR, Lehmann LE. Visceral varicella zoster virus (vzv) after allogeneic hematopoietic stem cell transplant (HSCT) in pediatric patients with chronic graft-versus-host disease (cGvHD). J Pediatr Hematol Oncol. (2008) 30:931-4. doi: 10.1097/MPH.0b013e31817e4b14

268. Mikulska M, Raiola AM, Bruno B, Furfaro E, Van Lint MT, Bregante S, et al. Risk factors for invasive aspergillosis and related mortality in recipients of allogeneic SCT from alternative donors: an analysis of 306 patients. Bone Marrow Transplant. (2009) 44:361-70. doi: 10.1038/bmt.2009.39

269. Hol JA, Wolfs TFW, Bierings MB, Lindemans CA, Versluys ABJ, Wildt De A, et al. Predictors of invasive fungal infection in pediatric allogeneic hematopoietic SCT recipients. Bone Marrow Transplant. (2014) 49:95101. doi: $10.1038 / \mathrm{bmt} .2013 .136$

270. Hovi L, Saarinen-Pihkala UM, Vettenranta K, Saxen H. Invasive fungal infections in pediatric bone marrow transplant recipients: single center experience of 10 years. Bone Marrow Transplant. (2000) 26:999-1004. doi: 10.1038/sj.bmt.1702654

271. Barmettler S, Ong M-S, Farmer JR, Choi H, Walter J. Association of immunoglobulin levels, infectious risk, and mortality with rituximab and hypogammaglobulinemia. JAMA Netw Open. (2018) 1:e184169. doi: 10.1001/jamanetworkopen.2018.4169

272. Maschmeyer G, De Greef J, Mellinghoff SC, Nosari A, Thiebaut-Bertrand A, Bergeron A, et al. Infections associated with immunotherapeutic and molecular targeted agents in hematology and oncology. A position paper by the European Conference on infections in leukemia (ECIL). Leukemia. (2019) 33:844-62. doi: 10.1038/s41375-019-0388-X

273. Zhao Y, Ouyang G, Shi J, Luo Y, Tan Y, Yu J, et al. Salvage therapy with low-dose ruxolitinib leads to a significant improvement in bronchiolitis obliterans syndrome in patients with cGvHD after allogeneic hematopoietic stem cell transplantation. Front Pharm. (2021) 12:668825. doi: 10.3389/fphar.2021.668825

274. Abedin S, Mckenna E, Chhabra S, Pasquini M, Shah NN, Jerkins J, et al. Efficacy, toxicity, and infectious complications in ruxolitinib-treated patients with corticosteroid-refractory graft-versus-host disease after hematopoietic cell transplantation. Biol Blood Marrow Transplant. (2019) 25:168994. doi: 10.1016/j.bbmt.2019.04.003

275. Velickovic VM, Mcilwaine E, Zhang R, Spelman T. Adverse events in second- and third-line treatments for acute and chronic graft-versus-host disease: systematic review. Ther Adv Hematol. (2020) 11:1-18. doi: 10.1177/2040620720977039

276. Baker KS, Bresters D, Sande JE. The burden of cure: long-term side effects following hematopoietic stem cell transplantation (HSCT) in children. Pediatr Clin North Am. (2010) 57:323-42. doi: 10.1016/j.pcl.2009. 11.008

277. Eissa HM, Lu L, Baassiri M, Bhakta N, Ehrhardt MJ, Triplett BM, et al. Chronic disease burden and frailty in survivors of childhood HSCT: a report from the st. Jude lifetime cohort study. Blood Adv. (2017) 1:22436. doi: 10.1182/bloodadvances.2017010280

278. Bresters D, Lawitschka A, Cugno C, Pötschger U, Dalissier A, Michel G, et al. Incidence and severity of crucial late effects after allogeneic HSCT for malignancy under the age of 3 years: Tbi is what really matters. Bone Marrow Transplant. (2016) 51:1482-9. doi: 10.1038/bmt.2016.139

279. Vrooman LM, Millard HR, Brazauskas R, Majhail NS, Battiwalla $\mathrm{M}$, Flowers $\mathrm{ME}$, et al. Survival and late effects after allogeneic hematopoietic cell transplantation for hematologic malignancy at less than three years of age. Biol Blood Marrow Transplant. (2017) 23:1327-34. doi: 10.1016/j.bbmt.2017.04.017

280. Armenian SH, Sun CL, Kawashima T, Arora M, Leisenring W, Sklar CA, et al. Long-term health-related outcomes in survivors of childhood cancer treated with HSCT versus conventional therapy: a report from the bone marrow transplant survivor study (BMTSS) and childhood cancer survivor study (CCSS). Blood. (2011) 118:1413-20. doi: 10.1182/blood-2011-01-3 31835

281. Sanders JE. Chronic graft-versus-host disease and late effects after hematopoietic stem cell transplantation. Int J Hematol. (2002) 76(Suppl. 2):15-28. doi: 10.1007/BF03165081

282. Hilgendorf I, Greinix H, Halter JP, Lawitschka A, Bertz H, Wolff D. Longterm follow-up after allogeneic stem cell transplantation. Dtsch Arztebl Int. (2015) 112:51-8. doi: 10.3238/arztebl.2015.0051

Conflict of Interest: The authors declare that the research was conducted in the absence of any commercial or financial relationships that could be construed as a potential conflict of interest.

Publisher's Note: All claims expressed in this article are solely those of the authors and do not necessarily represent those of their affiliated organizations, or those of the publisher, the editors and the reviewers. Any product that may be evaluated in this article, or claim that may be made by its manufacturer, is not guaranteed or endorsed by the publisher.

Copyright (c) 2022 Sobkowiak-Sobierajska, Lindemans, Sykora, Wachowiak, Dalle, Bonig, Gennery and Lawitschka. This is an open-access article distributed under the terms of the Creative Commons Attribution License (CC BY). The use, distribution or reproduction in other forums is permitted, provided the original author(s) and the copyright owner(s) are credited and that the original publication in this journal is cited, in accordance with accepted academic practice. No use, distribution or reproduction is permitted which does not comply with these terms. 